Check for updates

Cite this: DOI: 10.1039/d1ma00456e

\title{
Optical fiber sensors based on sol-gel materials: design, fabrication and application in concrete structures
}

\author{
Rita B. Figueira, $\dagger^{\star * a}$ José M. de Almeida, ${ }^{b c}$ Bárbara Ferreira, ${ }^{a}$ Luís Coelho ${ }^{b}$ and \\ Carlos J. R. Silva $\ddagger^{a}$
}

\begin{abstract}
Optical fiber sensing systems have been widely developed for several fields such as biomedical diagnosis, food technology, military and industrial applications and civil engineering. Nowadays, the growth and advances of optical fiber sensors (OFS) are focused on the development of novel sensing concepts and transducers as well as sensor cost reduction. This review provides an overview of the state-of-the-art of OFS based on sol-gel materials for diverse applications with particular emphasis on OFS for structural health monitoring of concrete structures. The types of precursors used in the development of sol-gel materials for OFS functionalization to monitor a wide range of analytes are debated. The main advantages of OFS compared to other sensing systems such as electrochemical sensors are also considered. An interdisciplinary review to a broad audience of engineers and materials scientists is provided and the relationship between the chemistry of sol-gel material synthesis and the development of OFS is considered. To the best of the authors' knowledge, no review manuscripts were found in which the fields of sol-gel chemistry and OFS are correlated. The authors consider that this review will serve as a reference as well as provide insights for experts into the application of sol-gel chemistry and

OFS in the civil engineering field.
\end{abstract}

\begin{abstract}
Received 22nd May 2021, Accepted 7th September 2021

DOI: $10.1039 / \mathrm{d} 1 \mathrm{ma} 00456 \mathrm{e}$
\end{abstract}

rsc.li/materials-advances

\section{Introduction and background}

The applications of sensors are limitless and the future applications of optical fiber sensors (OFS) include devices placed in locations that range from nuclear power plants to the human body to monitor vital signs or even signal a call for help in case of emergency. Ideally, a perfect sensor would provide high selectivity towards the species of interest, suitable sensitivity and/or a suitable dynamic range, a stable and proportional signal output to the amount of analyte, fast response time, a good signal-to-noise ratio, no hysteresis, and long-term stability.

In the last few decades, the extensive research in chemical sensors based on sol-gel materials, either at an industrial and academic level, has led to remarkable achievements, particularly

\footnotetext{
${ }^{a}$ Centro de Quimica, Universidade do Minho, Campus de Gualtar, 4710-057 Braga, Portugal. E-mail: isrita@figueira.pt, rita.figueira@vgcolab.com

${ }^{b}$ INESC TEC - Institute for Systems and Computer Engineering, Technology and Science and FCUP - Faculty of Sciences, University of Porto, 4169-007 Porto, Portugal

${ }^{c}$ Department of Physics, School of Sciences and Technology,

University of Trás-os-Montes e Alto Douro, 5001-801 Vila Real, Portugal

$\dagger$ Presently at Vasco da Gama CoLAB, Rua Roberto Frias, 4200-465 Porto, Portugal $\$$ This paper is dedicated to the memory of Professor Carlos J. R. Silva who passed away suddenly on August 27th, 2020.
}

in terms of sensitivity, selectivity, and stability. Such materials have attracted attention for their use in the sensing field due to their simple preparation, their physical properties, and the wide diversity of precursors available. The sol-gel method has been widely implemented in a wide range of fields such as biosensors, ${ }^{1}$ optics, ${ }^{2}$ electronics, ${ }^{3}$ the environment,${ }^{4}$ medicine, ${ }^{5}$ functional smart coatings, ${ }^{6}$ fuel and solar cells, ${ }^{7}$ catalysts, ${ }^{8}$ chemical sensors,${ }^{9}$ and civil engineering, ${ }^{10-12}$ among others. Several chemical sensors and biosensors, in different transduction modes, from electrochemical ${ }^{13}$ to optical ${ }^{14}$ detection, have been proposed. Fig. 1 shows some noteworthy examples of sol-gel material applications.

The research progress in OFS is nearly as old as the optical fiber communication research. OFS show unique advantages such as their immunity to electromagnetic interference, high sensitivity, small size, lightweight, robustness, and ability to provide multiplexed or distributed sensing. However, OFS have not achieved the commercial success of optical fiber communications. They have been continuously and actively studied in the past twenty years and the use of OFS functionalized with sol-gel materials dates to the early nineties. The degree of interest in this technology derives mainly from their attractive features offered as interesting contenders for monitoring different parameters mainly due to their several advantages over electrochemical sensors (e.g. tiny dimensions, less electrical 
operation and high resistance to corrosion). ${ }^{15}$ The awareness in this field is easily shown by the vast number of research papers found in the last few decades focused on optical sensors based on sol-gel materials, ${ }^{16-18}$ as well as review manuscripts. ${ }^{19,20}$ The main advantages of the sol-gel method are the easy fabrication of sol-gel materials, the flexibility of the process, the large number of precursor reagents available with tuneable functional groups and low environmental impact. ${ }^{21}$ Moreover, such materials also exhibit high optical transparency and chemical, thermal, physical and mechanical stability under demanding operational conditions. A key step in developing a sensor device is the immobilization of sensing agents within the matrix.

Therefore, the matrix, besides working as a supporting material, must not affect the response of the components to be immobilized. The encapsulation of biological/sensing components in sol-gel materials offers numerous advantages when compared to other immobilization procedures. Naturally, this has boosted the development of sol-gel materials, worldwide, particularly in biosensors, ${ }^{28}$ and the fields of medicine and health care. ${ }^{24,29}$

In the last few years, the development of OFS for application in the civil engineering area has gained significant attention. ${ }^{10-12}$

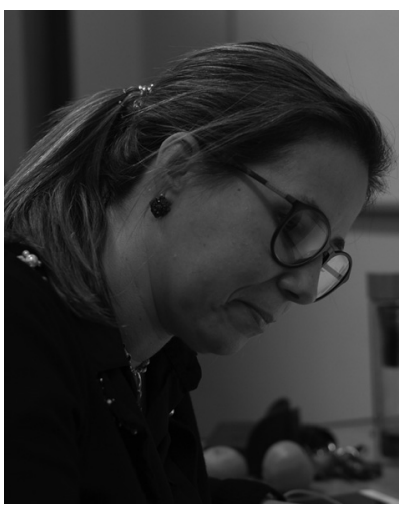

Rita B. Figueira
Rita Maria Burguete Bacelar Marreiros Figueira concluded her chemistry degree at the University of Lisbon, Portugal in 2002. In 2008, she got a MSc degree in Technological Chemistry at the same University. She obtained her PhD from the University of Minho in 2015 in Sciences - specialization in Chemistry. She worked as a research fellow at the Department of Materials, LNEC, Lisbon, Portugal between 2007 and 2016. She held a position as Junior Researcher at the University of Minho from 2018 until March 2021. Currently, she is $R \& D$ Coordinator at Vasco da Gama CoLAB - Energy Storage, Porto, Portugal. Her research interests involved the synthesis, structural and physical characterization of hybrid sol-gel materials for corrosion and sensing applications. Currently, she is focused on the development of new solutions and materials for redox flow batteries and on electroreduction of $\mathrm{CO}_{2}$ in gas-phase.

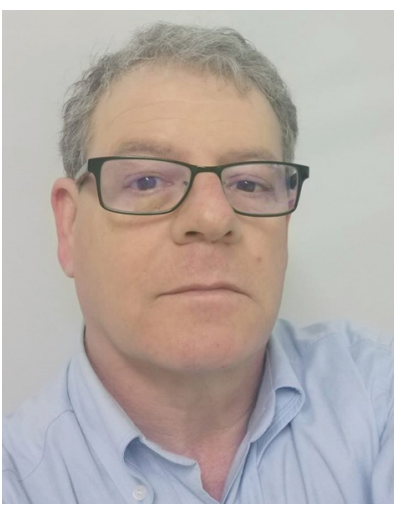

José M. de Almeida
José Manuel Marques Martins de Almeida received the Graduate degree in applied physics (optics and electronics) in 1987 and the PhD degree in 1998 from the University of Porto, Porto, Portugal. Since 2000, he has the position of an Associate Professor at the Department of Physics, Univ. de Trás-os-Montes e Alto Douro, Vila Real, Portugal, and received Habilitation in 2006 from the same University. He is currently a Senior Researcher in the Centre for Applied Photonics of INESC TEC, Porto. His current research interests include optical sensors, integrated optics, spectroscopy, and biophysics.

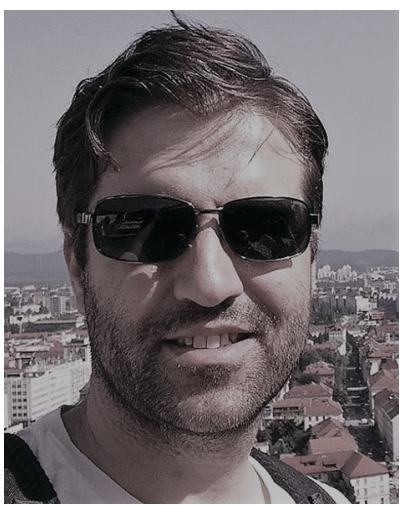

Luís Coelho
Luis Coelho received his $P h D$ in Physics from University of Porto, Portugal, with the focus on thin films technology applied to optical fibre sensors. His main research interests are related to the detection and monitoring of chemical entities and biological targets through the application of a wide variety of optical technologies using the effect of fluorescence, absorption or the evanescent field combined with plasmonics. $\mathrm{He}$ is currently working in the development of fibre optic probes to real-time monitor pollutants and contaminants on water systems.

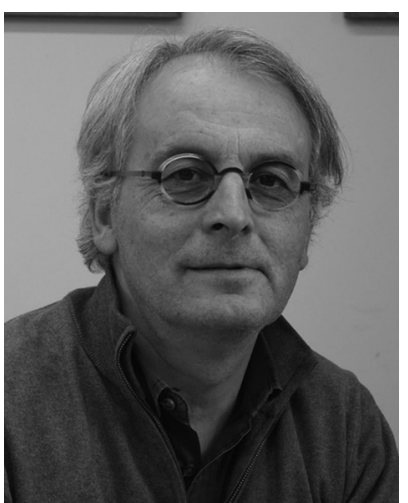

Carlos J. R. Silva
Carlos Jorge Ribeiro da Silva obtained his bachelor's degree in chemistry from the University of Porto, Portugal, in 1985, and received his $P h D$ in Sciences specialization in Chemistry from the University of Minho in 1996. He held the position of Auxiliar Professor from 1992 to 2008 in the Department of Chemistry at University of Minho, Portugal, and was Associate Professor at the same University until he passed away on August 27th,

2020. His main research interests were, back then, in the synthesis and characterization of functional materials based on organicinorganic gels for sensing applications. 


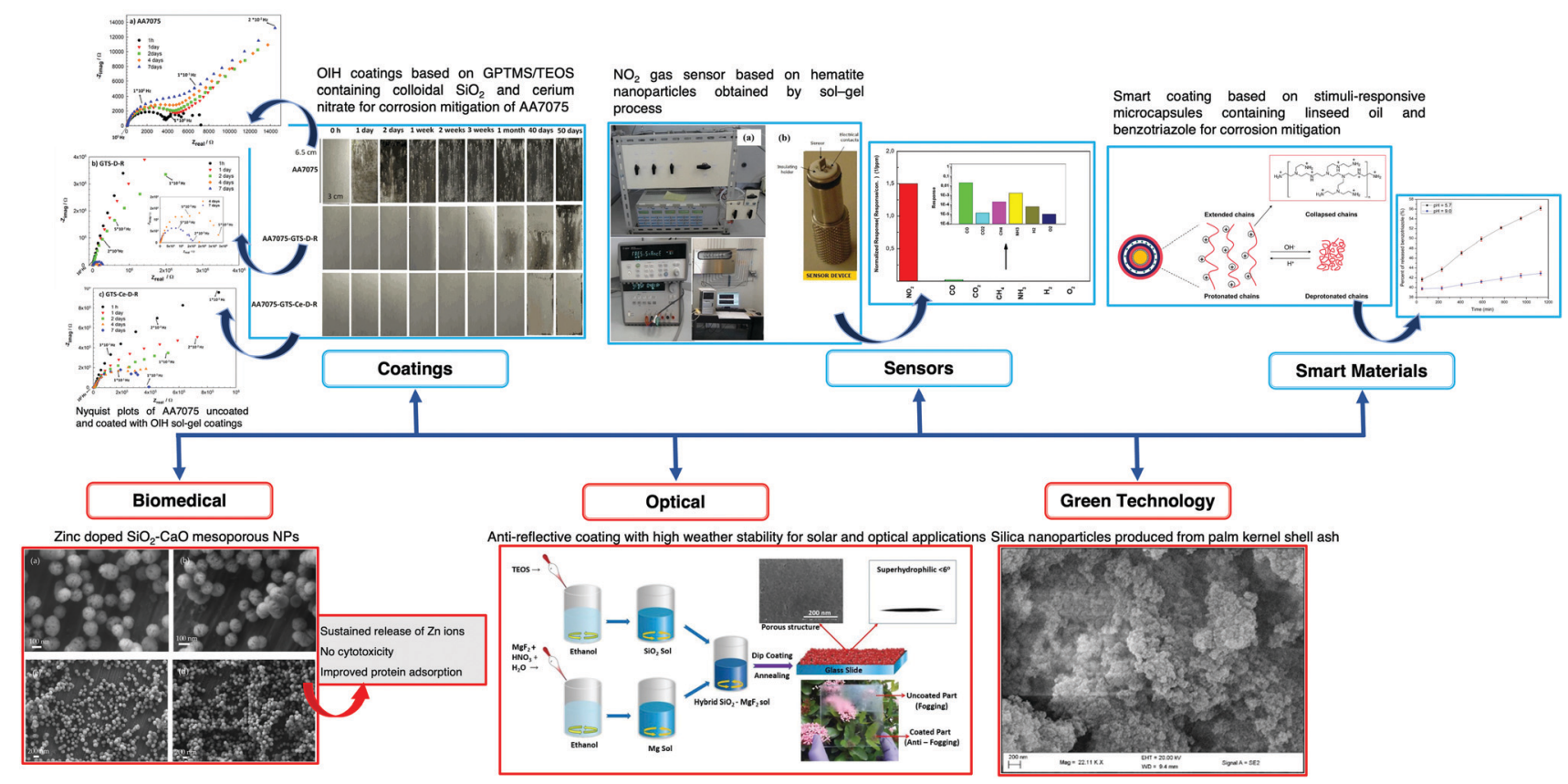

Fig. 1 Schematic of sol-gel technology applications in a wide range of fields, i.e., coatings, sensors, biomedical diagnosis, smart materials and green technology. Reprinted and adapted with permission from ref. 22-27. Copyright 2018 Springer. Copyright 2018 Elsevier. Copyright 2019 Elsevier. Copyright 2020 Springer.

Being a field extremely important in structural engineering, structural health monitoring (SHM) of infrastructures is becoming more and more relevant. Fiber optic technology has shown significant features in monitoring systems when compared to traditional solutions. In the past few decades, the depreciation of infrastructures (e.g., dams, bridges, roadways, buildings) has shown the need for the development of high-performance sensing systems for SHM that allow monitoring, through the years and accurately, their transformations. ${ }^{30}$ The collapse of the Morandi viaduct in Genoa in the August of 2018, due to corrosion, is one of the most recent events that proves the need for the development and implementation of such systems. Moreover, SHM systems have the potential to allow real time monitoring and infrastructure preventive maintenance. ${ }^{30}$

The installation of OFS in different structures such as bridges ${ }^{31}$ and highways ${ }^{32,33}$ to monitor their global and local mechanical behavior has been widely reported. These OFS for mechanical monitoring are, generally, applied to key structural components of bridges, such as anchorages, cables, decks, piers and pavements, ${ }^{34}$ allowing monitoring properties such as the curvature and deflection of bridges, ${ }^{35-37}$ as well as the onset of cracking. ${ }^{38,39}$ OFS applied on highway pavements allow monitoring the impact stress waves generated by high speed vehicles. ${ }^{34}$ Besides their mechanical properties, other parameters such as temperature, ${ }^{40}$ concrete pH levels, ${ }^{41,42}$ concrete relative humidity $(\mathrm{RH}),{ }^{43}$ concrete chloride content ${ }^{44}$ and alkali-silica reaction (ASR) $)^{45}$ are also responsible for earlier failure of concrete structures.

Concrete is a very heterogenous material consisting of gas, liquid and solid phases. Therefore, the degradation of concrete properties is a very complex process and results from the combination of multiple factors. Furthermore, the concrete degradation process is widely determined by the environment and by the physicochemical properties of the concrete itself. Generally, the most common causes of reinforced concrete structure (RCS) degradation are the incorporation of chloride ions $\left(\mathrm{Cl}^{-}\right)$and the reaction of atmospheric carbon dioxide $\left(\mathrm{CO}_{2}\right)$ with the components of concrete and/or a combination of the two. The $\mathrm{pH}$ in a Portland cement based concrete is generally between 12.5 and $13.8 .^{42}$ The high $\mathrm{pH}$ values of the concrete mitigate the corrosion development of steel reinforcement by forming a passivation layer on its surface (vide Fig. 2a). ${ }^{46}$ Nevertheless, due to deterioration processes such as carbonation, ${ }^{47} \mathrm{Cl}^{-}$ingress ${ }^{44}$ and acid attack, ${ }^{48}$ this passivation layer can be disrupted due to the $\mathrm{pH}$ decrease (vide Fig. 2c). During the carbonation process, the atmospheric $\mathrm{CO}_{2}$ dissolves into the concrete pore solution forming $\mathrm{CO}_{3}{ }^{2-}$ ions, which react with the products of cement hydration, leading to lower $\mathrm{pH}$ values. ${ }^{49} \mathrm{The}^{\mathrm{Cl}}{ }^{-}$ions that ingress into the concrete, by diffusion or migration processes, can end in a $\mathrm{pH}$ reduction due to the formation of hydrochloric acid. Once the $\mathrm{pH}$ of the concrete reaches values below approximately 10 , the steel reinforcement is no longer protected against corrosion, and in the case of lower $\mathrm{pH}$ values, the threshold chloride concentrations are even smaller and the corrosion of rebars embedded in the concrete may occur earlier than expected. Fig. 2 shows a schematic representation of the reinforcement corrosion process in concrete. An embedded rebar without any corrosion attack in the concrete is presented in Fig. 2a. The cathodic and anodic processes (vide Fig. 2c) as well as a picture of a corroded RCS (vide Fig. 2b) are also included.

The corrosion of RCS leads to expansion forces that when exceed the concrete tensile strength cause cracking or spalling 


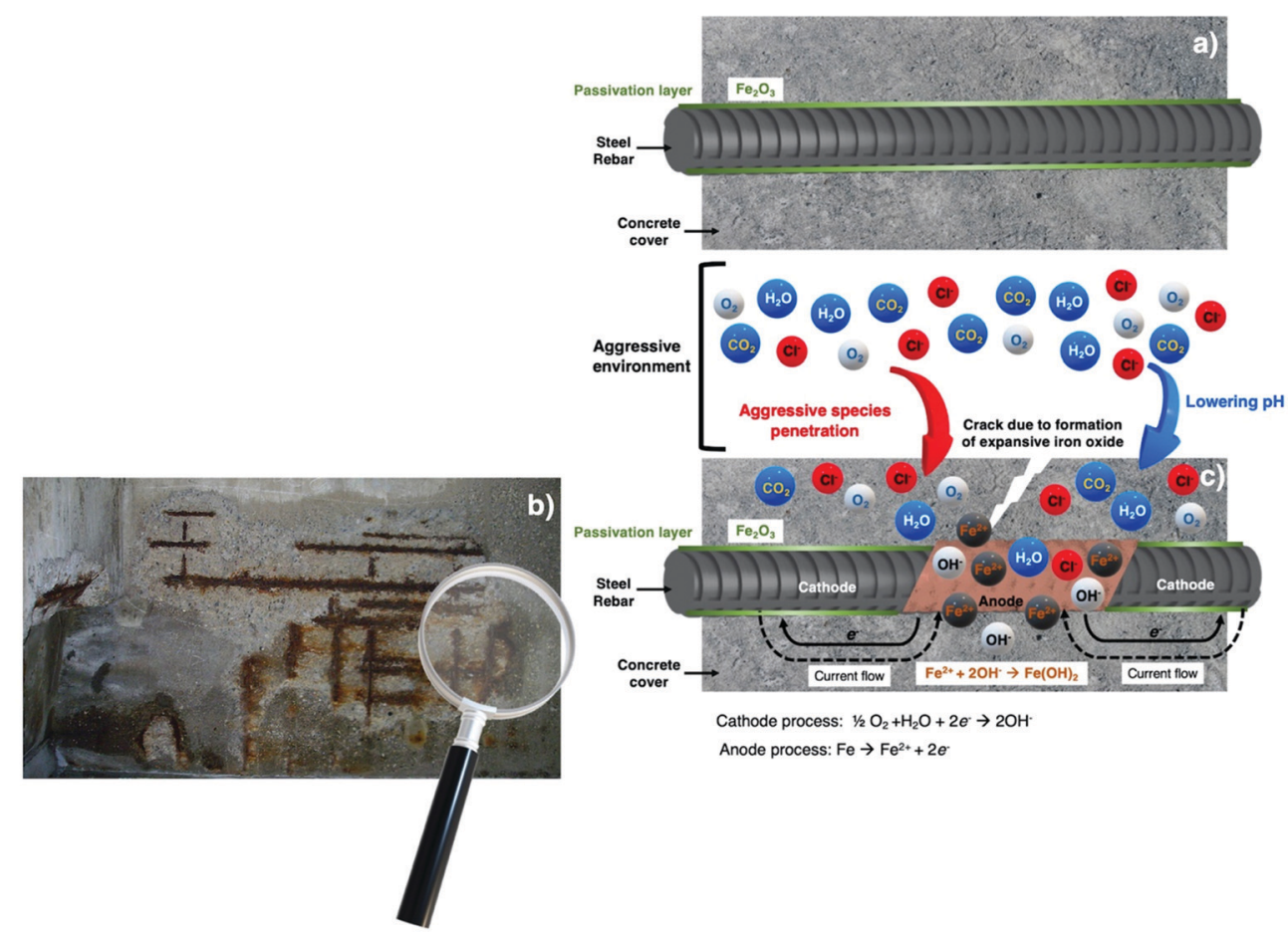

Fig. 2 Schematic representation of the reinforcement corrosion process in concrete. (a) Rebar embedded in concrete in which the protective passivation layer is represented in green; (b) photograph of a RCS highly corroded where detachment of the concrete occurred due to the formation of expansive iron oxides; and (c) corrosion process in the presence of aggressive species.

followed by concrete detachment, exposing the steel rebars (vide Fig. $2 \mathrm{~b}$ and 3 ). The progression and advancement of the corrosion process results in loss of adhesion between concrete and steel rebars, section reduction of the steel rebar and loss of ductility compromising the stability of the RCS and, in extreme cases, may lead to its collapse. ${ }^{30}$ Fig. 3 shows a schematic

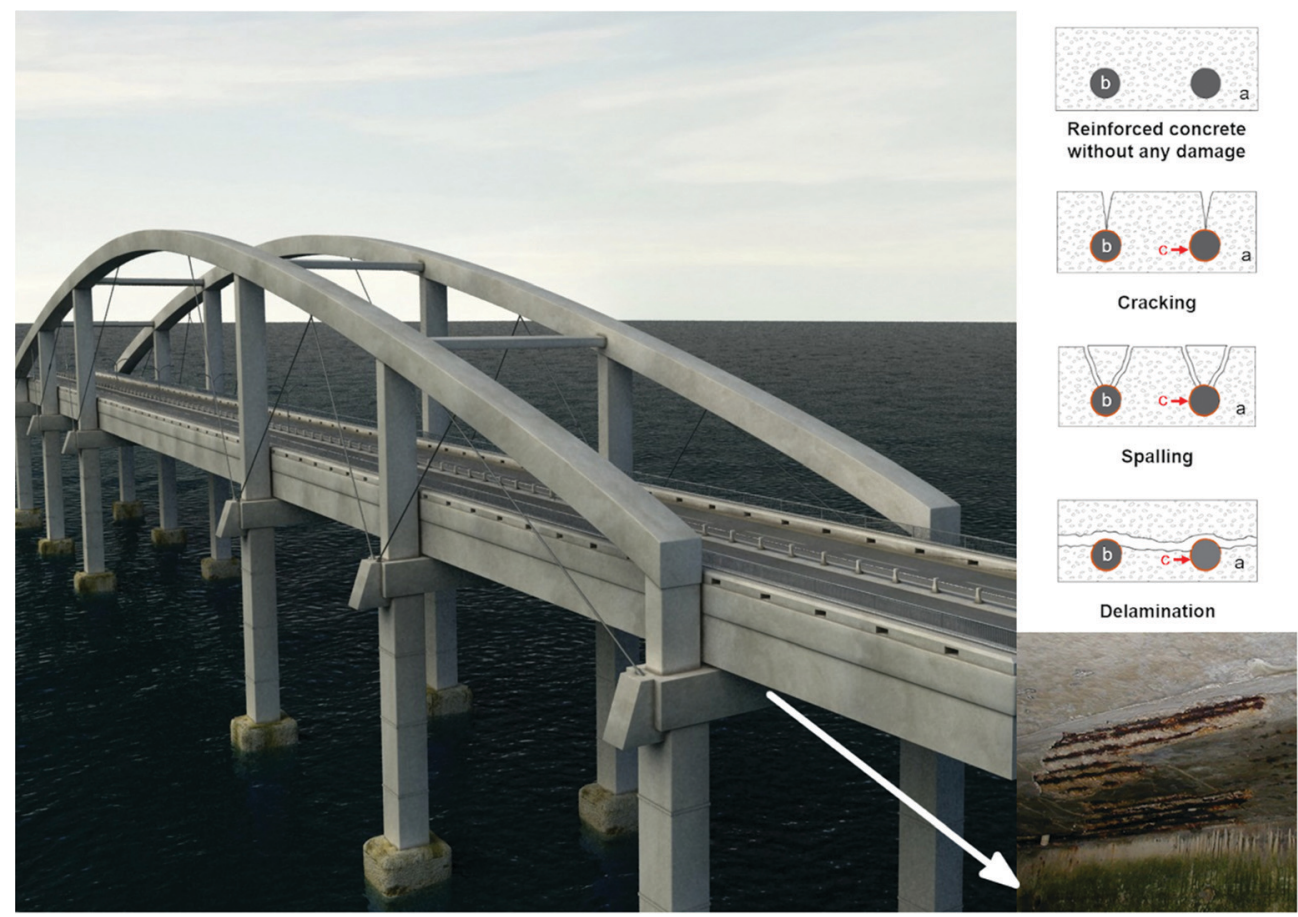

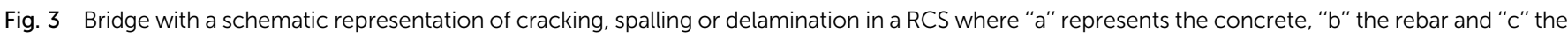
oxide layer. The photograph in the bottom right corner shows the typical feature of concrete detachment due to rebar corrosion. 
representation of cracking, spalling and delamination occurring in a RCS.

The implementation and development of effective systems and strategies for SHM of new and existing concrete and RCS allows both cost and safety benefits. Monitoring a wide range of physicochemical parameters (e.g. strain, displacement, rotation, $\mathrm{pH}, \mathrm{Cl}^{-}$, moisture, ASR) provides a rational approach for the assessment of repair options and the schedule of inspection, maintenance programs, increases the structures' service lives and therefore mitigates the environmental impact responsible for most of the construction structure degradation..$^{50}$

Optical fiber technology based on sol-gel materials has attracted increasing attention in the past two decades as one of the most researched topics within SHM sensors. ${ }^{51}$ The development of OFS based on organic-inorganic hybrid (OIH) sol-gel materials opens the opportunity of producing highly accurate and reliable sensing systems at controlled costs for SHM of civil infrastructures.

In the past thirty years, several review articles have been published in the design and application of $\mathrm{OIH}$ sol-gel materials. ${ }^{6,52-55}$ Nevertheless, most were approached from the points of view of materials and synthesis strategies. ${ }^{56,57}$ This review aims to assess the existing knowledge concerning the development of OFS based on OIH sol-gel materials with particular emphasis on OFS for SHM in the civil engineering field. The most recent advances, development, and application of this type of sensor focused on monitoring different parameters (e.g., temperature, $\mathrm{pH}$ level, $\mathrm{RH}, \mathrm{Cl}^{-}$) for SHM of concrete and RCS are discussed. The OFS reported for monitoring potassium ions $\left(\mathrm{K}^{+}\right)$and sodium ions $\left(\mathrm{Na}^{+}\right)$are also approached since it is considered that these are key parameters to monitor the development of ASR. ${ }^{45,58}$ The advantages and disadvantages as well as the perspectives for further research and future research challenges are also identified and discussed.

\section{OlH sol-gel materials: smart materials for OFS}

\subsection{Sol-gel method}

The interest in the sol-gel method was initiated in the mid-1880s on silica gel..$^{59}$ However, it was only in the 1980 s that this method was adopted by Schmidt ${ }^{60}$ and Wilkes ${ }^{61}$ for the synthesis of OIH materials. A thorough and complete review from a historical perspective can be found elsewhere. ${ }^{54}$ In the review aforementioned, the authors approached very well and in a detailed way the periods linked to the OIH beginnings to nowadays applications. Regarding the researchers that developed remarkable OIH materials, it was found that, generally, all had a common feature, their open-mindedness and spirit. ${ }^{54}$

The understanding of the mechanisms underlying sol-gel processes has been the subject of several textbooks and reviews, ${ }^{21,54,62-66}$ with several definitions being proposed. ${ }^{21,67,68}$ Therefore, the fundamentals of the sol-gel method will not be approached nor discussed in depth in this review.
The well-known sol-gel method shows numerous advantages ${ }^{21,62}$ particularly the easy fabrication of sol-gel materials and the flexibility of the process, the large number of commercial precursors available with tuneable functional groups and low environmental impact; it is a low temperature synthetic route, and enables easy composition modification and introduction of functional groups. Moreover, sol-gel materials are chemically inert, can exhibit stable host properties, and show high surface area, optical transparency, mechanical rigidity, thermal stability and negligible swelling in aqueous solvents; and their pore size and distribution can be tuned. All these features make these materials excellent choices for several purposes. The simple processing conditions and the possibility of tuning their physicochemical properties, for specific requirements, are the two main reasons for their development in a wide range of fields. This approach is outstanding compared with conventional methods (e.g., adsorption on glass surfaces, entrapment in polymer matrices and impregnation in porous glass powders). Tuning the sol-gel network porosity allows the entrapped species to remain accessible and interact with external chemical species or analytes. ${ }^{69}$ However, regardless of all these benefits, diffusional limitations inside the porous sol-gel network, poor reproducibility of results and low sensitivity may occur. Fig. 4 shows a schematic representation of the main products obtained by the sol-gel process.

The materials obtained by the sol-gel method range from inorganic glasses to complex OIH materials. Compared with pure inorganic glasses, OIHs show significant advantages including an improvement/increase of the flexibility of the silica gel, enabling production of thick and crack-free films and introduction of reactive functional groups into the $\mathrm{OIH}$ network which can be used to anchor molecular recognition groups $^{71,72}$ and also allow entrapping higher concentrations of species with sensing abilities. The components used during the synthesis will dictate the final properties of the materials. The use of an inorganic network is strongly limited in terms of implementation and new functionality input. A way to ease the shaping step and to tailor the bulk properties of the final OIH materials is the introduction of an organic component covalently linked to the network. This can be achieved using an organo-alkoxy-silane. The organic component brings flexibility to the hybrid network and modulates either the chemical or mechanical properties. ${ }^{57}$ Some organic precursors such as methyltriethoxysilane (MTES) (vide Scheme 1) may provide flexibility, while fluorinated alkyl-silanes are known for their hydrophobic properties. Precursors such as 3-trimethoxysilylpropyl-methacrylate (MEMO), 3-aminopropyl-triethoxysilane (APTES) and 3-glycidoxypropyl-methyltriethoxysilane (GPTMS) (vide Scheme 1) need to be thermally or photo-chemically cured. These precursors lead to the formation of an organic network linked to an inorganic one. Scheme 1 shows the chemical structures of the most common silicon alkoxides (including organic alkoxides) used as precursors in the synthesis of OIH materials. The precursors that contain polymerizable functional groups such as vinyl (VTMS), epoxide (GPTMS) and methacrylate (MAPTS) allow forming an organic network 


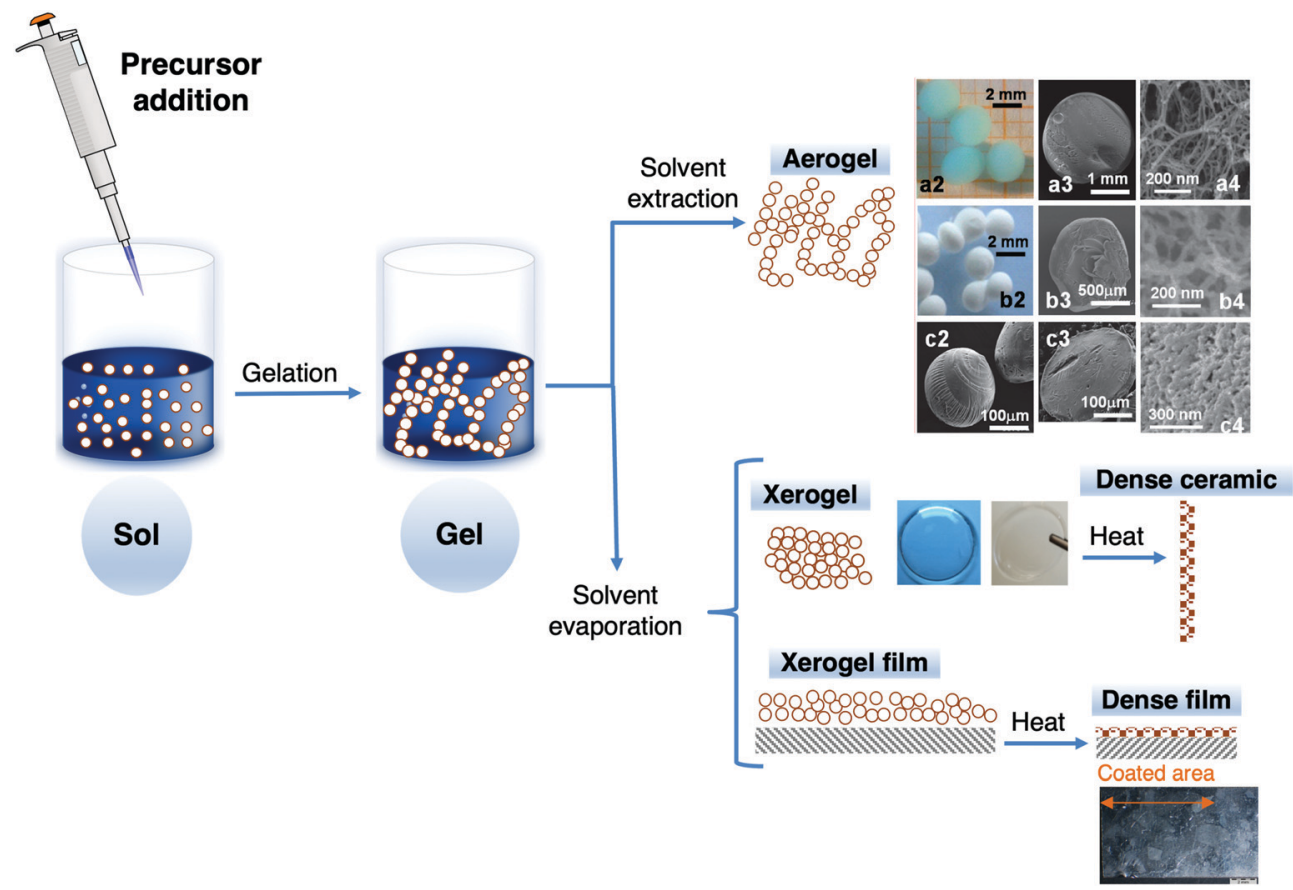

Fig. 4 Products obtained by the sol-gel process including aerogel spheres ( $a 2$, b2 and c2) and cross-sections of aerogel spheres (second and third columns) of Cu-alginate (row a), chitosan (row b) and carrageenan (row c), xerogel and films. Adapted and reproduced by permission of The Royal Society of Chemistry. ${ }^{70}$
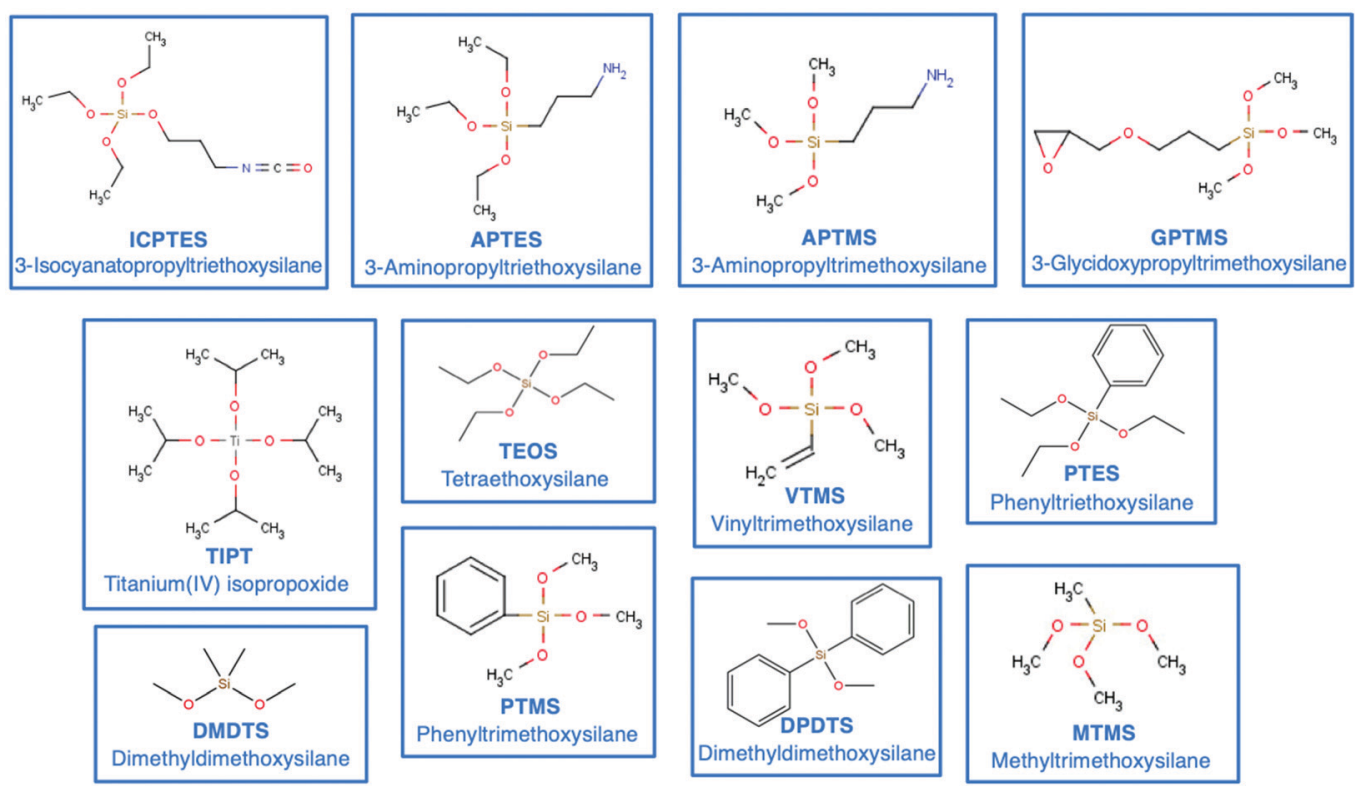

Scheme 1 Chemical structures and acronyms of the most common silicon alkoxides (including organic alkoxides) used as precursors in the synthesis of $\mathrm{OIH}$ materials.

and contributing to additional densification of the final product.

The main steps involved in the sol-gel process are schematized in Fig. 5 and 6.

In the last few decades, different types of aerogels have emerged $^{73}$ mainly due to the combination of low density and high mesoporosity silica aerogels. Several reported applications are related to thermal insulation in the aerospace and building sectors. Linhares et $a l^{74}$ published a review paper where the main research achievements on silica-aerogel matrices with different types of fibers were highlighted. The properties of the different fibers available, as well as the strategies used to advance their applications, were debated. The effect of the fiber properties (i.e., morphology, orientation, amount, and thermal 

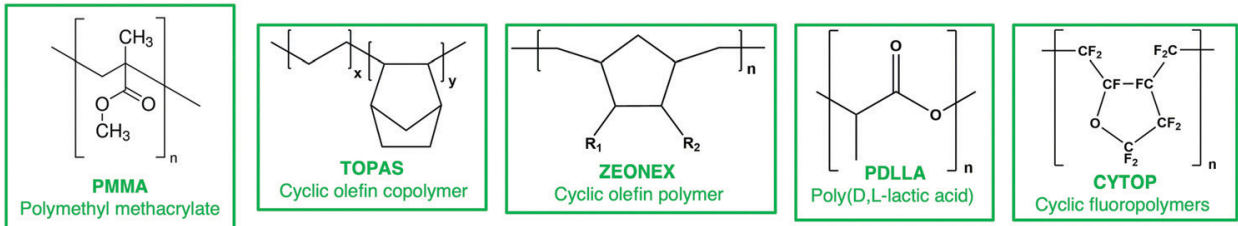

Scheme 2 Chemical structures of typical polymers used in POF.

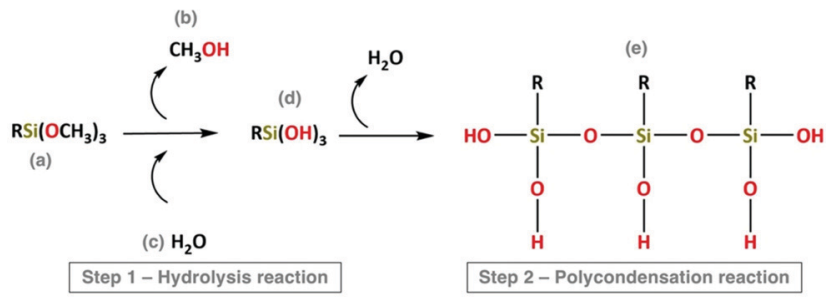

Fig. 5 Schematic representation of hydrolysis (step 1) and polycondensation reactions (step 2). Reproduced under the terms and conditions of the Creative Commons Attribution (CC-BY) license (http://creativecommons. org/licenses/by/4.0/). ${ }^{55}$

resistance) on the aerogel composites was also assessed. Considering the silica aerogels' main properties, it is undeniable that their potential is huge for thermal insulation purposes. ${ }^{75}$ Generally, a roof without traditional thermal insulation materials to start with, the energy cost associated with maintaining the known comfortable temperature $\left(20-22{ }^{\circ} \mathrm{C}\right)$ is saved, typically, within seven years, depending on the material chosen. Regarding materials with higher performances and considering the same investment cost, this can be achieved within two to three years. Therefore, the construction field has remarkable market opportunities in the insulation thermal application using aerogel materials.

Aerogels also have interesting applications such as hydrophobic surfaces, ${ }^{76}$ catalysis, ${ }^{77}$ flame retardants, ${ }^{78}$ adsorption ${ }^{79,80}$ and environmental cleanup, ${ }^{73}$ piezoresistive sensors, ${ }^{81}$ energy storage devices ${ }^{82,83}$ and biomedical. ${ }^{5}$ Fig. 7 shows relevant examples of aerogel applications in different fields including aerospace, biomedicine, environmental remediation, electrotechnics, green and food related technologies, and construction.

To obtain devices with higher energy storage capacity, aerogels are required as bulk materials (even reduced graphene oxide) do not have a surface area as large as that of aerogels. Remarkable developments have been achieved (vide Fig. 7); an example is the synthesis of an aerogel based on graphene oxide. The surface area of graphene oxide $\left(2630 \mathrm{~m}^{2} \mathrm{~g}^{-1}\right)$ can be improved by two or three times in the aerogel form. ${ }^{82}$ This aerogel showed notable properties by combining very low density, high electrical conductivity and compressibility within the same matrix. ${ }^{84}$ This work was a landmark for further development in the field of aerogel materials for several purposes including sensing applications. Another study that deserves to be mentioned was the development of a reticulate dual-nanowire aerogel composed of $\mathrm{FeS}_{2}$ nanowires and carbon nanotubes (CNTs). ${ }^{85}$ In this case, a low-cost solvothermal method was used and the adjustment of the precursor concentration allowed tuning the Young's modulus, density and conductivity of the aerogel.

Fig. 8 shows remarkable examples of OIH sol-gel materials for multi-functional applications. Ghajeri et al. reported a successful case of aerogel technology transfer from the laboratory

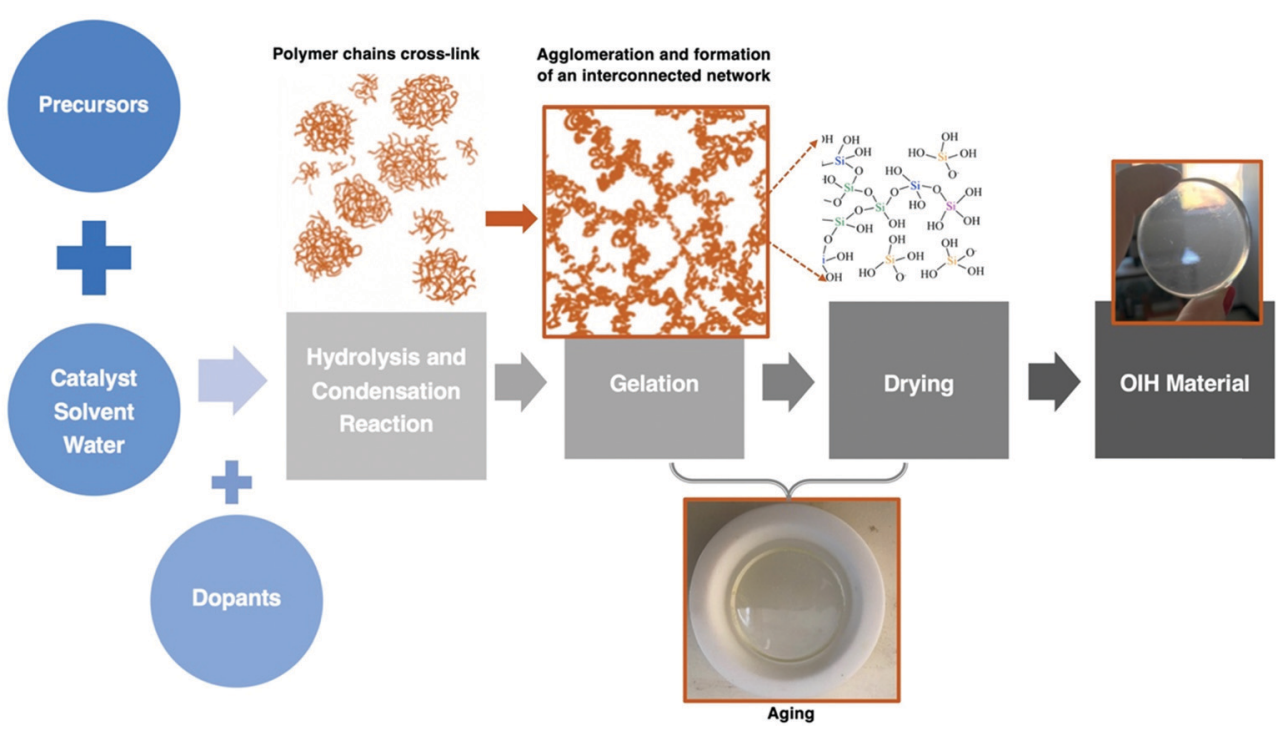

Fig. 6 Schematic of the main stages involved in the sol-gel method. Adapted from ref. 21. 


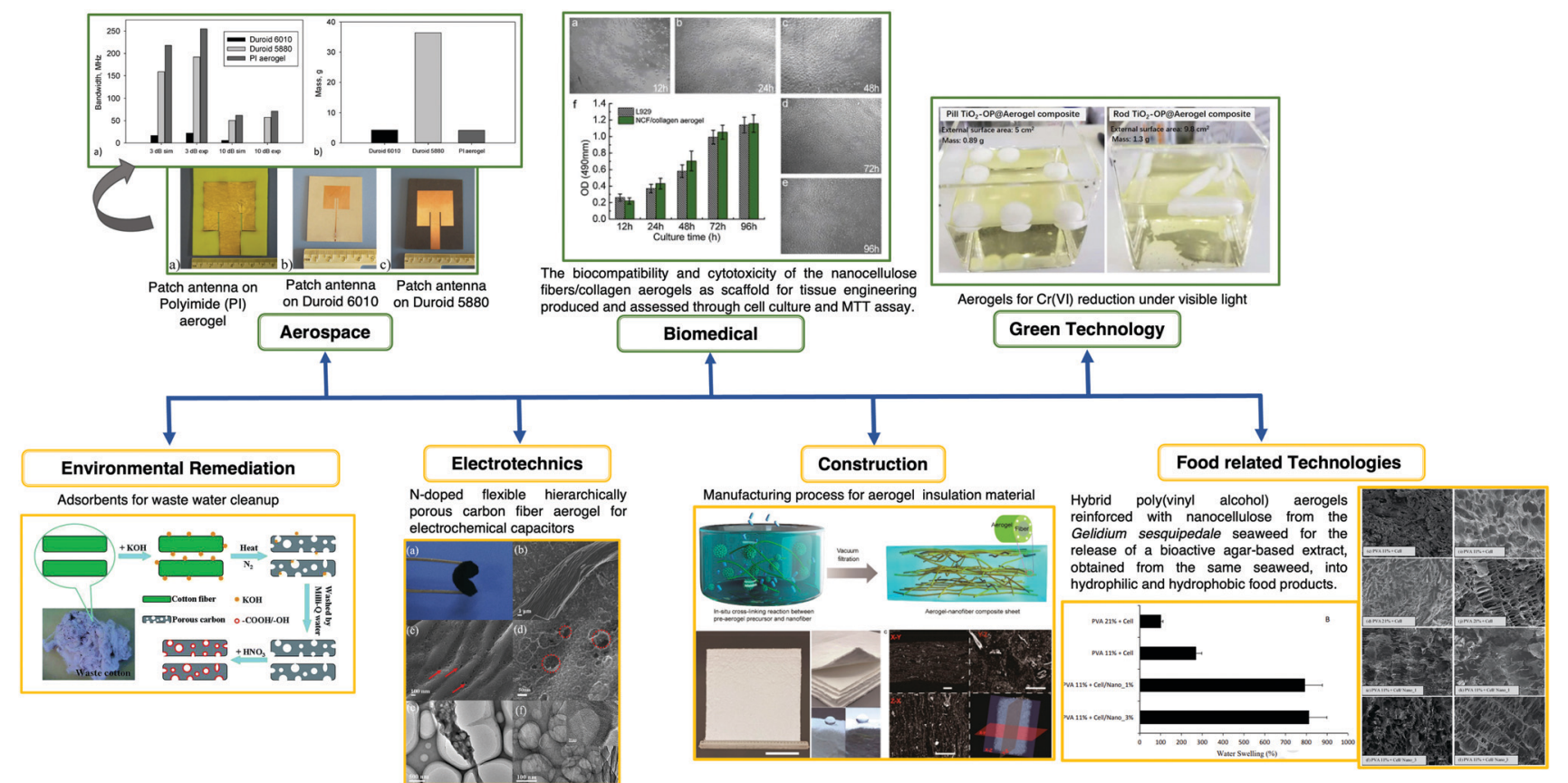

Fig. 7 Schematic of aerogel applications in a wide range of fields, i.e., aerospace, biomedicine, environmental remediation, electrotechnics, green and food related technologies, and construction. Reprinted and adapted with permission from ref. 86-92. Copyright 2012 American Chemical Society. Copyright 2014 Elsevier. Copyright 2015 Royal Society of Chemistry. Copyright 2018 American Chemical Society. Copyright 2019 Elsevier. Copyright 2020 American Chemical Society.

to the market. ${ }^{93}$ A green nano-porous material known as Quartzene $^{\circledR}$ (vide Fig. 8) is synthesized using low-cost precursors (i.e., $\mathrm{MgCl}_{2} \cdot 6 \mathrm{H}_{2} \mathrm{O}, \mathrm{CaCl}_{2} \cdot 2 \mathrm{H}_{2} \mathrm{O}$ and a sodium silicate solution) and a drying process at ambient pressure. Quartzene ${ }^{\mathbb{R}}$ was reported for several industrial applications such as air/water cleaning and thermal insulation.

\subsection{Types and roles of sol-gel materials used on optical sensors}

Optical sensors (OS) are a topic of extensive research and development due to the number of attractive features offered by this technology. These include the multiplicity of optical techniques already well established for chemical and biochemical analysis, the availability of materials and components and the geometric flexibility allowing miniature disposable optical waveguides to remote OFS.

Generally, an OS consists of a recognition element, where specific interaction and identification of the analyte occurs; a transducer element, which converts the recognition process into a measurable optical signal; and an optical device (process unit), which involves at least a light source and a detector that identifies and converts the change in the optical properties. The optical properties measured can be absorbance, reflectance, luminescence, light polarization, Raman scattering, etc. Systems for monitoring of an analyte through optical means can be classified into direct and reagent-mediated sensing systems. For direct sensing systems, the optical properties (absorption, fluorescence, emission, etc.) of the analyte are monitored. In the case that the analyte does not have adequate intrinsic optical properties to monitor, a reagent-mediated sensing system may be applied. ${ }^{94}$

The use of the sol-gel process to produce sensor film materials for OFS attracted considerably research interest in distinct research areas. ${ }^{95,96}$ As already mentioned, this is mainly explained due to the easy fabrication of materials and the design flexibility of the process. In most applications, a sol-gel-derived material is used to provide a microporous support matrix in which the analyte-sensitive species are entrapped and into which the analyte molecules may diffuse and interact. Such materials have been used in a wide range of sensor configurations including monoliths ${ }^{97}$ and deposited films, ${ }^{16}$ end-coated and side-coated optical fibers ${ }^{98,99}$ and planar waveguides. ${ }^{100}$ The deposition of thin coatings on the fiber surface is currently attained by dipping the OFS in the solution between the sol and the gel phase at a controlled withdrawal speed. After removing the OFS from the OIH sol, the material attached onto the surface of the substrate will undergo the subsequent steps, i.e., gelation and drying processes. The low amount of material deposited will result in a very thin and porous film with a thickness ranging from a few nanometers to micrometers. Due to the low thickness of the material deposited, the gelation and drying processes occur much faster than the one for the formation of the respective monolith. Nevertheless, it should be kept in mind that the thickness of the dipped layer is highly dependent on the viscosity of the sol and on the withdrawal speed. Generally, if the withdrawal speed decreases and/or the sol viscosity increases, the result will be a film with higher thickness. The evaporation rate also 

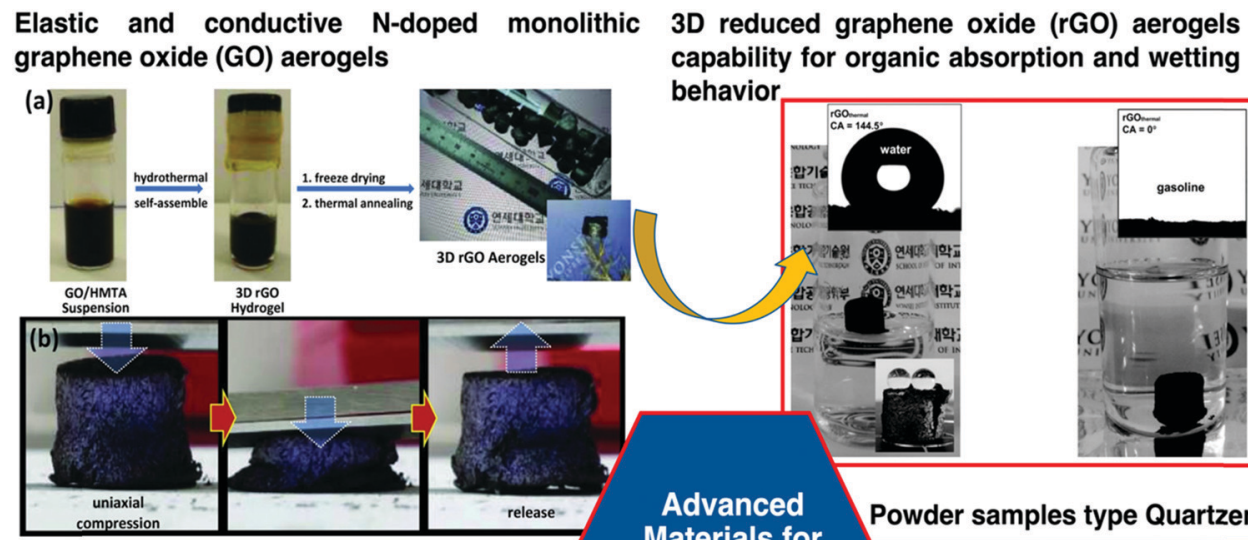
behavior

High-performance strain sensor and a high areal capacity rechargeable Anode

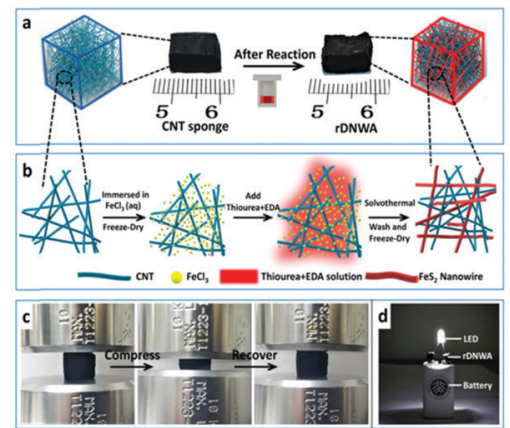

Advanced

Materials for

Multifunctional

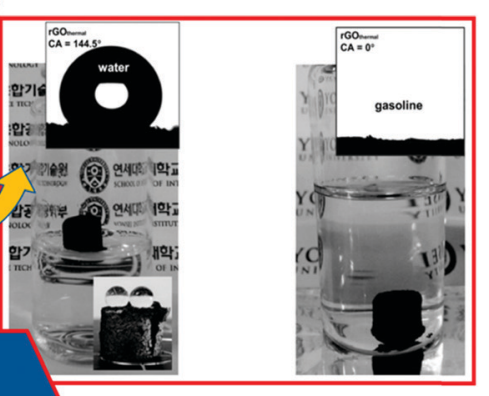

Powder samples type Quartzene ${ }^{\circledR}$

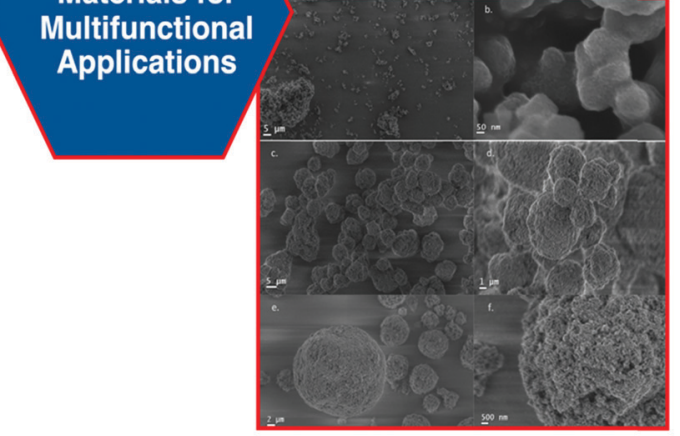

Fig. 8 Schematic of aerogel applications in a wide range of fields, i.e., aerospace, biomedical, environmental remediation, electrotechnics, green and food related technologies, and construction. Reprinted and adapted with permission from ref. 84, 85, and 93 . Copyright 2015 Elsevier. Copyright 2018 Wiley. Copyright 2019 Wiley.

influences the film thickness, and the final properties of the material will be highly conditioned by the environmental atmosphere around the substrate. The temperature, moisture or operating in still environments or under flow will affect the final properties of the film; therefore, the parameters should be cautiously controlled in order to attain reproducible results.

Sol-gel materials have been extensively reported in bioelectrochemistry. ${ }^{29,101}$ Several authors described the immobilization of biomolecules within functionalized sol-gel materials to construct biosensors ${ }^{9,24}$ mostly due to their high biocompatibility. Besides all advantages, most sol-gel derived materials are electronic insulators with low charge-transfer efficiency and substrate diffusion. To overcome this drawback several studies have been conducted to obtain suitable sol-gel materials for sensing applications.

The use of luminescent films has attracted high attention for sensing applications, which is driven mainly by their stability, tuneability, real-time detection capability, selectivity, and sensitivity to the analyte. Moreover, the application of sol-gel materials as immobilization membranes in luminescent sensing systems has been shown in a wide diversity of frameworks. ${ }^{102-105}$ When a sensing luminophore (or another doping species) is introduced into the initial sol-gel solution, its molecules will be encapsulated within the resulting $\mathrm{OIH}$ matrix structure. The properties of the sol-gel thin films proved to be very auspicious for the encapsulation of different materials such as organic and inorganic species with distinct response, e.g., luminescent and/or colorimetric for detection of distinctive types of analytes (gas, $\mathrm{pH}$, ions, biomarkers) in different environments such as gaseous, aqueous, and biological environments.

OIHs may be classified according to the type of bond established between the organic and inorganic components. Therefore, OIHs are generally divided into three classes, namely: class I includes the OIHs in which the organic and inorganic components interact via hydrogen bonds, van der Waals forces or ionic bonds; class II includes the OIHs in which the organic and inorganic components are bonded by covalent bonds and class III includes the OIHs in which the interactions between the organic and inorganic components are based on the combination of both types of interactions assigned to the OIHs from classes I and II. ${ }^{106}$ Particular types of OIH materials have been designated as ORMOSILs, which is an acronym generated from ORganically MOdified SILicates. It has been reported that class II ORMOSILs using as precursors tetraethoxysilane (TEOS) and mono-alkylsiloxanes, i.e. $\left(\mathrm{C}_{n} \mathrm{H}_{2 n+1}\right)-\mathrm{Si}-$ $(\mathrm{OR})_{3}$, showed suitable sensitivity and long-term stability. ${ }^{107}$ Others ${ }^{108}$ described xerogels using the precursors methoxysilanes, tetraethylorthosilane (TEOS) and n-propyltrimethoxysilane doped with $\mathrm{Ru}$ (II) or $\mathrm{Pt}(\mathrm{II})$. The obtained products led to the production of sensing materials with improved sensitivity compared with those of class II ORMOSILs. 
The OIH sol-gel matrix can also be doped by introducing a dry film in a solution containing a dye. The species are transferred inwards into the OIH matrix network. The strength and form of interaction established between the host network and the attached species are determined by the chemical affinities of the respective functional groups. This alternative, however, is more prone to leaching when sensing is conducted in certain environments such as aqueous media. The leaching of the species, as previously mentioned, may be avoided by adjusting the properties of the $\mathrm{OIH}$ pore structure. The pore sizes, besides promoting or avoiding species leaching, influence how the analyte diffuses in and out of the OIH sensing membrane, which in turn influences the sensor sensitivity and response time. This is particularly pronounced for sensing by luminescence quenching. In the case of the $\mathrm{OIH}$ film, the presence of distinctive microenvironments, i.e., the luminophore does not have steady access to the analyte, may lead to non-linear outputs. Another important property that may influence the sensing membrane selectivity is the sol-gel material polarity. For instance, TEOS based materials are generally hydrophilic, ${ }^{109}$ which promote proton permeability and make them appropriate matrices for $\mathrm{pH}$ and ion detection. When the organic component increases, the material will become more hydrophobic with low permeability and, in that case, thicker films and higher elasticity are achieved, reducing the cracking probability.

The large availability of precursors (vide Scheme 1) allows tuning the optical properties and porosity. The refractive index (RI) of fused silica is 1.46 in the visible range, and when the porosity of the sol-gel material increases, the RI decreases. The other case includes aerogels, structures which are highly porous and whose RI can be as low as $1.01 .{ }^{110}$ In contrast, the RI of a titanate-based sol-gel material is above 2.2 in its amorphous form, which makes sol-gel glasses suitable for optical waveguide applications. Few studies have reported one-step sol-gel preparation of ORMOSIL materials with adjustable RIs changing from
1.22 to 1.44 . OIH sol-gel materials synthesised are generally used for adjusting the RI of ORMOSIL materials from 1.22 to 1.0. This can be achieved due to the organic components in ORMOSIL materials that can suppress capillary pressure during the drying process and therefore relieve the network shrinkage and maintain suitable porosity. The precursors generally used to achieve such properties may be TEOS with methyltriethoxysilane (MTES) (vide Scheme 1) and dimethyldiethoxylsilane. The use of TEOS and PTES as precursors (vide Scheme 1) allows adjusting the RI from 1.21 to $1.27 .^{111}$

\section{Optical fiber sensors and applications}

Optical fiber sensors are a topic of study for many scientists. The proof of this is the number of publications found since 1990. Searches in Springer Link, RSC (Royal Society of Chemistry Journals database), Science Direct and Wiley Online Library including the keywords "fiber" plus "optical" and "sensors" returned more than 138000 scientific articles published since 1990. A bar chart with the number of identified scientific publications found in the last few decades is shown in Fig. 9.

From the bar chart (vide Fig. 9) it can be observed that the number of publications in 2019 is about eight times higher than the number of those published in 1990. Fig. 9 also shows that in the past ten years the number of publications increased every year. Besides, it should be emphasized that a mature and lucrative industry using OFS in fields such as monitoring of physical parameters, i.e., temperature or strain, has been achieved in the last few decades. Nevertheless, despite their attractive properties, research on OFS is still a broad R\&D field to fulfil the high demand of sensing devices for industrial applications. This is reflected by the huge number of publications found.

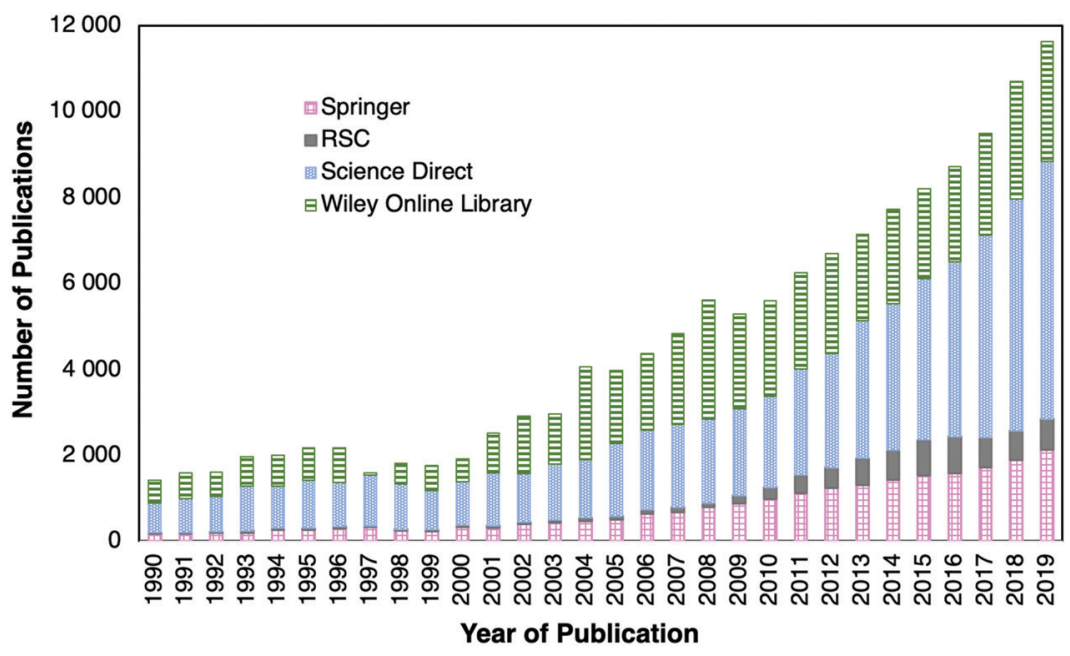

Fig. 9 Bar chart of scientific publications published from 1990 until 2019 found on Springer Link, RSC (Royal Society of Chemistry Journals database), Science Direct and Wiley Online Library using the keywords "fiber", "optical" and "sensors". 
Klimant et $a l .{ }^{112}$ were the first researchers to report the use of chloroform-soluble OIHs on OFS for oxygen sensing. Soluble phenyl-substituted OIHs were prepared using as precursors PTMS and trimethylmethoxysilane. The synthesis method described in the aforementioned manuscript is the basis for the thousands of OIH based oxygen sensors. These OIHs have replaced the Clark oxygen electrode in several fields and are nowadays produced by many such as PreSens GmbH, Germany. ${ }^{113}$

Regarding the medical sensors developed, the vast majority of the work reported for advanced biochemical parameters, when compared to the ones commercially available, ${ }^{114}$ remains at the laboratory stage. The main reasons for this outcome may be the additional constraints that are present together with the need for a multidisciplinary approach. Research resilience and funding in pursuing further developments are also causes that explain why so many prototypes remain at the laboratory stage. The main limitations include the immobilization of the recognition elements in host materials, leaching of sensing recognition elements and diffusion of interfering species. In each case a specific development solution needs to be tailored and years of research are necessary. Moreover, this means dealing with several research areas including biology, chemistry, physics, and materials science. Moreover, biocompatibility, chemical and mechanical stability, easy fabrication and compatibility with mass production are likewise challenging concerns requiring also engineering and medical knowledge. A biosensor based on immobilized biomolecules should provide information such as whether or not the analyte is present (specificity), fast time response, and at the level (sensitivity) at which the response is transduced into an optical signal that can be amplified and analyzed. The complexity and diversity of analytes include proteins (antigens, antibodies, and enzymes), nucleic acids, or other biological or metabolic receptors, and whole cells for the detection of target analytes. Such sensing biomolecules should be bound to the surface of a signal transducer with a required specific chemical, electrical, or optical property. The biological recognition generates a quantifiable signal, which is linked to the amount or concentration of the analyte. Therefore, biomolecule immobilization plays a vital role in developing biosensors with high sensitivity, selectivity, time response and acceptable lifetimes. Nevertheless, most of the developments over the past thirty years lead to a huge progress of OFS for a wide range of applications. This is clearly evidenced in Table 1 that shows the most representative review articles published since 1989. It is undeniable that the number of review manuscripts published is remarkable, supporting that several research efforts were made in the OFS field. Wolfbeis ${ }^{115-119}$ and later the same author together with Wang ${ }^{120-123}$ showed an outstanding performance in this field and published several review manuscripts focused on this theme. Their reviews reflected the state of the art since 1997 and published reviews on a regular basis until 2020. These authors were, undoubtedly, the ones that most contributed with review manuscripts in this field. The new materials and innovative systems based on OFS were also discussed. These publications are strong evidence that OFS had a remarkable impact in a wide range of fields including chemistry, the environment, and biochemistry.

According to Table 1, the year that reported the highest number of review manuscripts was 2015. The review manuscripts focused on the application of OFS in other fields such as civil engineering were much less reported when compared to fields such as medicine and biosensors. This huge difference is easily explained by the research community interest that generally tackles large-scale problems (Health Conditions \& Diseases), which naturally have a higher impact in society. Few things impact your life more than a serious health problem, and therefore, considering the funding availability and rationalization it is easier to leave other areas less explored such as areas related to and within the civil engineering field.

\subsection{OFS: operating principles and structures}

Quantitative measurement of physical, chemical, or biological quantities that interact with optical properties can be attained with the advantages of using optical fibers. ${ }^{165}$ Fig. 10 shows a tridimensional illustration of an optical fiber in a bundle cable.

Fibers are often united into cables for mechanical and environmental protection. A polyethylene sheath encloses the fibers within a strength element such as steel or Kevlar strands. ${ }^{166}$ Typically, they are made of fused silica, but other materials have proved to be suitable to form waveguide structures, such as heavy metal fluoride glasses such as ZBLAN ( $\left.\mathrm{ZrF}_{4}-\mathrm{BaF}_{2}-\mathrm{LaF}_{3}-\mathrm{AlF}_{3}-\mathrm{NaF}\right)$, due to their almost perfect attenuation signature. ${ }^{167}$ Chalcogenide glass fibers for midinfrared emission and transmission have been the subject of research for several years now, ${ }^{168}$ as they have the advantages of a wide transparency window (over $20 \mu \mathrm{m}$ ) and high optical nonlinearity (up to a thousand times higher than those of silica glasses).

Plastic optical fibers (POF) are polymer based (Scheme 2), typically polymethyl methacrylate (PMMA), coated with an external layer to improve their guiding properties. ${ }^{169}$ Other low water absorption materials are cyclic olefin copolymers (TOPAS), ${ }^{170}$ high glass transition temperature cyclic-olefin polymer (ZEONEX), ${ }^{171}$ biocompatible poly(D,L-lactic acid) (PDLLA) ${ }^{172}$ and cyclic transparent amorphous fluoropolymers (CYTOP). ${ }^{173}$

OFS are generally classified based on their geometry, dispersion, signal processing ability, birefringence and polarization properties. ${ }^{174}$ They can also be classified according to the number of optical modes that can propagate through the fiber into single-mode and multi-mode. Fig. 11 shows the single mode and multimode fibers. Additionally, OFS can also be classified according to the RI shape into step-index and gradedindex. In the former case the RI profile is uniform along the fiber core, while in the latter case the RI is made to change as a function of the distance from the center of the fiber.

Fig. 12 shows the elementary building blocks of an OFS involved in a system where the optical source can be either a laser (tunable or single frequency) or a broadband source, a transducer and a receiver and further signal processing blocks. 
Table 1 The main review articles about OFS published in the last few decades

Discussed subject matter

\begin{tabular}{|c|c|c|}
\hline Year & Ref. & Authors \\
\hline 1989 & 124 & Norris \\
\hline 1993 & 125 & Narayanaswamy \\
\hline 1996 & 126 & Merzbacher et al. \\
\hline 1999 & 127 & Rogers \\
\hline 2000 & 115 & Wolfbeis \\
\hline \multirow[t]{2}{*}{2001} & 128 & Kuswandi et al. \\
\hline & 129 & Leung \\
\hline 2002 & 116 & Wolfbeis \\
\hline \multirow[t]{2}{*}{2003} & 130 & B. Lee \\
\hline & 131 & James and Tatam \\
\hline 2004 & 117 & Wolfbeis \\
\hline 2006 & 118 & Wolfbeis \\
\hline 2007 & 132 & Sharma et al. \\
\hline \multirow[t]{4}{*}{2008} & 133 & McDonagh et al. \\
\hline & 134 & Yeo et al. \\
\hline & 135 & Majumder et al. \\
\hline & 119 & Wolfbeis \\
\hline 2010 & 136 & Annamdas \\
\hline 2011 & 137 & Peters \\
\hline
\end{tabular}

The advantages, disadvantages and applications of chemical OFS were discussed as well as their transduction principles. OFS classification was also given.

The principles of chemical transduction and the signal processing systems that are used in conjunction with optical chemical sensors were reviewed.

OFS developed until 1995 to detect strain in concrete were debated.

Review focused on distributed optical fiber sensing.

Review based on the period from 10/1997 to 01/2000 and focused on OFS for chemical, environmental, and biochemical applications.

Review focused on OFS based on immobilized enzymes for biosensing applications.

The potential of OFS for monitoring of concrete structures was reviewed.

Review on OFS covering the period from $01 / 2000$ to $12 / 2001$.

Review on OFS where the author concluded that FBGs have been the most widely studied topic among different OFS technologies.

The properties of LPGs as well as the methods employed in their fabrication were discussed. LPGs' background, and their sensitivities and implementation as sensor elements were reviewed.

Review on OFS covering the period from 01/2002 to 01/2004.

Review on OFS covering the period from $01 / 2004$ to $12 / 2005$.

Review on the past, present, and future scope of surface plasmon resonance (SPR) based OFS. The mechanism of the SPR technique for sensing purposes was debated. Different techniques and models were discussed.

Developments in optical chemical sensing between 2000 and 2007. The optical principles used in chemical sensing were also debated.

Different OFS reported for humidity monitoring covering intrinsic and extrinsic sensor configurations. The application in concrete was superficially discussed.

Review focused on the research development of FBGs for SHM. FBG sensors in strain detection and the effect of temperature in strain measurement were debated. It was concluded that FBG sensors are a suitable solution in a number of applications.

Review on OFS covering the period from 01/2006 to 01/2008.

A complete overview on OFS systems and their applications was presented.

Review focused on the advances in both multi- and single-mode POF based strain and temperature sensors. It was concluded that polymer FBG or microstructured POF sensors, which can deform along with a flexible structure, may be incorporated into thin film sensing devices or structural skins for several applications (e.g., aerospace, marine and civil engineering).

138 Chen et al.

139 Bogue

$140 \quad$ Steiner et al.

141 Kemling et al.

$201214 \quad$ Monton et al.

$2013 \quad 120 \quad$ Wang and Wolfbeis

142 Sabri et al.

143 Rego

Alwis et al.

$2014144 \quad$ Berghmans and Thienpont 145 Kotowski et al.

Wang and Wolfbeis

$201510 \quad$ Leung et al. 146 Pospíšilová et al.

Qazi et al.

Ricciaridi et al.

Urrutia et al.

Di Sante
FBG sensor technology and the status of research and applications were reviewed. The authors concluded that FBG sensor technology is one of the most practical technologies.

The applications of commercially available OFS since the 1970s were reviewed. It was shown that OFS are employed in several physical sensing applications.

Review focused on optical sensing of glucose and the different methods used to monitor the optical properties. The advantages and disadvantages of the different methods were assessed.

Perspective focused on recent optical sensor devices that use nanostructured materials.

Sol-gel methods for immobilization of proteins and functional nucleic acids within silica-based materials for OFS, microarray-based multianalyte sensors and bioactive paper-based test strips.

Review on OFS covering the period from $01 / 2008$ to $09 / 2012$.

Review focused on OFS and their most beneficial applications.

Fabrication of LPFGs in the turning points using the electric arc technique was discussed. The configurations for refractometric sensing systems based on evanescent fields combining LPFGs and SPR to reach higher resolutions were reviewed.

Review on OFS application for RH and moisture monitoring in a wide spectrum of applications including SHM of civil engineering structures.

Developments in POF technology. The potential advantages from the nature point of view of the polymer materials were debated.

Summary of the strategies for patterning the flat tip of an OFS. The techniques self-assembly, lithographies, through-fiber patterning, hybrid techniques, and strategies for mass manufacture were discussed.

Review focused on the optical methods for sensing $\mathrm{O}_{2}$. The properties of the most often used indicator probes and polymers were discussed.

OFS principles were described. OFS application to monitor different structures was reviewed.

Theory, fabrication techniques and analytical results reached with OFS (chemical/biological) were reviewed. The main OFS advantages stated were the measurement of small sample volumes in flammable and explosive/harsh environments, immunity to electrical noises, miniaturization, geometrical flexibility, remote sensing in inaccessible sites and multi-sensing.

The optical chemical sensors for determination of environmental pollutants were reviewed. The classes and sensing techniques for optical chemical sensing were discussed, including FOS.

Broad overview of lab-on-fiber biosensors focused on lab-on-tip platforms, in which the labs are integrated on the optical fiber surface.

A classification of OFS based on coatings doped with NPs was proposed. Absorbance, interferometry, fluorescence, gratings, and resonance phenomena were briefly reported.

SHM of composite aircraft structures using OFS was reviewed, considering both the multi-point and distributed sensing techniques. 
Table 1 (continued)

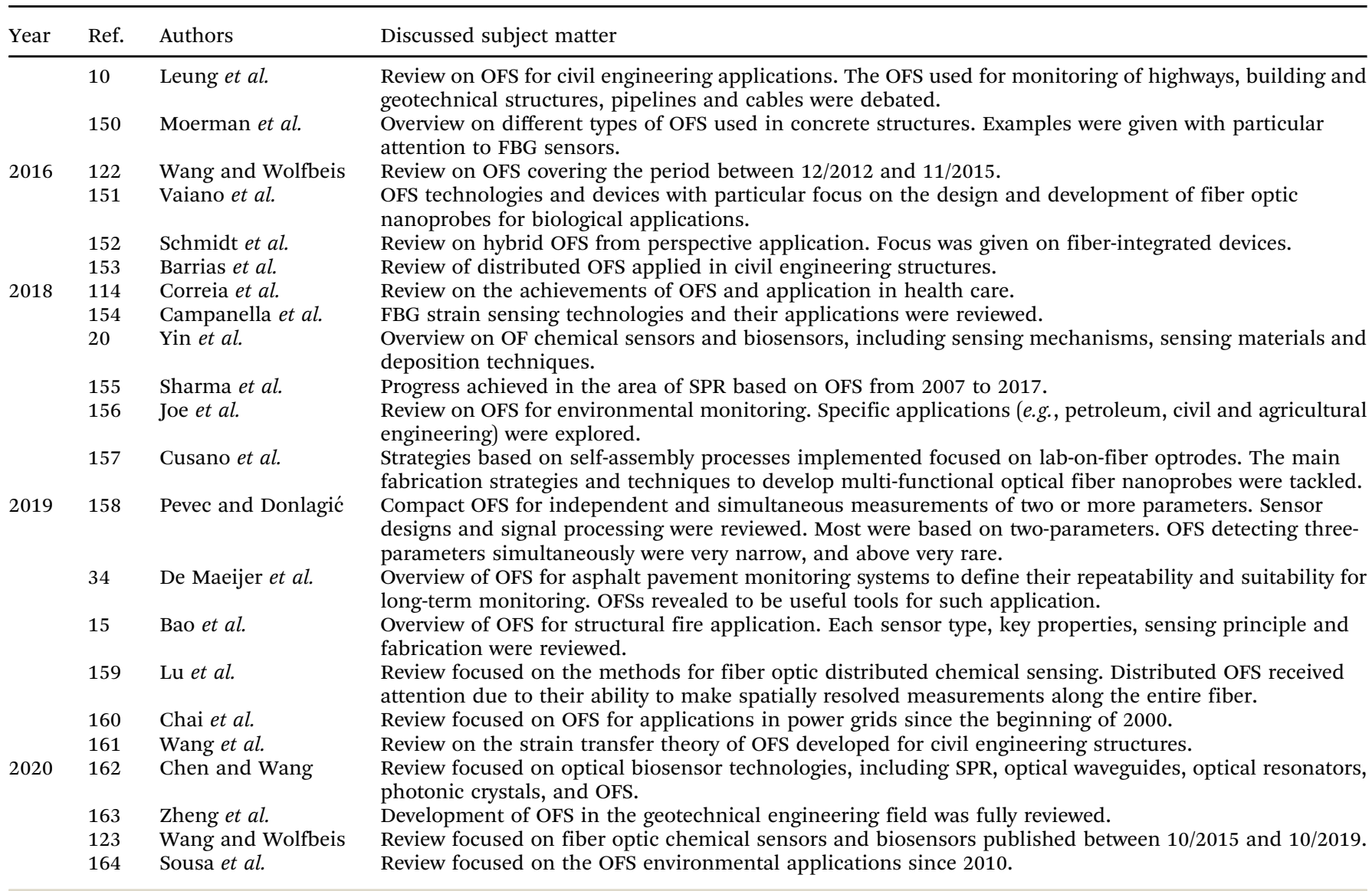

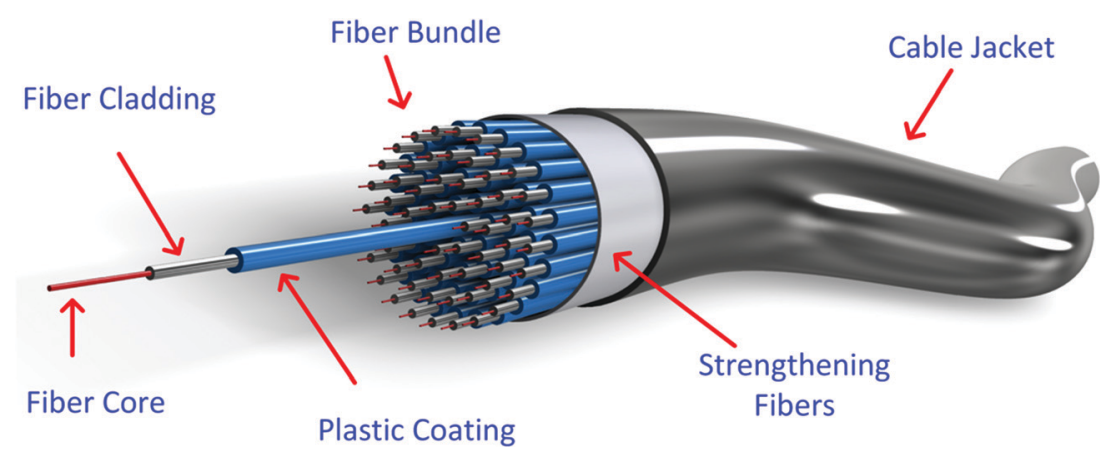

Fig. 10 Optical fiber in a bundle cable.

The transducer can be the optical fiber itself or/and an external sensitive bulk element. A spectrometer, an optical spectrum analyzer (OSA) or a simple photodetector can be used to detect variations on the optical signal that are caused by perturbations on the transducer. OFS are generally divided into two main groups, direct and indirect. Direct OFS measure a physical property or phenomenon of sample solutions, for example their RI or their temperature. Direct chemical OFS can measure an analyte directly if it has a spectroscopic property such as an infrared absorption band or fluorescence (such as polycyclic aromatic hydrocarbons). Indirect OFS use an indicator probe (for example, a polymer to measure the $\mathrm{pH}$ value). Indirect biological OFS (biosensors) make use of a biological component such as an enzyme, an antibody or an aptamer. $^{94}$

As already emphasized, an OFS should, ideally, be highly sensitive and selective, continuous, reversible, with a fast time response, stable during the measurements and able to detect/ monitor a wide range of analytes. ${ }^{94,175}$ Depending on the physical parameters that are susceptible to change due to 


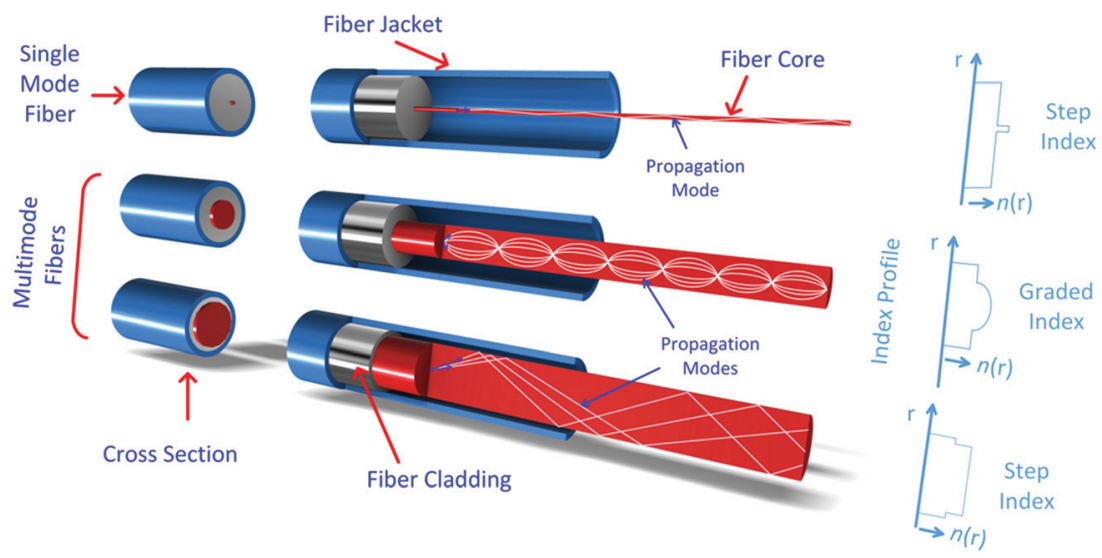

Fig. 11 Optical fiber types (i.e., multimode fiber and single mode fiber (SMF)).

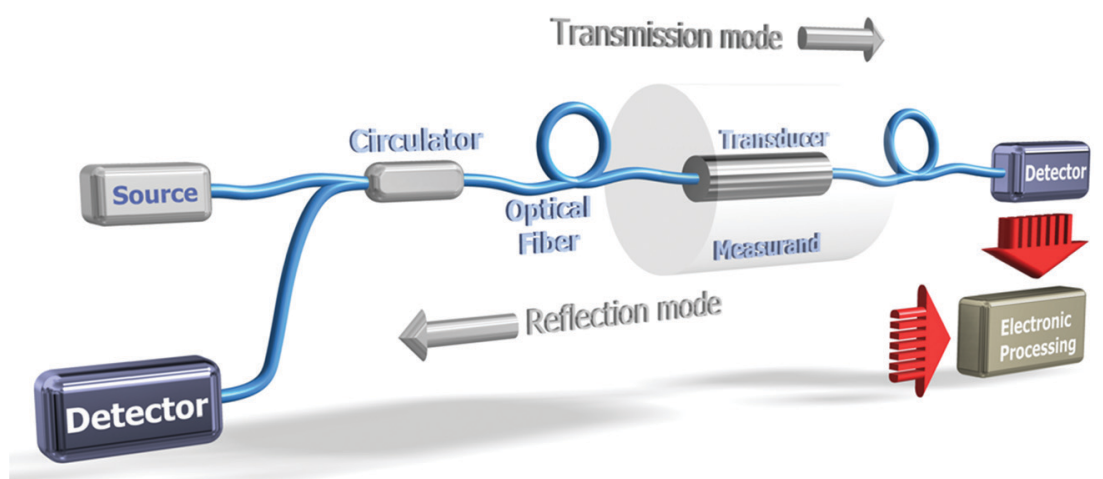

Fig. 12 Elementary building blocks of an OFS system.

interaction with external media, OFS can be used as intensity, phase, wavelength or polarization probes. OFS have been used, for instance, for sensing of strain, ${ }^{176}$ bending and temperature, ${ }^{171}$ for the detection of organic aromatic compounds ${ }^{177}$ and as immobilized antibody biosensors. ${ }^{178}$ Biosensors and diagnostic platforms can be used to monitor parameters such as blood glucose levels in diabetics, ${ }^{179}$ detect pathogens, ${ }^{180}$ and diagnose and monitor cancer. Environmental applications of biosensors include the detection of harmful bacteria or pesticides in air, water ${ }^{164}$ or food. ${ }^{181}$ The military has strong interest in the development of biosensors as counter-bioterrorism devices that can detect elements of chemical and biological warfare to avoid potential exposure or infection. The challenges and advantages of working with POF sensors were compared to silica fiber-based sensors. ${ }^{137}$ POF sensors have a strong impact on monitoring large structures or geotechnical foundations. Their low cost and flexibility to be integrated into complex structural geometries are the main reasons for this impact and interest. These sensors have been applied successfully for the measurement of cracks in concrete. ${ }^{137}$

\subsection{Fiber Bragg gratings}

A fiber Bragg grating (FBG) is an optical device with a periodic modulation of the RI of the fiber core that reflects wavelengths of the electromagnetic radiation depending on the period of the modulation according to eqn (1):

$$
\lambda_{\mathrm{B}}=2 n_{\mathrm{eff}}(\lambda) \Lambda
$$

where $n_{\text {eff }}(\lambda)$ is the effective RI in the fiber core and $\Lambda$ is the period of the FBG. The periodic modulation of the RI in the fiber core can be achieved by a number of techniques such as the UV laser interference method, ${ }^{182} \mathrm{UV}$ laser with phase mask $\operatorname{method}^{183}$ and femtosecond laser. ${ }^{184-186}$ Fig. 13 shows a schematic of a FBG with the sections where the core RI was increased and the typical reflection and transmission spectra are schematized.

The development and application of FBG sensors in concrete SHM is already a reality. Many studies on FBGs for monitoring corrosion have been published. ${ }^{187-191}$ The development and application of FBG sensors was reported to monitor vertical displacement and strain in concrete bridges. ${ }^{31}$ Campanella et al. ${ }^{154}$ published a review in which FBG strain sensing technologies and their applications were discussed. The physical principles, the interrogation techniques, and the main parameters for performance assessment of FBG strain sensing technologies were described. The key market sectors and the main market players were identified. 


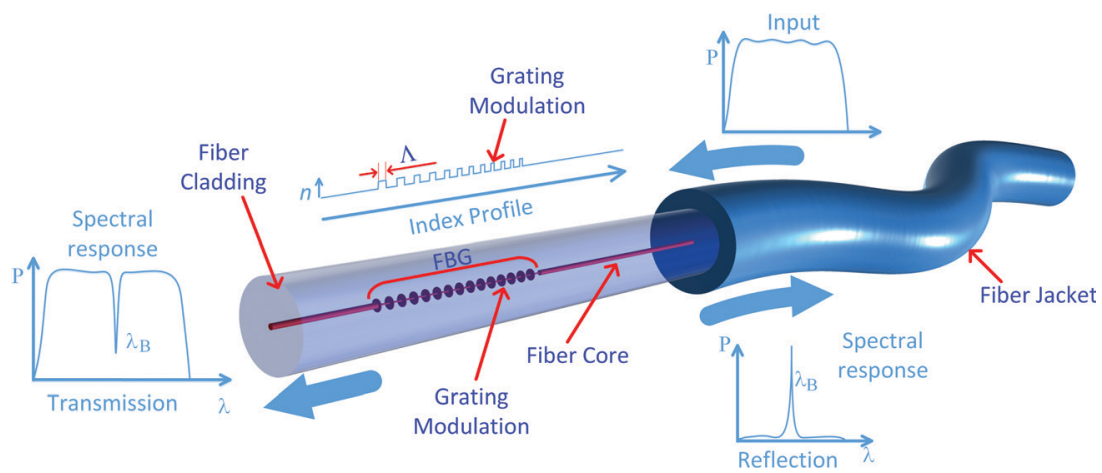

Fig. 13 FBG showing the sections where the core RI was increased, and typical reflection and transmission spectra.

The corrosion of a rebar is a very important aspect that affects the robustness of a RCS. The most visible result of a rebar corrosion is the volume expansion. This basic feature can be easily monitored using a FBG sensor. Therefore, a rebar corrosion FBG sensor was designed and tested. Based on the results of the calibration experiment, a relationship between the corrosion ratio and the change in wavelength was established. ${ }^{187}$ Despite the interesting results obtained, the authors were not able to develop a complete model. Cracking in concrete is another cause of failure and, therefore, an important active area of research. Cracking is, generally, linked to the ASR, ${ }^{45}$ also known as "concrete cancer", or to D-cracking which is due to the freezing of aggregates that has reached a threshold level of moisture saturation. Childs et al. ${ }^{192}$ proposed FBG sensors to be embedded into concrete cylinders to monitor cracking deep within the specimens. Loading cycles and loading until failure were performed, with measurements from the sensors collected up to and during failure. Calibration of the off-axis angle of the OFS was performed and the spread of that angle was noted. The use of the bandwidth of the gratings to indirectly measure the differential strain across the grating and thus the amount of internal cracking within the specimens was proposed and tested.

A sensor based on a pair of pre-strained FBG sensors was reported by Lee et al. ${ }^{188}$ for monitoring structural corrosion. The signal was obtained by the pre-strain that progressively decreases as the corrosion process develops. The sensor head was immersed in a $3.5 \mathrm{wt} \% \mathrm{NaCl}$ solution for $\sim 100$ hours. The FBG sensor wavelength decreased exponentially with immersion time. In a periodic mass loss measurement process, the corroded metals were extracted from the container and measured with a precision of $0.01 \mathrm{mg}$. The mass loss per surface area was measured and a linear decrease was found. A sensitivity of $10^{-6} \mathrm{mg} \mathrm{s}^{-1} \mathrm{~mm}^{-2}$ was obtained. Further information concerning physical based monitoring techniques for corrosion of RCS can be found in a review published by Lei and Zheng in 2013. ${ }^{193}$

Long period fiber gratings (LPFGs) are produced by introducing a periodic modulation in the RI of the fiber core. Generally, the RI modulation period is in the range 100 to $1000 \mu \mathrm{m}$ and has a length of a few centimeters. The most common techniques to obtain this modulation are UV laser irradiation, electric-arc discharge, periodic etching, $\mathrm{CO}_{2}$ laser irradiation and mechanical processes. ${ }^{143}$ The most important property of a LPFG is its sensitivity to the RI of the material adjacent to the cladding in the grating region. ${ }^{194,195}$ This feature allows the use of LPFGs as sensing element devices in chemical and biochemical analytical measurements. ${ }^{131}$

Theoretical and numerical research studies showed that high index coatings were able to favor the transition between cladding guided modes and overlay guided modes, changing the wavelength and the minimum transmission value of the attenuation band. ${ }^{196-199}$ The response of the LPFG is modified according to the RI and the thickness of the film.

\subsection{Applications}

Measurement of properties and phenomena such as mechanical, thermal, electrical, magnetic, atomic and nuclear characteristics or events requires a transducer which converts fundamental quantities into signals that can be measured using an instrument. ${ }^{200} \mathrm{~A}$ device that measures the concentration of a given analyte, either in a static or in a dynamic configuration, as shown in Fig. 14, is in general called a chemical sensor. Its complexity depends on the fundamental characteristics of the system to be analyzed and on the nature of the analyte. The analyte is often present in the liquid phase, but gas/vapor or solid phases are present in real systems. Volumes of solution ranging from cubic meters to tiny surface layers in the nanoscale range require different approaches.

There are many applications of OFS reported in the literature and several OFS based solutions were already implemented in real situations. OFS for bending (or curvature), shape sensing and pressure measurements are very well developed and are currently established. ${ }^{201-203}$ Temperature measurement is very well characterized and is used in countless configurations, vide ref. 176 and references therein.

Several sol-gel based OFS for measurement of parameters such as strain, temperature, rotation and acceleration were reported. A quantum dot-based OFS using sol-gel for temperature measurement was demonstrated. A hydrolyzed and polymerized mixture of GPTMS and APTMS (vide Scheme 1) was used as a carrier for CdSe/ZnS quantum dots (QDs) in the fabrication of an OFS. ${ }^{204}$ The mixture was a flexible carrier for the QDs, improving their thermal shock resistance and enabling them to be used for temperature sensing in the range of $0-100{ }^{\circ} \mathrm{C}$. 


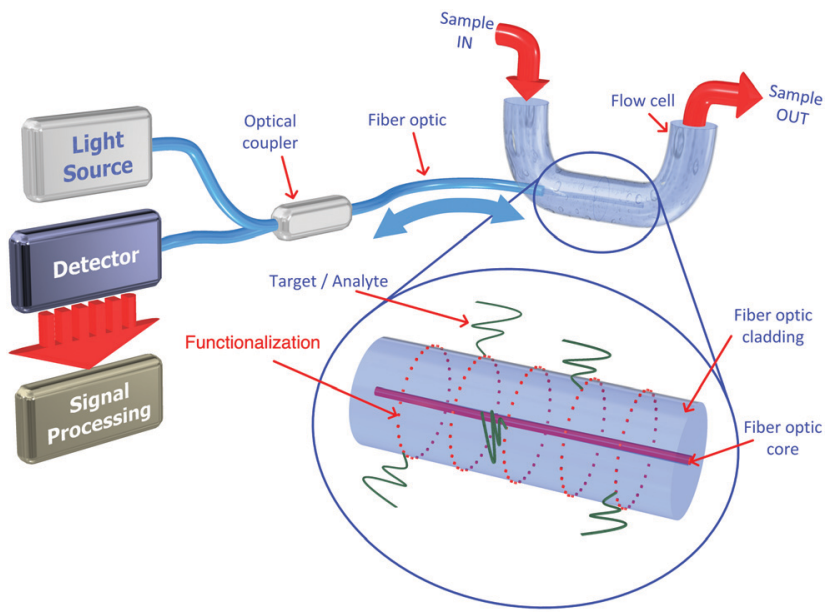

Fig. 14 Principle of operation of a chemical sensor based on optical fibers.

A review on multiparameter OFS was published recently. ${ }^{158}$ The sensor designs and corresponding signal processing schemes were compared. Most of the studies reported were focused on the development of two-parameter sensors. Sensors for simultaneous temperature and RI detection were the most reported, and as expected, considering the developments of the past decade, the temperature was the more frequent parameter. Instrument optical voltage transformers (OVTs) have been provided by the electric power industry as an alternative to the conventional iron and copper inductive instrument transformers from the last few years. OVTs based on OFS (specifically FBG) and piezoelectric crystals are on their way to practical applications. $^{205}$

Recently, excellent development has been achieved in optical sensing for electromagnetic field measurement, and a variety of sensors have been reported. Several types of magnetic field optical sensors were described, including probes based on the Faraday effect, magneto-strictive materials, and magnetic fluids. This type of sensor is subject to frequent developments and a recent review was published. ${ }^{206}$

Chemical sensing using OFS shows fundamental challenges since silica fibers are chemically inert. To overcome this issue, a transducer system must be used to transform the analyte's chemical characteristics into optical properties that can be retrieved through an OFS, such as the wavelength, phase or optical power shift. ${ }^{146,207}$ Plenty of examples of OFS able to detect the presence of, or even to quantify, a countless number of analytes can be found in the literature. For example, a Pd coated FBG made of silica fibers can be used for $\mathrm{H}_{2}$ sensing. The presence of $\mathrm{H}_{2}$ leads to an increase of the Pd volume which in turn causes a wavelength shift of the light that travels through the fiber core of the FBG. ${ }^{208}$ However, in many OFS configurations light is made to travel out of the fiber core, enabling the interaction with the system where the analyte is.

Multiparameter OFS using sol-gel have been reported and are one of the areas most investigated in the last few years. For instance, a plastic OFS for sensing of temperature and oxygen was described, and consisted of indicators that were coated on the fiber end. ${ }^{209}$ A fluorinated xerogel doped with platinum tetrakis(pentrafluorophenyl)porphine (PtTFPP) and 5(6)-carboxyfluorescein (CF) serves as the oxygen and temperature sensing material. The temperature and oxygen indicators can both be excited with a LED of $405 \mathrm{~nm}$, and the two emission wavelengths can be detected separately. A large number of published studies rely on micro-structured optical fibers ${ }^{210}$ or standard fibers with structural modifications, such as fiber tapers, ${ }^{211}$ micro-fibers, ${ }^{212}$ tilted FBGs, ${ }^{213,214}$ fiber facets ${ }^{215}$ and LPFGs. ${ }^{216}$ Fig. 15 shows representative examples of tapered OFS, tilted FBGs, fiber facets and LPFGs.

\section{OFS based on sol-gel materials for civil engineering field application}

In the early 2000s, a critical review of the current status of OFS $^{130}$ conducted by Lee allowed to conclude, back then, that OFS reached the stage at which optics specialists must cooperate with experts in other research fields. This is realistic for most research fields, and regarding OFS development for civil engineering, this is even more evident. The development of OFS for such application if conducted by multidisciplinary teams including materials engineers, civil engineers, physics, and chemistry experts will allow achieving OFS systems with the necessary level of accuracy for practical application in concrete structures. OFS have the advantage of deforming along their length (due to their flexible structure) and may be functionalized with $\mathrm{OIH}$ sol-gel films or structural membranes with sensing abilities for a variety of applications as aforementioned.

In the last few decades, several review manuscripts that focused on the use of OFS in civil engineering structures have been published (vide Table 1). Civil SHM systems, when implemented correctly, provide significant quantitative and qualitative information about the structure. This information is simultaneously convenient for the structure's owner and for structural designers since it provides real world structural behavior information for upcoming designs. SHM systems have gained particular attention in the past two decades. However, the application of SHM civil engineering systems still lacks reliable and economical solutions mainly due to the scarcity of standardized and efficient methodologies.

Generally, the first assessment of a structure is carried out by civil engineers through visual inspection. The advantages of this methodology are its easiness and speed that allow a frequent update of the health condition of the structures. However, it is a subjective method since it is based on the interpretation of the defects found and on the inspector experience and is only a qualitative assessment of the visible and accessible parts of the structure. The introduction of SHM systems mitigates part of this subjectivity. Nevertheless, the reliability and robustness of a SHM system is strongly correlated with the accuracy and robustness of the sensors deployed for each application and the later analysis of the gathered data.

Optical fiber technology has attracted increasing attention in the past two decades as one of the most researched topics 

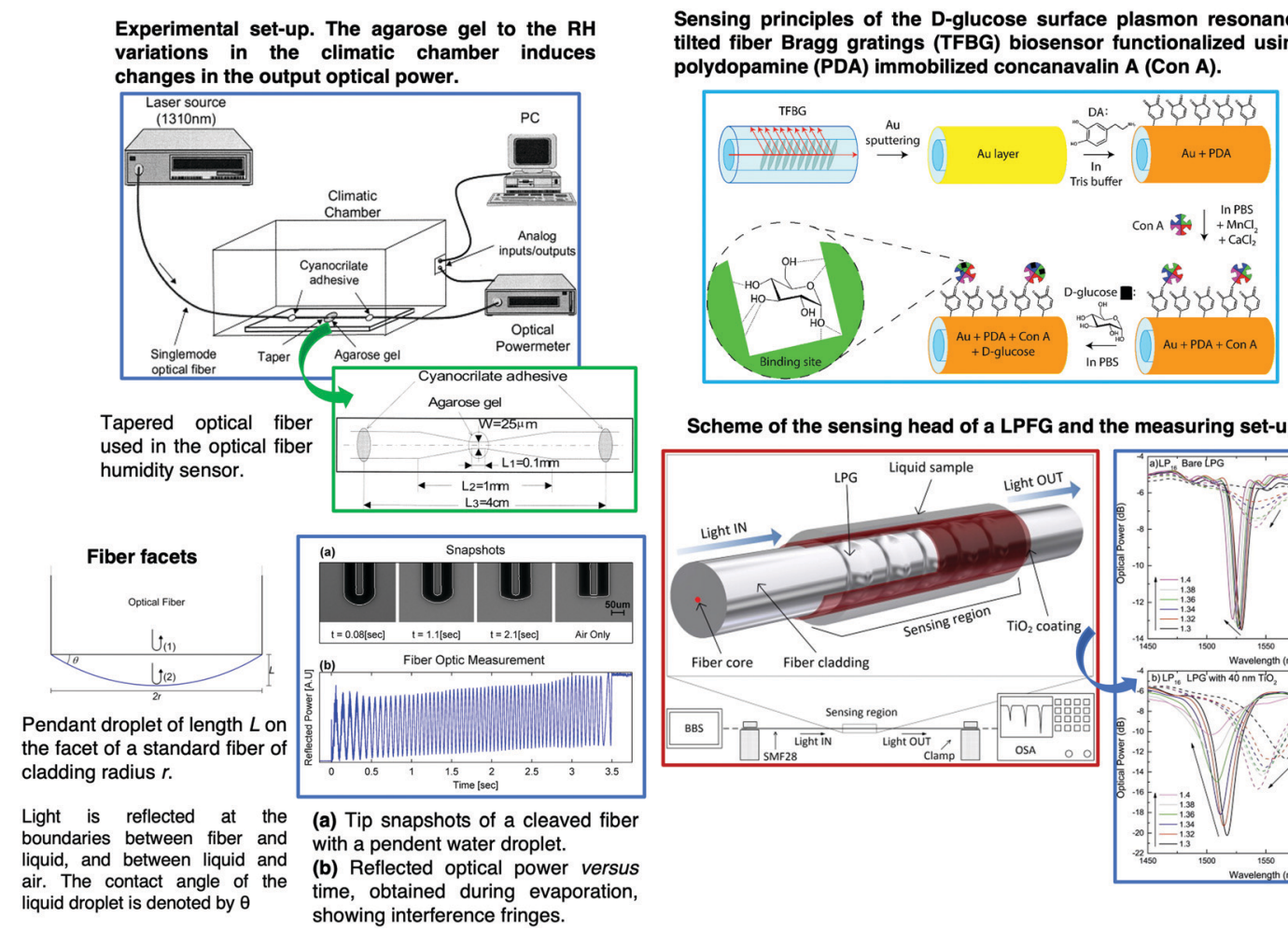

Scheme of the sensing head of a LPFG and the measuring set-up used.

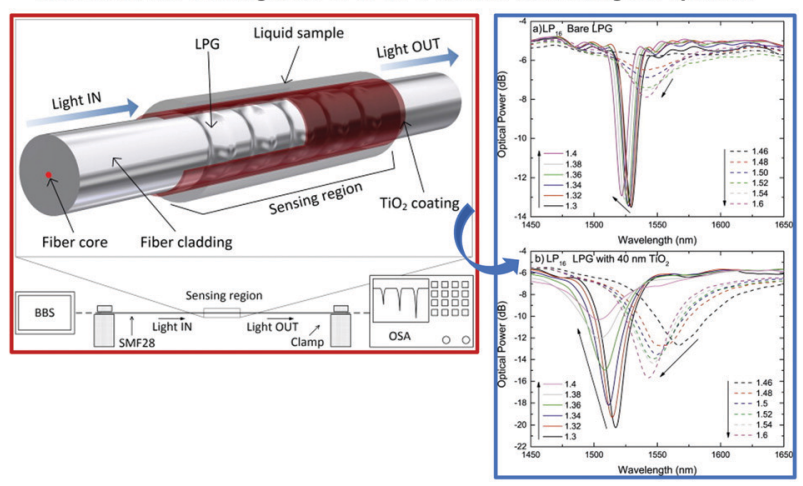

Fig. 15 Schematic of different OFS based on micro-structured optical fibers ${ }^{210}$ or standard fibers with structural modifications, such as fiber tapers, ${ }^{211}$ tilted FBGs, fiber facets ${ }^{215}$ and LPFGs. ${ }^{216}$ Reprinted and adapted with permission from ref. 211, 213-216. Copyright 2000 Elsevier. Copyright 2014 Elsevier. Copyright 2019 Elsevier.

within SHM sensors. ${ }^{51}$ Most of the applications reported for SHM of civil structures employed discrete or quasi-distributed FBG sensors. ${ }^{154,217}$ Generally, standard monitoring is based on the use of a low number of sensors in which it is assumed that these are representative of the global structural behavior. However, the use of discrete sensors provides only local information which is not relevant when the global information of the structure performance is required. This is particularly critical for civil SHM large-scale structures such as bridges, dams, and nuclear power plants. Additionally, concrete is a very heterogenous material; therefore when only a few discrete sensors are available, it is very difficult (if not impossible) to detect the exact damage location such as concrete cracking and rebar corrosion. On the other hand, civil SHM systems based on electrochemical sensors face critical challenges. ${ }^{30}$ An electrochemical system requires embedding a huge quantity of conducting wires which is very laborious and expensive, and potential maintenance of damaging sensors including periodic calibration. The use of OFS systems excludes these drawbacks, and additionally allows multiple chains on a single fiber, contributing to the reduction of the SHM systems' weight and complexity. Furthermore, optical fibers do not corrode or conduct like copper wire, the risk of damage due to lightning is reduced and therefore the durability is increased. These features, together with the fact that optical sensors and interrogators do not require calibration, drastically reduce the amount of maintenance required. Nevertheless, despite the huge potential of OFS systems for SHM and the research development in the last few decades, these systems still lack reliable solutions for application in the civil engineering field particularly for monitoring concrete parameters such as $\mathrm{pH}$, chloride ions, ASR and moisture. The choice of the mentioned parameters relies on a simple and basic principle, i.e., the information on all the parameters indicated above allows having a full picture of the whole structure health. The following sections will discuss the main developments achieved in the OFS progress for $\mathrm{pH}$ monitoring, chloride ion detection, and ASR and moisture monitoring, highlighting in particular their application in concrete and RC structures.

\subsection{OFS based on sol-gel materials for $\mathrm{pH}$ monitoring}

The $\mathrm{pH}$ level has an important role in the well-being of both nonliving and living systems. For instance, in the medical field a slight decrease in the blood pH level is an important aspect and is known as acidosis, which means an excess of acid in the blood, causing the $\mathrm{pH}$ to fall below $7.35 .^{218}$ In soil, the $\mathrm{pH}$ influences plant growth by its effect on microorganisms that decompose organic matter for absorption by vegetation. In concrete, $\mathrm{pH}$ is one of the most important parameters to be monitored since most of the concrete and RCS deterioration mechanisms including corrosion, ${ }^{30}$ carbonation ${ }^{219}$ and acid attack ${ }^{48}$ are generally linked to the level of concrete alkalinity. Therefore, it is quite patent that the capacity to acquire information on $\mathrm{pH}$ changes in a wide range of systems is of tremendous importance. 


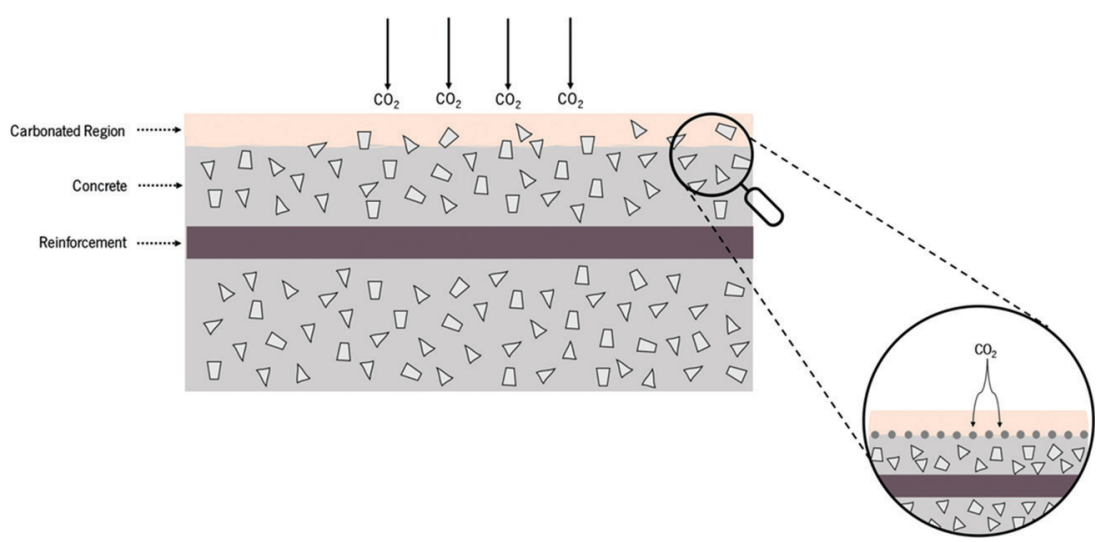

Fig. 16 Concrete carbonation scheme. Reprinted and adapted with permission from ref. 220. Copyright 2017 Elsevier.

The concrete carbonation schematized in Fig. 16 shows that this phenomenon initiates on the surface of the concrete and may evolve until it reaches the surface of the rebar.

This process is generally characterized by the reaction of the alkaline components of the concrete with the $\mathrm{CO}_{2}$ present in the atmosphere according to eqn (2):

$$
\mathrm{CO}_{2}+\mathrm{Ca}(\mathrm{OH})_{2} \rightleftharpoons \mathrm{CaCO}_{3}+\mathrm{H}_{2} \mathrm{O}
$$

The formation of $\mathrm{CaCO}_{3}$ (eqn (2)) leads to the release of $\mathrm{H}_{2} \mathrm{O}$ that is bound in concrete components (e.g., portlandite and other hydrates), leading to changes in the total solid volume. These changes depend on the cement chemistry and may have impact on the porosity and therefore on the transport properties of the carbonated concrete. ${ }^{221}$ Moreover, exposure conditions such as the $\mathrm{CO}_{2}$ concentration, $\mathrm{RH}$ and temperature strongly influence the carbonation kinetics of concrete as well as the amount of carbonation products.

In 2020, von-Greve Dierfeld et al. published a detailed and interesting review that focused on the carbonation of concrete. The several steps of carbonation were discussed in detail. The main conclusions were that the carbonation mechanism in cementitious systems containing supplementary cementitious materials differs from that in plain Portland cement systems. This was explained, mainly, by the differences in the pore structure and pore solution chemistry. Moreover, it was concluded that the portlandite carbonation was the main contributor to water released during the carbonation, leading to a reduction in the pore size and total volume of meso- and macro-pores due to the precipitation of $\mathrm{CaCO}_{3}$. It was also concluded that carbonation happened quickly in systems with low contents of portlandite.

The most common way to quantify the carbonation process is, undoubtedly, the measurement of the carbonation depth in concrete samples using phenolphthalein ( $\mathrm{Phph}$ ) as a $\mathrm{pH}$ indicator. ${ }^{222}$ Non-destructive methods (NDM) have also been reported such as embedding reference electrodes ${ }^{223}$ or OFS. ${ }^{10,224}$ The evolution of carbonation can also be characterized by the concentration of hydroxyl ions $\left(\left[\mathrm{OH}^{-}\right]\right)$in the interstitial concrete pore solution. Once the $\left[\mathrm{OH}^{-}\right]$is determined, the $\mathrm{pH}$ of the interstitial concrete pore solution can be determined, allowing differentiating, in the cementitious material, between the carbonated $(\mathrm{pH}<9)$ and non-carbonated $(\mathrm{pH}>9)$ regions. ${ }^{225} \mathrm{The} \mathrm{pH}$ assessment of the concrete can also be achieved by destructive methods (DM) through extraction of the concrete pore solution under pressure ${ }^{41}$ and by the in situ ${ }^{226}$ and ex situ leaching ${ }^{227}$ methods.

In 2016, a critical review regarding the methods developed for measuring the pHs of fresh and hardened concrete was published. ${ }^{41}$ The advantages and disadvantages of the different methods available, DM and NDM, were scrutinized and compared. The OFS were assessed by NDM, and the OFS were found to be very efficient for real-time $\mathrm{pH}$ monitoring. However, OFS for such application need further progress to be considered consistent namely concerning repeatability, reproducibility, and a reliable level of resolution. Moreover, until now no applications of OFS in situ (real structures) have been performed.

$\mathrm{pH}$ measurement in water-based solutions is highly advanced and sophisticated, and several techniques (e.g. electrochemical and non-electrochemical) have been developed, including sol-gel derived potentiometric sensors for $\mathrm{pH}$ monitoring. ${ }^{228}$ However, the $\mathrm{pH}$ measurements in non-aqueous systems, particularly in the solid state, are underdeveloped when compared to aqueous systems. Nevertheless, the usual glass membrane $\mathrm{pH}$ electrodes employed are not fit for highly alkaline environments, such as concrete, and are fragile materials. Nowadays, the conventional approach for $\mathrm{pH}$ monitoring in RCS is the use of a reference electrode. ${ }^{222}$ The performance of $\mathrm{pH}$ sensors based on reference electrodes essentially depends on the structure and preparation of the electrodes.

$\mathrm{pH}$ electrochemical sensors show some limitations such as electrode failures, low sensitivity, and uncertainty in case of impedance changes. Therefore, several alternatives to traditional electrochemical methods have been proposed. Badini et al. showed for the first time the use of a sol-gel based methodology to develop an OFS for $\mathrm{pH}$ sensing. ${ }^{229}$ The OFS was produced by coating the plastic clad silica fiber with a sol-gel material, in which TEOS (vide Scheme 1) was used as a precursor, doped with cresol red (CR) indicator dye (pH range 8-13). After that, several publications ${ }^{230,231}$ have been reported for $\mathrm{pH}$ monitoring. Browne et al. reported the development of 
an intrinsic fluorescein-doped sol-gel clad sensor distributed along a fiber-optic waveguide. ${ }^{232}$ Hiruta et al. reported the use of a sol-gel method to produce a double-layer $\mathrm{pH}$ optrode. ${ }^{233}$ The primary fluorescent layer was fabricated by spin-coating a glass substrate with a silica sol solution doped with QDs. The subsequent layer was obtained by spin-coating it with a silica sol solution doped with two different $\mathrm{pH}$ indicators (e.g., Congo red and basic fuchsin). The silica sol solution was prepared using TEOS and PTES as precursors. The resulting $\mathrm{pH}$ optrode allowed for reversible and accurate $\mathrm{pH}$ response in aqueous sample solutions. Two kinds of $\mathrm{pH}$ indicators in the second layer were used, which allowed obtaining a fluorescence response in the $\mathrm{pH}$ range between 4 and $10 .{ }^{233}$ Nguyen $e t$ al. reported the development of an $\mathrm{OFS}^{190}$ based on a fluorescent polymer bearing imidazolyl groups as the recognition element (e.g., coumarin imidazole dye). The protonation/deprotonation of the nitrogen on the imidazolyl groups allowed the determination of $\mathrm{pH}$ in the alkaline region of the $\mathrm{pH}$ scale. ${ }^{190}$ Recently, Sousa et $a l .{ }^{234}$ reported the development of sol-gel materials based on polydimethylsiloxane (PDMS) and APTES by forming an aminoalcohol precursor. Different ratios between PDMS and APTES were considered. It was shown that the developed materials have the potential to be used as sensing materials on OFS to assess the $\mathrm{pH}$ of concrete. Nevertheless, the materials reported were not deposited on OFS nor studied in contact with concrete only with solutions simulating the concrete $\mathrm{pH}$. Therefore, further studies need to be conducted since the interface between the fiber and the membrane, response time and selectivity of the possible functionalized OFS are still unknown.

Table 2 summarizes the most relevant OFS based on $\mathrm{OIH}$ sol-gel materials, reported in the past twenty years, for $\mathrm{pH}$ monitoring in different areas of application for different $\mathrm{pH}$ ranges. The table indicates the recognition molecule (RM), the precursors and reagents used for the synthesis of matrix support, the response time (RT) and the $\mathrm{pH}$ range of the sensor.

Table 2 shows that the most used precursor to prepare the supporting matrix, doped with the recognition molecule, was TEOS. The recognition molecules generally employed were indicators that were chosen according to the $\mathrm{pH}$ range to fit the designated purpose. The structures of the most common dyes reported for the development of OFS for $\mathrm{pH}$ monitoring are shown in Fig. 17.

The most used indicator was CR $28.6 \%$ of the reported manuscripts in Table 2) followed by $\mathrm{Phph}(19.2 \%$ of the reported manuscripts in Table 2). From the 22 studies described in Table 2 almost $43 \%$ of the reported manuscripts do not indicate the response time and only one publication reported a RT lower than $1 \mathrm{~s}$ for a pH range between 3 and 9 .

Despite the broad range of methods used for measuring the $\mathrm{pH}$ of concrete, none of the studied and mentioned methods has been standardized yet. Therefore, and considering all the information exposed and discussed, it should be kept in mind that developing a specific and standard test method for measuring the $\mathrm{pH}$ of fresh and hardened concrete, with high levels of repeatability and reproducibility, will impact significantly in the construction industry. The use of functionalized OFS for $\mathrm{pH}$ monitoring may become an auspicious and reliable alternative considering all the progress achieved in the past two decades.

\subsection{OFS based on sol-gel materials for chloride ion detection}

Chloride induced corrosion in RCS has been substantially studied in the past five decades under different conditions. ${ }^{250-253}$ The corrosion process in marine and coastal environments is often initiated by the ingress of $\mathrm{Cl}^{-}$into $\mathrm{RCS}{ }^{254} \mathrm{Cl}^{-}$may also arise from the use of salt (e.g. $\mathrm{NaCl})$, during winter seasons in areas that go through freezing temperature conditions, to melt ice and snow on roads and bridges. ${ }^{255}$ The $\mathrm{Cl}^{-}$ingress is highly dependent on the presence of moisture since moisture is necessary to disperse and carry the chemical species into the porous concrete (vide Fig. 2). It is widely accepted that free chloride is present in the ionic form in the concrete pore solution which may diffuse towards the reinforcing steel through the pores. Diffusion is generally described by Fick's law regardless of whether the process takes place in the steady state or not and can be described as eqn (3): ${ }^{256}$

$$
\frac{\partial C_{i}}{\partial t}=D_{i} \frac{\partial^{2} C_{i}}{\partial^{2} x}
$$

where $C_{i}$ is the concentration of species $i$ at distance $x$ at time $t$ and $D_{i}$ is the diffusion coefficient. However, most diffusion processes such as $\mathrm{Cl}^{-}$diffusion in concrete take place under unsteady conditions, i.e., the ion concentration gradient and ion diffusion flux change with time and space. The mechanism that controls the $\mathrm{Cl}^{-}$behavior in concrete is generally formulated with Fick's 2nd law, i.e., eqn (4) and the Nernst-Einstein equation.

$$
C_{i}(x, t)=C_{i 0}\left(1-\operatorname{erf} \frac{x}{2 \sqrt[2]{D_{i} t}}\right)
$$

where $C_{i}(x, t)$ is the concentration of species $i$ at distance $x$ at time $t$ and $C_{i 0}$ is the concentration of species $i$ at $x=0$. The use of Fick's 2nd law to explain $\mathrm{Cl}^{-}$in concrete considers two assumptions, namely: (a) the species involved in the diffusion flux must not react with the matrix and (b) the matrix is homogeneous in composition and structure. ${ }^{256}$ Considering eqn (4), it can be observed that the knowledge of the concentration of ions in the environment and the diffusivity of the concrete allows modulating the penetrating profile. On the other hand, if the concentration profile is known, the diffusivity of ions can be obtained by assuming values for $C_{i 0}$. Nevertheless, this method is time-consuming. ${ }^{256}$

In the case of concrete, the electrolyte is considered to be solid and the diffusivity of charged species $i$ in concrete is related to its partial conductivity $\sigma_{i}$ by the Nernst-Einstein equation (eqn (5)):

$$
D_{i}=\frac{R T \sigma_{i}}{Z_{i}^{2} F^{2} C_{i}}
$$

where $D_{i}$ is the diffusivity of species $i, R$ is the gas constant, $T$ is the temperature, $Z_{i}$ is the charge of species $i, F$ is the Faraday constant and $C_{i}$ is the concentration of species $i^{256}$ 


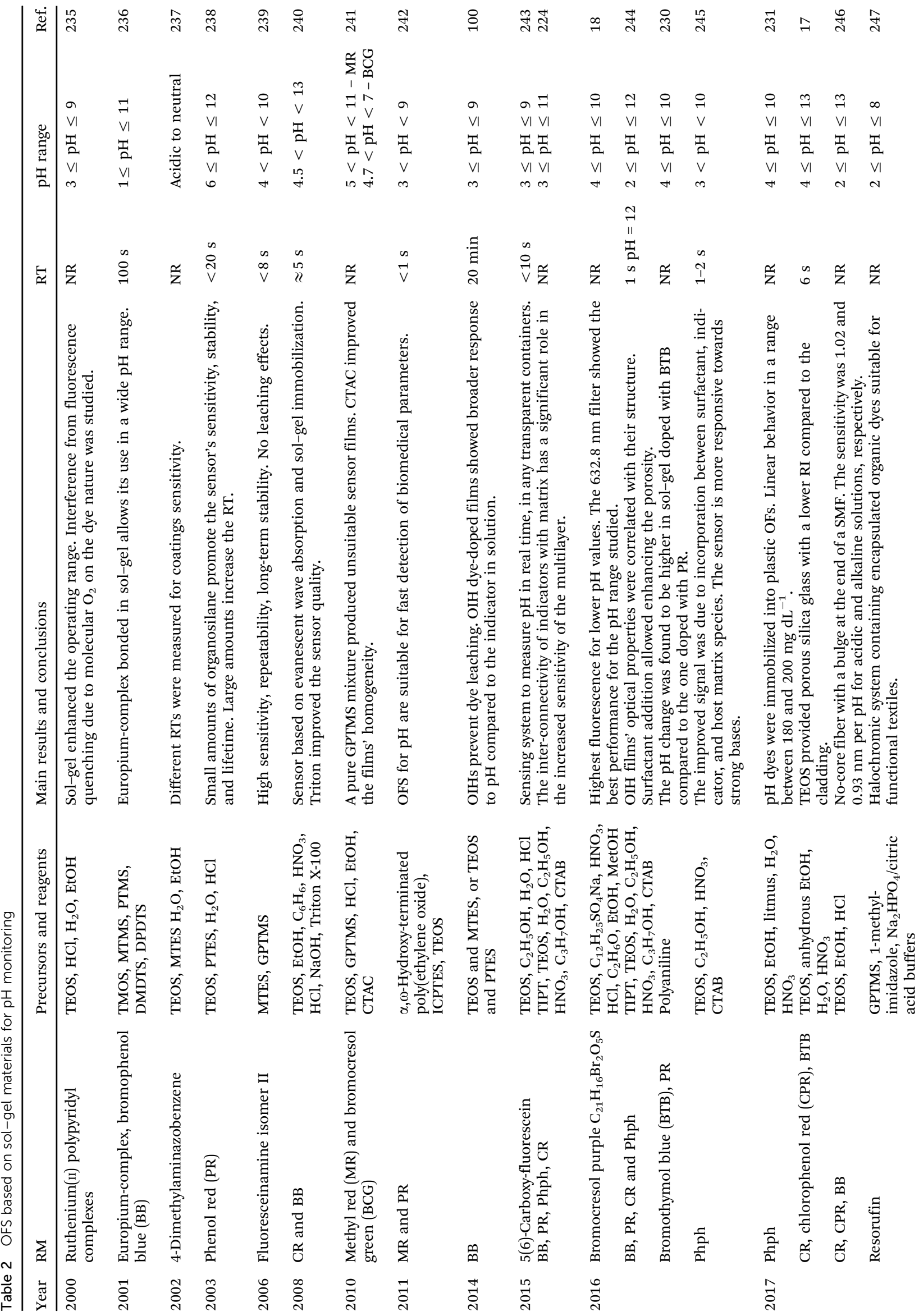


Therefore, the diffusivity of $\mathrm{Cl}^{-}$can be easily obtained from eqn (5) by measuring the $\sigma_{i}$ or the total conductivity of the concrete, and the corrosion of the reinforcement can be monitored and predicted by measuring the concrete conductivity change when eqn (5) is used and combined with corrosion mechanisms. ${ }^{256}$ However, these data should always be validated with experimental results.

The conventional methods for free $\mathrm{Cl}^{-}$determination involve the extraction of the concrete pore solution by applying pressure, or by leaching of chloride from the concrete sample by a solvent. However, it has been reported by some authors that these techniques are generally prone to inaccuracy. For instance, this destructive extraction may overestimate the free chloride content in a range between $30 \%$ and $200 \% .^{257}$

In this context, the monitoring of chloride ions in concrete environments is of extreme importance. However, their detection is demanding considering the specificity and the interference of environmental factors. ${ }^{258,259}$ Several methods have been reported for $\mathrm{Cl}^{-}$detection, in a wide range of fields and applications, using different techniques such as fluorescence, ${ }^{260,261}$ ionic chromatography $^{262}$ electrochemical, ${ }^{263,264}$ spectrophotometric ${ }^{265}$ and optical methods. ${ }^{266,267}$

In the last few years many researchers have studied and explored the in situ measurements of $\mathrm{Cl}^{-}$in concrete using mainly electrochemical methods ${ }^{263,268}$ such as potentiometric methods. ${ }^{269}$ Chemical $^{260}$ and optical methods ${ }^{261,270,271}$ were also reported but with less impact. Details about the diverse techniques reported so far for non-destructive in situ measurement of chloride ion concentration $\left(\left[\mathrm{Cl}^{-}\right]\right)$in concrete can be found in a review published by Y. Abbas et al. ${ }^{272}$ The NDM were divided into two main approaches, i.e. electrochemical and electromagnetic.

Potentiometry is generally the electrochemical technique chosen to determine $\left[\mathrm{Cl}^{-}\right]$in concrete. However, this technique requires a stable reference electrode which is generally fragile and needs regular recalibration, making long-term measurements unreliable. The use of $\mathrm{Ag} / \mathrm{AgCl}$ electrodes embedded into cement-based materials for $\mathrm{Cl}^{-}$detection has been reported since the 1990s. ${ }^{250,273}$ However, several external factors may affect their use in monitoring the $\left[\mathrm{Cl}^{-}\right]$in concrete. The difference of temperature between the measurement and the reference electrode may lead to errors, and in seawater, the presence of bromide may lead to overestimation of $\left[\mathrm{Cl}^{-}\right] .^{274}$ On the other hand, the chemical methods are time consuming and labor intensive.

Despite the mentioned disadvantages, numerous efforts to embed $\mathrm{Ag} / \mathrm{AgCl}$ electrodes into cement-based materials have been progressively reported by several researchers. ${ }^{275-278}$ Angst et al., in 2010, reported that $\mathrm{Ag} / \mathrm{AgCl}$ electrodes could be successfully used to measure the chloride ion activity in highly alkaline environments ( $\mathrm{pH}$ close to 14), and the detection limit for $\mathrm{Cl}^{-}$in the presence of interfering $\left[\mathrm{OH}^{-}\right]$was below $10^{-2} \mathrm{M}$ even at a $\mathrm{pH}$ close to $14 .^{269}$ It was also found that in the complete absence of $\mathrm{Cl}^{-}$the potential was influenced by the $\mathrm{pH}$; yet the sensors were able to recover when in contact with $\mathrm{Cl}^{-}$. Nevertheless, the authors stated that additional research was 

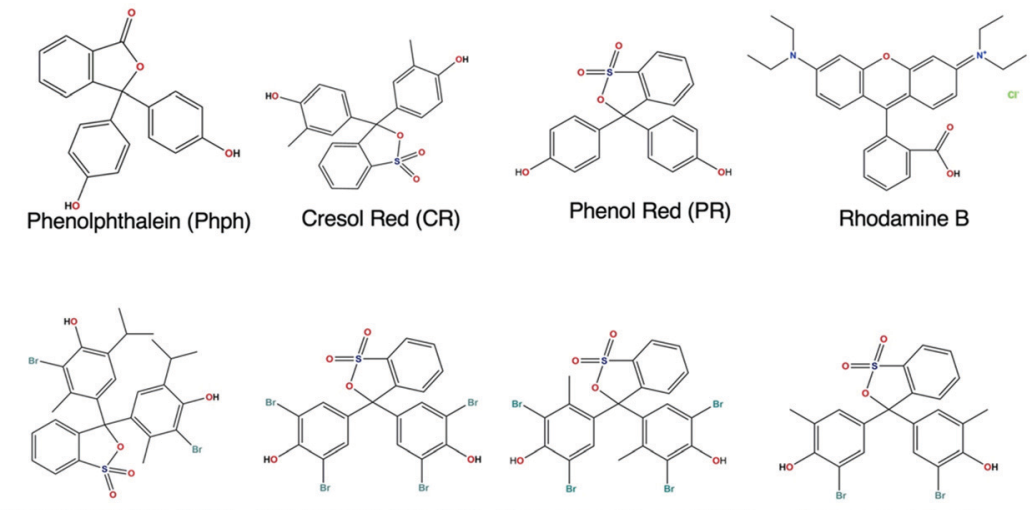

Bromothymol Blue (BTB) Bromophenol Blue (BB) Bromocresol Green (BCG)

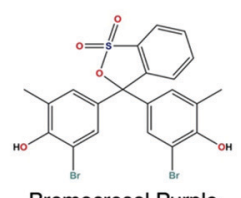

Fig. 17 Structures of the most common dyes used in OFS based on sol-gel materials for $\mathrm{pH}$ monitoring

required in this regard. Also, due to the high alkalinity of concrete, some studies showed that embeddable $\mathrm{Ag} / \mathrm{AgCl}$ electrodes in concrete were not stable for extended service lives, ${ }^{279}$ and in the presence of $\mathrm{OH}^{-}$the silver activity near the surface was determined by eqn (6): ${ }^{280}$

$$
2 \mathrm{AgCl}+2 \mathrm{OH}^{-} \rightarrow \mathrm{Ag}_{2} \mathrm{O}+2 \mathrm{Cl}^{-}+\mathrm{H}_{2} \mathrm{O}
$$

The $\mathrm{AgCl}$ membrane is not stable at high $\mathrm{pH}$ values. $\mathrm{AgCl}$ partially, and in some cases totally, turns into $\mathrm{Ag}_{2} \mathrm{O}$ at high $\mathrm{pH}$ values. The continuous transformation of the electrode surface into $\mathrm{Ag}_{2} \mathrm{O}$ leads to a mixed potential development at the electrode/solution interface, which makes the electrode unable to determine the chloride content accurately. To increase the $\mathrm{Ag} / \mathrm{AgCl}$ electrode stability and minimize the $\mathrm{OH}^{-}$interference, Blaz et al. and Ha et al., in the same year, reported the use of a conducting alkaline stable conjugated polymer coating on $\mathrm{Ag} / \mathrm{AgCl}$ electrodes. ${ }^{280,281}$ Karthick et al. studied in detail the effect of a polypyrrole polymer matrix on $\mathrm{Ag} / \mathrm{AgCl}$ electrodes for in situ $\mathrm{Cl}^{-}$sensing application in concrete structures. The presence of the polypyrrole polymer on the $\mathrm{Ag} / \mathrm{AgCl}$ electrode prevented the formation of $\mathrm{Ag}_{2} \mathrm{O}$ and did not compromise the electrochemical behavior of the sensor, showing good stability and high sensitivity. In the $\left[\mathrm{Cl}^{-}\right]$range of $1 \times 10^{-3} \mathrm{M}$ to $1.0 \mathrm{M}$, the RT to reach the steady state potential was $90 \mathrm{~s}^{282}$ Polypyrrole was chosen since it is one of the most used and studied polymers, can be easily synthesized, is low cost and stable and has higher conductivity when compared to similar polymers. Despite the results reported so far, the properties and performance of $\mathrm{Ag} / \mathrm{AgCl}$ electrodes in alkaline medium are yet to be established for a standard application in RCS.

OFS compared with electrochemical sensors for $\mathrm{Cl}^{-}$have several advantages such as energy saving, high sensitivity to low $\mathrm{Cl}^{-}$contents, small volume, electromagnetic stability, and flexible shape, allowing them to be embedded into any part of the concrete to achieve real-time, in situ, multi-point, and remote monitoring. Regarding OFS for $\mathrm{Cl}^{-}$detection two approaches have been reported, namely optical based-grating, i.e., based on changes in the RI and fluorescence-based. Tang and Wang proposed a low-cost chemosensor based on the modification of the grating portion of a LPFG with gold colloid nanoparticles (NPs) for $\left[\mathrm{Cl}^{-}\right]$measurement. The proposed optical sensor was sensitive to the RI of the cladding surface. ${ }^{266}$ The selectivity for chemical sensing was achieved by coating the cladding fiber surface with a monolayer of self-assembled gold colloids for the development of a fiber-optic evanescent-wave sensor. The optical properties (e.g., absorbance spectra and peak wavelength) arising from localized SPR of the gold NPs were sensitive to the RI of the surrounding target molecules under test. Based on the linear fit to experimental data, the lower limit of detection (LOD) of the LPFG sensor found in pure $\mathrm{NaCl}$ solution was estimated to be $0.04 \%$. A weight concentration of $17.5 \% \mathrm{NaCl}$ aqueous solution was used to determine the accuracy of the LPFG sensor. The accuracy of the concentration measurement was determined to be $0.6 \%$. The precision in the wavelength shift measurements reported was about $0.02 \mathrm{~nm}^{266}$ Regarding the LOD and precision reported, the proposed OFS showed encouraging and attractive properties for application in new and existing RCS. Lam et al. reported the development of a LPFG based on a Michelson interferometer sensor also coated with gold NPs for the measurement of $\left[\mathrm{Cl}^{-}\right]{ }^{283}$ The grating response created shifts in the spectral properties of the interferometer due to the change in the RI. The OFS assessment was performed in $\mathrm{NaCl}$ solutions in a concentration range (CRa) between $0.01 \mathrm{M}$ and $4.00 \mathrm{M}$. The sensitivity of the sensor LPFG-based interferometer with gold NPs was enhanced approximately 1.7 times when compared to the bare fiber. Proper tailoring of the NPs' size can be used to enhance the sensitivity and $16 \mathrm{~nm}$ gold NP-coated OFS can detect $\left[\mathrm{Cl}^{-}\right]$as low as $355 \mathrm{ppm}{ }^{283}$ Despite these promising results, further studies are necessary including the assessment of this type of sensor at different temperatures and in the presence of different moisture levels.

The fluorescence method for $\left[\mathrm{Cl}^{-}\right]$detection has gained relevant attention in the last few decades. ${ }^{271,284}$ Some indicators for fluorescence quenching in combination with $\mathrm{Cl}^{-}$have been reported. ${ }^{104,271,284-289}$ The use of fluorophores such as lucigenin (Luc) (vide Fig. 18a), ${ }^{270,271,290} 6$-methoxy- $N$-3'-sulfopropylquinolinium (vide Fig. 18b), ${ }^{288}$ 6-methoxy- $N$-ethylquinolinium iodide (vide Fig. 18c) ${ }^{285}$ and 3-amino-7-benzylbenzimidazo[3,2a]quinolinium (vide Fig. 18d) ${ }^{104,286}$ has been described. Nevertheless, some major drawbacks of the use of fluorophores are 


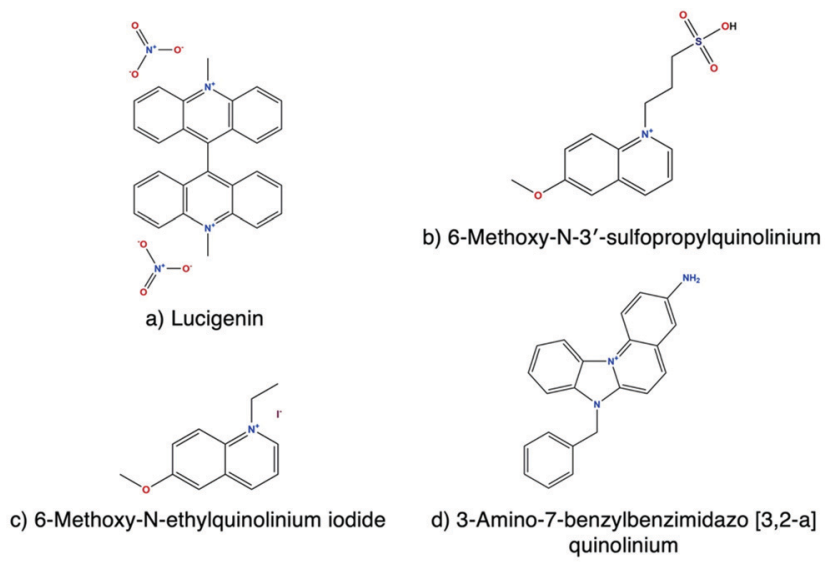

Fig. 18 Structures of some indicators used for fluorescence quenching in combination with chloride ions $\left(\mathrm{Cl}^{-}\right)$.

present, specifically, low stability due to photobleaching, and in certain cases, after fluorophore immobilization into the membrane or support matrix, the fluorescence properties were hindered. ${ }^{291,292}$

Fluorescent nanocomposites such as silica NPs doped with fluorescent dye when compared to traditional single fluorophores show higher photostability, durability, fluorescence intensity and good photostability. ${ }^{271}$ OFS by means of fluorescence quenching principle is a very interesting alternative to monitor $\mathrm{Cl}^{-}$in concrete environments. The quenching mechanism of Luc fluorescence by $\mathrm{Cl}^{-}$was reported by Legg and Hercules $^{293}$ and is commonly described in two steps as schematized in Fig. 19. Generally, the $\mathrm{Cl}^{-}$could be considered as a catalyst to break the excited singlet state $\left(\mathrm{Luc}^{2+}\right)^{*}{ }^{271}$

Considering the quenching mechanism of Luc (vide Fig. 19), a new OFS based on a sol-gel membrane was fabricated. The sol-gel matrix was obtained using TEOS, $-\mathrm{C}_{2} \mathrm{H}_{5} \mathrm{OH}$ and $\mathrm{H}_{2} \mathrm{O}$ as precursors for Luc immobilization onto the inner surface of the suspended core optical fiber to detect $\left[\mathrm{Cl}^{-}\right]$. The sol-gel membrane doped with Luc was deposited by dipping. The fabricated OFS was able to detect the chloride content both in standard solution and in simulated concrete pore solution with high sensitivity and fast response. ${ }^{271}$ Despite the promising results obtained with the different OFS proposed, further research is necessary, namely studies in contact with concrete in order to reach the next level - in situ tests.

Table 3 includes the publications reported in the last few years for OFS based on functionalized sol-gel materials for $\mathrm{Cl}^{-}$

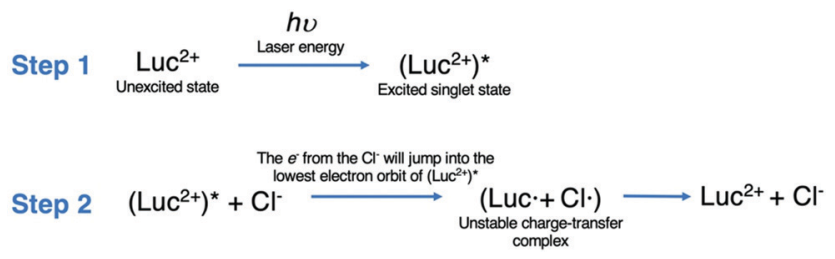

Fig. 19 Schematic representation of the quenching mechanism of Luc in the presence of $\mathrm{Cl}^{-}$. detection. The number of publications until now on OFS functionalized with sol-gel materials for $\mathrm{Cl}^{-}$detection is particularly low. Moreover, the literature shows that the design of OFS functionalized with sol-gel materials for $\mathrm{Cl}^{-}$, mainly for application in concrete and in situ, is still challenging and is at an infant stage.

\subsection{OFS for $\mathrm{K}^{+}$and $\mathrm{Na}^{+}$detection}

Potassium $\left(\mathrm{K}^{+}\right)$and sodium $\left(\mathrm{Na}^{+}\right)$metallic ions have important roles in a wide range of applications such as agriculture (e.g., fertilizers) and cellular processes and related biological functions. ${ }^{296,297}$ In certain areas, the level of progress is so high that electrochemical sensors for $\mathrm{Na}^{+}$detection are already commercially available. ${ }^{298}$ The civil engineering field is another area where the contents of $\mathrm{K}^{+}$and $\mathrm{Na}^{+}$have critical roles since these ions are involved in a well-known pathology - alkali-silica reaction (ASR), which is responsible for the early deterioration of concrete structures such as dams. Considering that several papers and books have been devoted to discussing and detailing the mechanisms behind the ASR, this topic will not be expanded here. Therefore, this section will only cover the basic and necessary information.

ASR is the chemical reaction between the reactive constituents of the aggregates of cement, certain forms of reactive silica are unstable, and the $\mathrm{K}^{+}, \mathrm{Na}^{+}$and $\mathrm{OH}^{-}$ions present in the interstitial concrete pore solution produce an expansive hydrous alkali silicate gel. ${ }^{45}$ For ASR to take place in concrete, four main requirements must be satisfied at the same time: (i) a source of reactive silica, (ii) high $\mathrm{OH}^{-}$ion concentration in the interstitial concrete pore solution (for silica attack), (iii) a source of soluble calcium to react with dissolved silica and form a deleterious gel, and lastly (iv) high humidity conditions (gel expansion). ${ }^{45}$ Alkali cations compete with calcium cations to compensate for the surface negative charge of the calcium silicate hydrate $(\mathrm{C}-\mathrm{S}-\mathrm{H})$ gel. Bivalent cations present a higher electrostatic interaction; therefore, high amounts of calcium cations can hinder alkali uptake. ${ }^{299}$ Generally, to mitigate ASR occurrence, preventive measures are employed such as limiting the alkali content in concrete by using supplementary cementitious materials. The use of such materials controls the ASR by reducing the concentration of $\mathrm{Na}^{+}, \mathrm{K}^{+}$and $\mathrm{OH}^{-}$ions in the concrete pore solution. Therefore, the development of sensors for $\mathrm{Na}^{+}$and $\mathrm{K}^{+}$detection in concrete will allow on one hand to monitor the $\mathrm{Na}^{+}$and $\mathrm{K}^{+}$content and on the other hand to correlate the concrete properties with the aforementioned content of cations and the ASR occurrence. Moreover, the threshold cation concentrations above which ASR has been initiated hitherto are not well established. ${ }^{300}$ Hence, reaching such detailed information will be a milestone in this field.

Determining the content of $\mathrm{Na}^{+}$and $\mathrm{K}^{+}$in different samples, regardless of whether for health or non-health applications, can be performed by different techniques such as flame emission spectrophotometry (flame photometry), ${ }^{301}$ atomic absorption spectrophotometry (AAS), indirect ion-selective electrode potentiometry (ISE), and direct ISE. Nevertheless, the mentioned analytical tools require large sample quantities and pre- 
Table 3 OFS based on functionalized sol-gel materials for $\mathrm{Cl}^{-}$detection

\begin{tabular}{|c|c|c|c|c|c|c|}
\hline Year & $\mathrm{RM}$ & Precursors and reagents & Main results and conclusions & RT & $\mathrm{CRa}$ & Ref. \\
\hline 2009 & $\begin{array}{l}\mathrm{AgNO}_{3}, \mathrm{Ag}_{2} \mathrm{CrO}_{4}, \\
\text { fluorescein }\end{array}$ & TEOS, $\mathrm{HCl}$ & $\begin{array}{l}\text { Several designs of chloride-sensitive OFS were created } \\
\text { and tested under lab conditions but were found } \\
\text { to be non-reversible. }\end{array}$ & NR & NR & 294 \\
\hline 2018 & Luc & TEOS, EtOH, $\mathrm{H}_{2} \mathrm{O}, \mathrm{HCl}$ & $\begin{array}{l}\mathrm{Na}^{+}, \mathrm{Ca}^{2+} \text {, and } \mathrm{Mg}^{2+} \text { had tiny impact on } \mathrm{Cl}^{-} \text {detection. } \\
\text { High }\left[\mathrm{SO}_{4}^{2-}\right] \text { values hinder the Luc quenching process. } \\
\mathrm{OH}^{-} \text {interfered with } \mathrm{Cl}^{-} \text {detection. }\end{array}$ & $10 \mathrm{~s}$ & $0.1-0.5 \mathrm{M}$ & 270 \\
\hline \multirow[t]{2}{*}{2019} & $\begin{array}{l}\text { Chloride-sensitive } \\
\text { fluorophore }\end{array}$ & Calcium alginate sol-gel & $\begin{array}{l}\text { The OFS were insensitive to environmental variations. } \\
\text { Promising results for early corrosion detection and } \\
\mathrm{Cl}^{-} \text {monitoring. }\end{array}$ & NR & $0.045-0.45 \mathrm{M}$ & 295 \\
\hline & Luc & $\begin{array}{l}\text { TEOS, EtOH, cellulose } \\
\text { acetate, } \mathrm{C}_{6} \mathrm{H}_{12} \text {, Triton } \\
\mathrm{X}-100, \mathrm{C}_{6} \mathrm{H}_{14} \mathrm{O} \text {, chitosan, } \\
\mathrm{NaOH}, \mathrm{NH}_{3} \cdot \mathrm{H}_{2} \mathrm{O}\end{array}$ & $\begin{array}{l}\text { OFS showed good linear characteristics from } 0.02 \mathrm{M} \\
\text { to } 0.06 \mathrm{M} \mathrm{KCl} \text { solutions by measuring the fluorescence } \\
\text { intensity based on the fluorescence quenching principle. } \\
\text { Good anti-interference performance for } \mathrm{Cl}^{-} \text {detection. }\end{array}$ & NR & $0.02-0.06 \mathrm{M}$ & 271 \\
\hline
\end{tabular}

concentration steps to obtain the total sodium concentration within the detection limits of the equipment. Therefore, one of the main challenges is to reduce the sample volume, for instance, to a few $\mu \mathrm{L}$ as usually used by current glucose meters. ${ }^{296}$ Additionally, detailed analytical methodology reports showed that the sodium concentrations measured by flame photometry and by ISE may diverge. These inconsistencies in the results lead to the development of alternative methods such as fluorescent probes that show high spatial and temporal resolution. ${ }^{296}$

Fluorescent probes based on crown ethers are typically used for the development of $\mathrm{Na}^{+}$and $\mathrm{K}^{+}$sensors. ${ }^{103,302}$ To discriminate between $\mathrm{Na}^{+}$and $\mathrm{K}^{+}$and from other ions (e.g. $\mathrm{Li}^{+}, \mathrm{Ca}^{2+}$, $\mathrm{Mg}^{2+}, \mathrm{Zn}^{2+}, \mathrm{Al}^{3+}$ ) using chemical probes, particular attention needs to be given to their chemical properties. Table 4 shows the sizes, hydrated ion sizes and coordination numbers of the above-mentioned ions.

In concrete pore solution the most competing ions are sodium, potassium and calcium ions. ${ }^{305}$ Alkali cations $\left(\mathrm{Na}^{+}\right.$ and $\mathrm{K}^{+}$) compete with calcium cations to compensate for the surface negative charge of the $\mathrm{C}-\mathrm{S}-\mathrm{H}$ gel. ${ }^{299}$ Table 4 shows that while bare $\mathrm{Na}^{+}$is smaller than $\mathrm{K}^{+}$, its hydrated radius is slightly higher due to its higher charge density. Also, $\mathrm{Ca}^{2+}$ shows the lowest bare ion size and the highest hydrated ion size compared with $\mathrm{Na}^{+}$and $\mathrm{K}^{+}$. These properties allow rationally designing sensors for $\mathrm{Na}^{+}$and $\mathrm{K}^{+}$, and crown ethers have interesting opportunities to be used for this application since they are capable of binding alkali metal ions selectively. Several polyoxygenated macrocycles of the crown ether kind have cavities/spaces that provide a favorable environment to welcome guest species (e.g., alkali, alkaline earth metal cations, ammonium, etc.). The ion-dipole interaction leads to binding whose strength and specificity are determined by the cation and the cavity size, the cation-counterion interactions, the receptor topology, the

Table 4 Examples of bare and hydrated ion radii and coordination numbers for some cations

\begin{tabular}{lllllllll}
\hline & $\mathrm{Li}^{+}$ & $\mathrm{Na}^{+}$ & $\mathrm{K}^{+}$ & $\mathrm{Ca}^{2+}$ & $\mathrm{Mg}^{2+}$ & $\mathrm{Zn}^{2+}$ & $\mathrm{Al}^{3+}$ & Ref. \\
\hline Bare ion radius/pm & 94 & 117 & 149 & 100 & 72 & 74 & 53 & 303 \\
Hydrated ion radius/nm & 382 & 358 & 331 & 412 & 428 & 430 & 480 & 303 \\
Coordination number & 4.4 & 5.3 & 6.1 & 7.1 & 7.4 & 7.4 & 7.4 & 304
\end{tabular}

number and disposition of ethereal oxygen atoms, the layer properties of the receptor, and the environmental properties of the system. ${ }^{306}$ These compounds have been widely reported in the design of fluorescent metal sensors. ${ }^{103,302,307}$ For instance, in $2017 \mathrm{Li}$ et al. published a very interesting and detailed review, which focused on the main advances and achievements in the design of crown ethers containing fluorescent probes and their applications in biological systems. ${ }^{103}$ Therefore, and considering the information already published, this review will focus only on the use of crown ethers reported in OFS for $\mathrm{K}^{+}$ and $\mathrm{Na}^{+}$detection in biological and non-biological samples.

Most of the sensors reported for $\mathrm{K}^{+}$and $\mathrm{Na}^{+}$monitoring were electrochemical and mainly for application in biological samples with particular emphasis in the medical field. ${ }^{308}$ The first OFS for $\mathrm{K}^{+}$detection dates back to $1987,{ }^{309}$ in which the working principle was based on the optical measurement of the potential created by an ion-carrier at the lipid/water interface by using a potentiometric indicator. The OFS reported correlated the potassium concentration indirectly with the membrane potential. In the same year, Alder et al. reported the development of an OFS for determination of $\mathrm{K}^{+} \cdot{ }^{310}$ The authors showed the feasibility of using immobilized crown ethers to determine $\mathrm{K}^{+}$in aqueous solution. An OFS was constructed, using a crown ether, that responded reversibly to aqueous $\mathrm{K}^{+}$in the CRa between $10^{-3} \mathrm{M}$ and $10^{-1} \mathrm{M}$, with a $\mathrm{K}^{+} / \mathrm{Na}^{+}$selectivity ratio of 6.4. The authors synthesized 2-hydroxy-1,3-xylyl-18-crown-5 according to the procedure found in the literature ${ }^{306}$ and made it to react with the diazonium salt derived from 4-nitroaniline. The chromogenic crown ether was immobilized onto the tip of the OFS. The output of the OFS changed its absorption when complexed with $\mathrm{K}^{+} \cdot{ }^{310}$ Nevertheless, both the OFS reported showed low $\mathrm{K}^{+} / \mathrm{Na}^{+}$selectivity ratios and could not be used unless a reference sodium sensor was present. One year later, in 1988, an ion-selective optrode for the continuous monitoring of $\mathrm{K}^{+}$was reported. ${ }^{311}$ The sensor was based on the optical measurement of the membrane potential between an aqueous solution and a lipid phase incorporating a potential-sensitive dye. The lipid phase was composed of a chemically modified rhodamine $\mathrm{B}$ dye (for its structure vide Fig. 16) together with either octadecan-1-ol or arachidic acid, with valinomycin as a neutral ion carrier. The fluorescence intensity of the 
potential-sensitive rhodamine dye was dependent on the $\mathrm{K}^{+}$ concentration in the sample and decreased with increasing $\mathrm{K}^{+}$ concentration. Furthermore, interferences were found with other metal ions; however, they were surpassed by using a reference optrode. A selectivity factor of 104 for potassium over sodium was reported. ${ }^{311}$ In 1990 Roe et al. ${ }^{312}$ described the development of an OFS based on the use of a hydrophobic indicator (7-decyl-2methyl-4-(3',5'-dichlorophen-4'-one)indonaphth-1-ol; MEDPIN), a plasticizer, an ionophore (valinomycin) and a fluorescent dye (1,1'-dioctadecyl-3,3,3', $3^{\prime}$-tetramethylindodicarbocyanine perchlorate). The MEDPIN, the ionophore and the fluorescent dye were doped within a poly(vinyl chloride) (PVC) membrane. The membrane was subsequently deposited on the tip of the OFS. The authors showed that the anionic form of the MEDPIN molecule formed a stable complex with the valinomycin- $\mathrm{K}^{+}$pair in the PVC membrane. The energy transfer between the fluorescent dye and the anionic form of the MEDPIN allowed detecting $\mathrm{K}^{+}$in different environments (e.g., aqueous media and human blood). The absorption spectrum of the indicator MEDPIN was successfully used for the determination of the $\mathrm{K}^{+}$, and the reaction was fast, sensitive and selective. ${ }^{312}$ In 1994, Diaz-Garcia et al. reported the construction and analytical properties of a reversible fluorometric OFS for $\mathrm{K}^{+}$detection in serum, urine and water samples. As a recognition molecule, a crown ether was used (i.e. 4-acryloylamidobenzo-18-crown-6). ${ }^{313}$ The crown ether was immobilized within a non-ionic resin (Amberlite XAD-2) and two different designs were studied. Their main advantages were their simple fabrication, reversibility, short RTs, selectivity, operational stability, and suitability for sensing potassium at low levels in complex matrices such as biological fluids. ${ }^{313}$

The first OFS for $\mathrm{Na}^{+}$was published in 1986 by Zhujun et $a .^{314}$ The authors used an anionic fluorophore, a copper-(II)polyethyleneimine complex and a neutral sodium-selective ionophore immobilized onto silica. ${ }^{314}$ In 1992, an OFS for $\mathrm{Na}^{+}$ containing an ion-sensitive fluorescent dye was immobilized using a chromatographic gel as a support matrix for the first time. ${ }^{315}$ The measurements were performed in a physiological $\mathrm{pH}$ range with no interference due to alkaline earth ions. The system proposed showed, back then, a long lifetime, reversibility over extended periods, a low LOD (i.e., $2 \times 10^{-5} \mathrm{M}$ ), and improved selectivity compared with the information available in the literature. The main disadvantages reported were the need for recalibration every three days according to the desired accuracy, variation in the signal over several days (about 5\% in fluorescence intensity at low $\mathrm{K}^{+}$concentrations), and long RTs (5-10 min, from $0 \mathrm{M}$ to $10^{-3}$ $\mathrm{M}$, and $30 \mathrm{~min}$ reverse). ${ }^{315}$

Table 5 lists the OFS published since 2000 for $\mathrm{K}^{+}$and $\mathrm{Na}^{+}$ detection.

Table 5 shows that the number of published papers concerning OFS for $\mathrm{K}^{+}$and $\mathrm{Na}^{+}$monitoring is quite low compared to other applications (e.g., $\mathrm{pH}$, chloride ions and $\mathrm{RH}$ in Section 4.4). The number of publications on OFS based on sol-gel materials for $\mathrm{K}^{+}$and $\mathrm{Na}^{+}$is insignificant, with only two publications found (one in 2002 and the other in 2009). Moreover, most of the developments are focused on physiological environments and so for application in the biological field. No publications were found for detection of $\mathrm{K}^{+}$and $\mathrm{Na}^{+}$in alkaline environments such as concrete. The main drawback/shortcoming in the development of sensors for $\mathrm{K}^{+}$and $\mathrm{Na}^{+}$is the immobilization procedure of an ion-selective dye, which often ends in a loss of selectivity or in a non-irreversible attachment of the dye. In the last few years, the number of cation-sensitive sensors that consist of an immobilized ion-selective dye, which exhibits change in its optical properties directly by the formation of an ion-dye complex, has reached high levels of development. However, the main achievements are quite far from practical applications and from reaching the industrial level with very low technological readiness levels (TRL). The fabrication of sensors assessing such molecules in practical applications has not yet reached the necessary TRL of progress, and only a very few OFS sensors have been reported and described so far. The development of OFS for detection of $\mathrm{K}^{+}$and $\mathrm{Na}^{+}$in concrete will be quite a challenge, particularly concerning their selectivity since several cations are available in the concrete pore solution.

\subsection{OFS based on OIH sol-gel materials for $\mathrm{RH}$ and moisture monitoring}

The use of sensors for moisture and $\mathrm{RH}$ monitoring shows practical advantages and are of interest for several applications.

Table 5 OFS for $\mathrm{K}^{+}$and $\mathrm{Na}^{+}$detection

\begin{tabular}{|c|c|c|c|c|c|c|}
\hline Year & $\mathrm{RM}$ & Precursors and reagents & Main results and conclusions & RT & CRa & Ref. \\
\hline \multirow[t]{2}{*}{2002} & $\begin{array}{l}\text { Bis[4- } N \text {-(1-aza-4,7,10,13-tetraoxa- } \\
\text { cyclopentadecyl)-3,5-dihydroxy-phenyl]- } \\
\text { squaraine for } \mathrm{Na}^{+} \text {; bis[4- } N \text {-(1-aza- } \\
4,7,10,13,16 \text {-pentaoxacyclo-octadecyl)- } \\
\text { 3,5-dihydroxyphenyl] squaraine for } \mathrm{K}^{+}\end{array}$ & $\begin{array}{l}\text { PVC, plasticizer, anionic } \\
\text { lipophilic additive } \\
\text { (potassium tetrakis- } \\
\text { (4-chlorophenyl)borate) }\end{array}$ & $\begin{array}{l}\text { LOD }=1 \times 10^{-9} \mathrm{M} \text {. The sensor was } \\
\text { reversible within the dynamic range. } \\
\text { For pH of } 6.2 \text { to } 7.3 \text { the cross sensitivity } \\
\text { was negligible. }\end{array}$ & $3 \min$ & $\begin{array}{l}10^{-9}-10^{-5} \\
\mathrm{M} \\
\text { for both } \\
\mathrm{Na}^{+} \text {and } \mathrm{K}^{+}\end{array}$ & 316 \\
\hline & $\begin{array}{l}\text { Bis }[4-N \text {-(1-aza-4,7,10,13,16-pentaoxacyclo- } \\
\text { octadecyl)-3,5-dihydroxyphenyl] squaraine } \\
\text { for } \mathrm{K}^{+}\end{array}$ & $\begin{array}{l}\text { TEOS, } \mathrm{HCl}, \mathrm{H}_{2} \mathrm{O} \text {, Triton } \\
\mathrm{X}-100\end{array}$ & $\begin{array}{l}\text { The sensor is fully reversible within } \\
\text { the dynamic range. }\end{array}$ & $2 \min$ & $\begin{array}{l}10^{-9}-10^{-6} \\
\mathrm{M}\end{array}$ & 317 \\
\hline 2009 & $\begin{array}{l}\text { Crown-ether,2-[2-(2,3,5,6,8,9,11,12,14,15- } \\
\text { decahydro-1,4,7,10,13,16- } \\
\text { benzohexaoxacyclo- } \\
\text { octadecin)ethe-nyl]-3-methyl } \\
\text { benzothiazolium-iodide for } \mathrm{K}^{+}\end{array}$ & $\begin{array}{l}\text { MTES, TEOS, EtOH, } \\
\mathrm{H}_{2} \mathrm{O}, \mathrm{HCl}\end{array}$ & $\begin{array}{l}\text { The apparent dissociation constants } \\
\text { in water and neutral buffer were } \\
\text { approximately } 1 \mathrm{mM} \text {. }\end{array}$ & $2 \min$ & $30-65 \mu \mathrm{M}$ & 318 \\
\hline 2013 & $\begin{array}{l}\text { Phenylaza-[18]crown-6-lariat-ether-based } \\
\text { fluoroionophore for } \mathrm{K}^{+}\end{array}$ & Hypan HN 80 hydrogel & High $\mathrm{K}^{+} / \mathrm{Na}^{+}$selectivity. & 2.5 & $1-10 \mathrm{mM}$ & 319 \\
\hline
\end{tabular}


Humidity is the moisture content of a certain atmosphere/ environment, while the $\mathrm{RH}$ is the ratio between the partial pressure of water vapor content and the equilibrium vapor pressure of water at a certain temperature. $\mathrm{RH}$ depends on the pressure and temperature of the system of interest. The air humidity is generally measured by using a hygrometer. The most commonly used instrument for the precise measurement of $\mathrm{RH}$ is a psychrometer (e.g. a wet-and-dry bulb thermometer). ${ }^{320}$

The humidity monitoring parameter is vital in a wide range of fields such as civil engineering and patrimonial buildings, ${ }^{321,322}$ soils, ${ }^{323,324}$ food packaging, ${ }^{325}$ and cultural relics. ${ }^{326}$ Several types of moisture and RH sensors have been reported and may be based on capacitance,,$^{327-329}$ polymers $^{330,331}$ or OFS. ${ }^{19,134}$ Nevertheless, it is difficult for most of the traditional humidity sensors to meet the necessary requirements to monitor the $\mathrm{RH}$ and moisture particularly in complex environments such as concrete. Compared with other traditional RH and moisture sensors, OFS have a number of advantages; however, the most prominent in the case of $\mathrm{RH}$ monitoring is the strong corrosion resistance. Kolpakov and colleagues published a review focused on the new perspectives and highlights of photonic humidity sensors. ${ }^{332}$ In this manuscript the scientific literature covering the years from 2004 to 2014 as well as the tendencies in the development of OFS for humidity measurements was analyzed and discussed. Based on the analysis performed, it was clear that a new generation of OFS was emerging. The authors quoted that ". . .electronic humidity sensors could soon be replaced by sensors that are based on photonic structures. ...". Also, the information concerning the performance of commercial optic humidity sensors was provided. ${ }^{332}$
Considering the humidity sensing field, different approaches have been proposed. Fig. 19 shows some examples of different types of OFS for RH monitoring.

OFS for $\mathrm{RH}$ based on evanescent wave interactions (vide Fig. 20), ${ }^{333,337}$ FBGs $^{338}$ and LPFGs (vide Fig. 20), ${ }^{334,339}$ interferometers, ${ }^{340,341} \mathrm{CNTs}^{335}$ (vide Fig. 20), polymers, ${ }^{336,342,343}$ and photonic crystal fibers ${ }^{344,345}$ have been proposed.

A low cost OFS based on the evanescent field-fiber loop ringdown technique for water and moisture monitoring in concrete was described for the first time by Kaya et al. ${ }^{337}$ The OFS used as a photodiode and was accomplished by embedding a section of a partially etched SMF into the concrete. The OFS developed compared with other sensors showed the highest response time (5 minutes), higher sensitivity $(10-80 \mathrm{~mL}$ of water), immunity to temperature variations and most importantly reproducibility and reversibility. ${ }^{337}$

OFS for humidity monitoring based on a Mach-Zehnder interferometer (MZI) have also been reported. Zhang et al. in 2013 described a sensor for measuring RH and temperature simultaneously with high accuracy. A photonic crystal fiber (PCF) based on a MZI (PCF-MZI) in-line with a FBG was used. ${ }^{338}$ The fiber was coated with a polyvinyl alcohol (PVA) film that is moisture sensitive and its RI changes with humidity variations. The FBG was only sensitive to temperature. The authors also reported that the PVA thickness coating as well as the length of the PCF used in the PCF-MZI did not affect the sensitivity of the RH measurement. Nevertheless, very small thicknesses of PVA coatings led to the formation of non-uniform coatings, while higher thicknesses decreased the RT for the RH measurement.
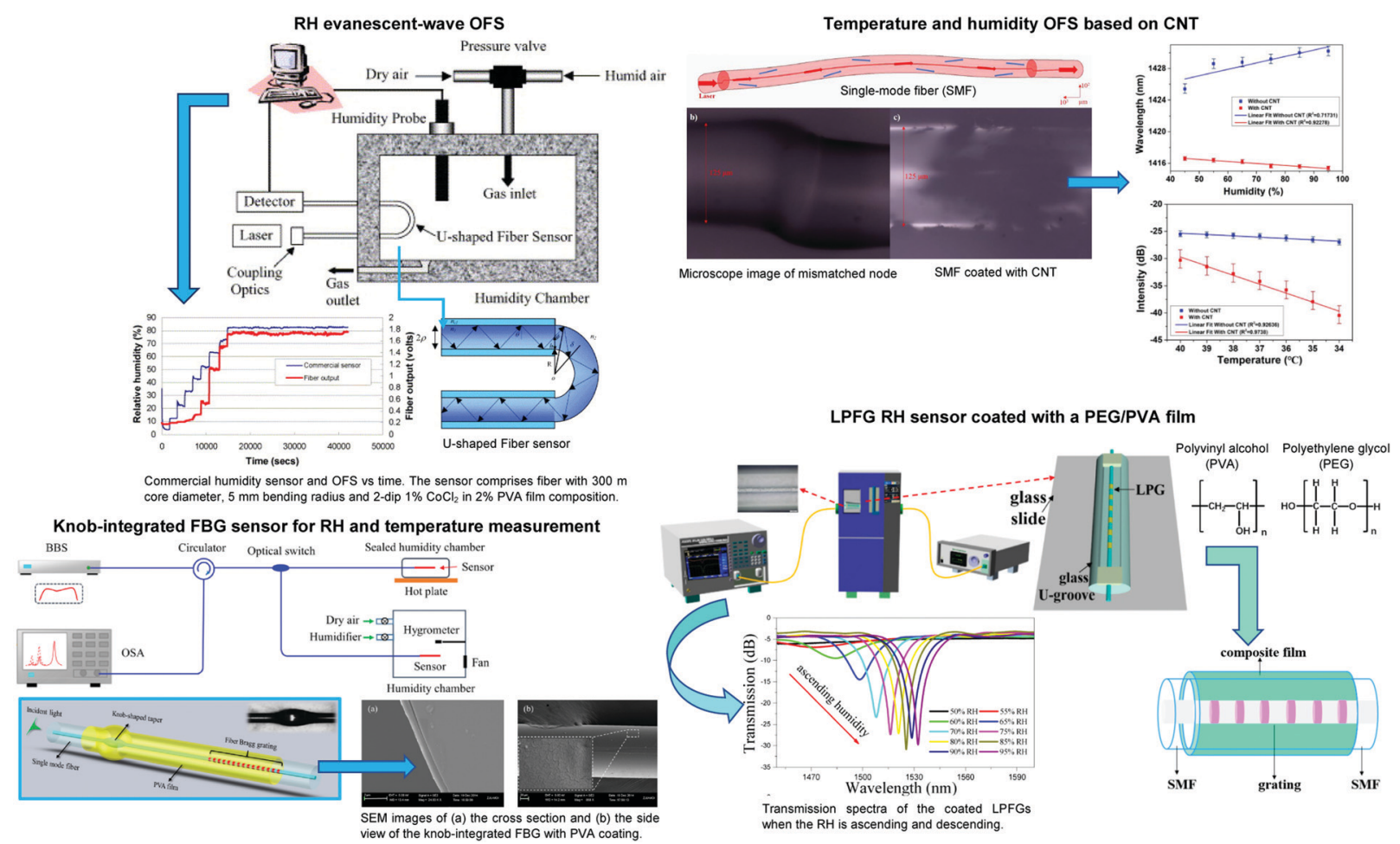

Fig. 20 Different approaches for the humidity sensing field, namely OFS based on evanescent wave interactions, knob integrated FBG sensors, OFS based on CNTs and LPFGs based on polymer coatings. Reprinted and adapted with permission from ref. 333-336. Copyright 2005 Elsevier. 
An optimum thickness between 6 and $8 \mu \mathrm{m}$ was achieved. ${ }^{338}$ Wang et al. reported a humidity sensor based on an in-fiber MZI coated with graphene oxide. ${ }^{346}$ Graphene oxide was chosen because its RI changes with the different external environments. A highly sensitive $(0.349 \mathrm{~dB} / \% \mathrm{RH}$; $\mathrm{RH}$ range of $60-77 \%)$ and stable OFS was obtained. Ni et al. described a low-cost and robust humidity sensor that adopted a MZI modified by the deposition of a chitosan layer on the cladding. ${ }^{347}$ The sensor developed showed, compared with the traditional humidity OFS, high performance with a high resolution of $\sim 0.17 \mathrm{RH}^{347}$ Bian et al. reported, for the first time, the combination of a calcium alginate hydrogel with a MZI structure. The calcium alginate hydrogel was chosen due to its humidity performance and water-retaining properties. Sodium alginate and calcium chloride solutions were combined. The alginate ions and calcium ions react, forming an organic crosslinked polymer material (CaAlg hydrogel). In this case the hydrophilic residues combine with water molecules and the hydrophobic groups expand. The authors obtained a sensitivity of up to $\sim 0.483 \mathrm{~dB} / \% \mathrm{RH}$ and realized that in terms of film preparation the CaAlg hydrogel was low cost, non-toxic and harmless and could be easily obtained. Compared to the literature abovementioned, the humidity sensitivity of the sensor proposed by Bian et al. increased by around 3 $(0.157 \mathrm{~dB} / \% \mathrm{RH})$ and $2(0.263 \mathrm{~dB} / \% \mathrm{RH})$ times, respectively. It was also concluded that the sensor showed good repeatability, stability and a fast response recovery time. ${ }^{348}$

Regarding civil engineering structures the moisture level may influence the concrete carbonation and the corrosion rate. Previous studies indicated that carbonation reached a maximum level at $\mathrm{RH}$ between $50 \%$ and $70 \%$. Moreover, it has been concluded that the $\mathrm{RH}$ influences, considerably, the carbonation depth of concrete. The carbonation depth increases with the increase of the $\mathrm{RH}$ and reaches the peak when the $\mathrm{RH}$ is in the range of $60-70 \% .{ }^{349}$ However, this is dependent on the moisture condition of the concrete surface; for example, cyclic wetting and drying conditions may lead to fluctuations in RH. ${ }^{349}$ It has also been proven that high carbonation kinetics are coupled to the moisture sorption and increase with the $w / c$ ratio. $^{225,350}$

Furthermore, the carbonation itself releases water which contributes to $\mathrm{CO}_{2}$ and portlandite dissolutions and therefore carbonation reactions. On the other hand, the corrosion rate in RCS with different $\left[\mathrm{Cl}^{-}\right]$is influenced by the internal $\mathrm{RH}$ level. ${ }^{351}$ Therefore, the monitoring of $\mathrm{RH}$ allows mitigating severe damage to RCS by taking in advance appropriate actions.

Typically, most OFS for humidity monitoring require a hygroscopic material that is generally deposited on the tip or on the section of the optical fiber. Moisture/humidity modifies the optical properties of the hygroscopic material, which changes a feature of the guided light, providing a detectable signal. The sensors based on FBGs ${ }^{352-354}$ for RH monitoring are usually obtained by coating the grating surface with a material that is sensitive to humidity and moisture that has the ability to shift the wavelength when the humidity of the environment changes. However, this type of sensor has low sensitivity since it is highly dependent on temperature, leading to errors during measurements. In the case of Fabry-Pérot interferometers ${ }^{340,343,355}$ a moisture sensitive coating is needed as a reflecting cavity and the fabrication of this type of sensor is complex. Regarding whispering gallery mode resonators, ${ }^{356-358}$ their structure is extremely delicate, which may lead to drawbacks in transport and during their use. Fig. 21 shows some representative examples of RH OFS reported namely FBGs, Fabry-Pérot interferometers and whispering gallery mode resonators.

Yeo et al. reported an OFS for measurement of moisture absorption in concrete. ${ }^{359}$ The sensor was fabricated using a FBG coated with polyimide. To enhance the adhesion between the polyimide layer and the silica surface, the FBG was treated with APTES (silane coupling agent) prior to polyimide coating. The deposition of the polyimide layer was performed by a multiple dip coating process which involved the deposition of 20 layers. Between depositions a thermal treatment at $150{ }^{\circ} \mathrm{C}$ for $\sim 5$ min was given in each dip coating step. In the end, the coated FBG was cured at $180{ }^{\circ} \mathrm{C}$ for $60 \mathrm{~min}$. The proposed OFS allowed controlling the changes in the moisture content in different concrete samples. ${ }^{359}$

Table 6 summarises the most relevant OFS based on functionalized sol-gel materials published since 2000 for moisture and $\mathrm{RH}$ monitoring.

Table 6 shows that the most used precursor to prepare the supporting matrix was TEOS, and most of the studies did not report the LOD. A wide range of recognition molecules were tested and only a study was reported in concrete. The highest humidity range reported was between $4 \%$ and $100 \%$ when a xerogel was prepared using TEOS with EtOH in a $4.75: 1$ molar ratio and $\mathrm{H}_{2} \mathrm{O}$ with TEOS in a 5.5:1 molar ratio. Another interesting humidity range reported $(30 \%$ to $100 \%)$ was obtained when the polyimide was used as a recognition molecule and APTES as a precursor to prepare the supporting matrix, and this was the only study performed in concrete.

\subsection{Multi-functional OFS based on OIH sol-gel materials for SHM}

It is undeniable that OFS technology has the required properties that when combined with new transduction concepts allows the development of highly sophisticated autonomous and multi-functional sensing systems with the inimitable advantages of optical fibers. Moreover, multi-functional sensors allow obtaining and exchanging information in a single device.

The key strategy for the development of multi-functional OFS with high efficiency, stability, and sensitivity and lower LODs is the progress in integrating functional materials displaying distinct properties combined with suitable transduction mechanisms. ${ }^{367,368}$ This will be a milestone on the development of multi-functional OFS and a new technological revolution that will lead to the development of a new generation of devices. From this perspective, these devices are the basis for the development of a world technology that is completely incorporated into a single optical fiber. In such a case, several materials at the micro- and nano-scales are assembled, embedded and connected all together, providing physical connections and 

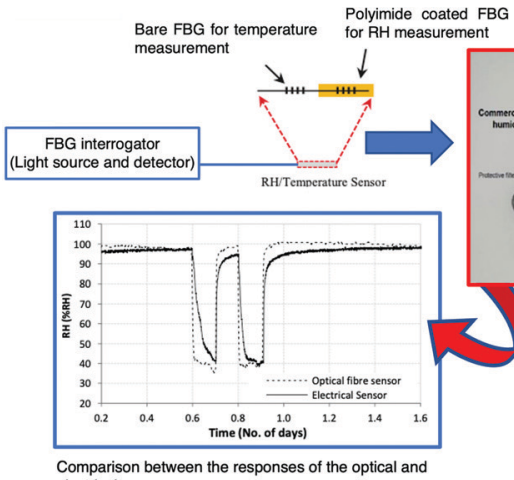
Comparison betwe
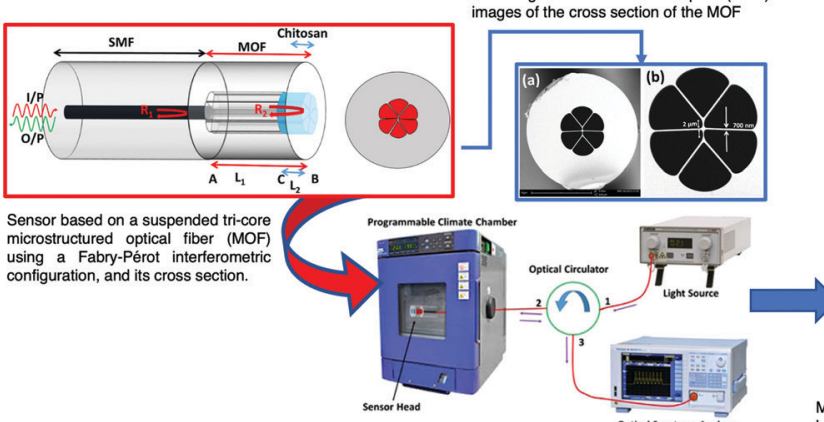

Experimental setup for the humidity sensing oxperiments.
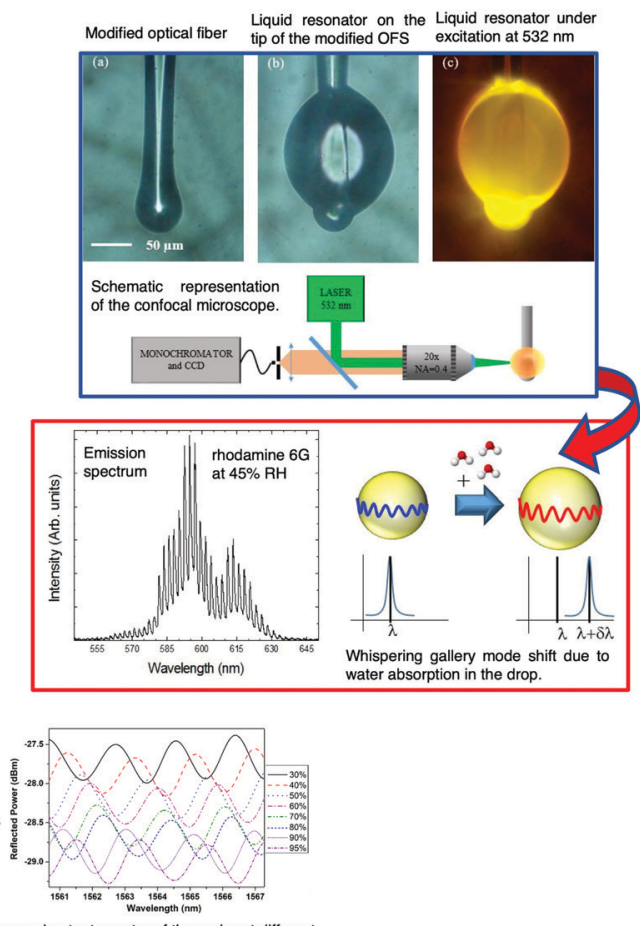

Measured output spectra of the probe at different humidity values in the climate chamber.

Fig. 21 Schematic of different OFS for humidity and moisture detection based on polyimide coated FBGs, Fabry-Pérot interferometers and whispering gallery mode resonators. Reprinted and adapted with permission from ref. 343, 352 and 356. Copyright 2016 Elsevier.

Table 6 OFS based on functionalized sol-gel materials for moisture and $\mathrm{RH}$ monitoring

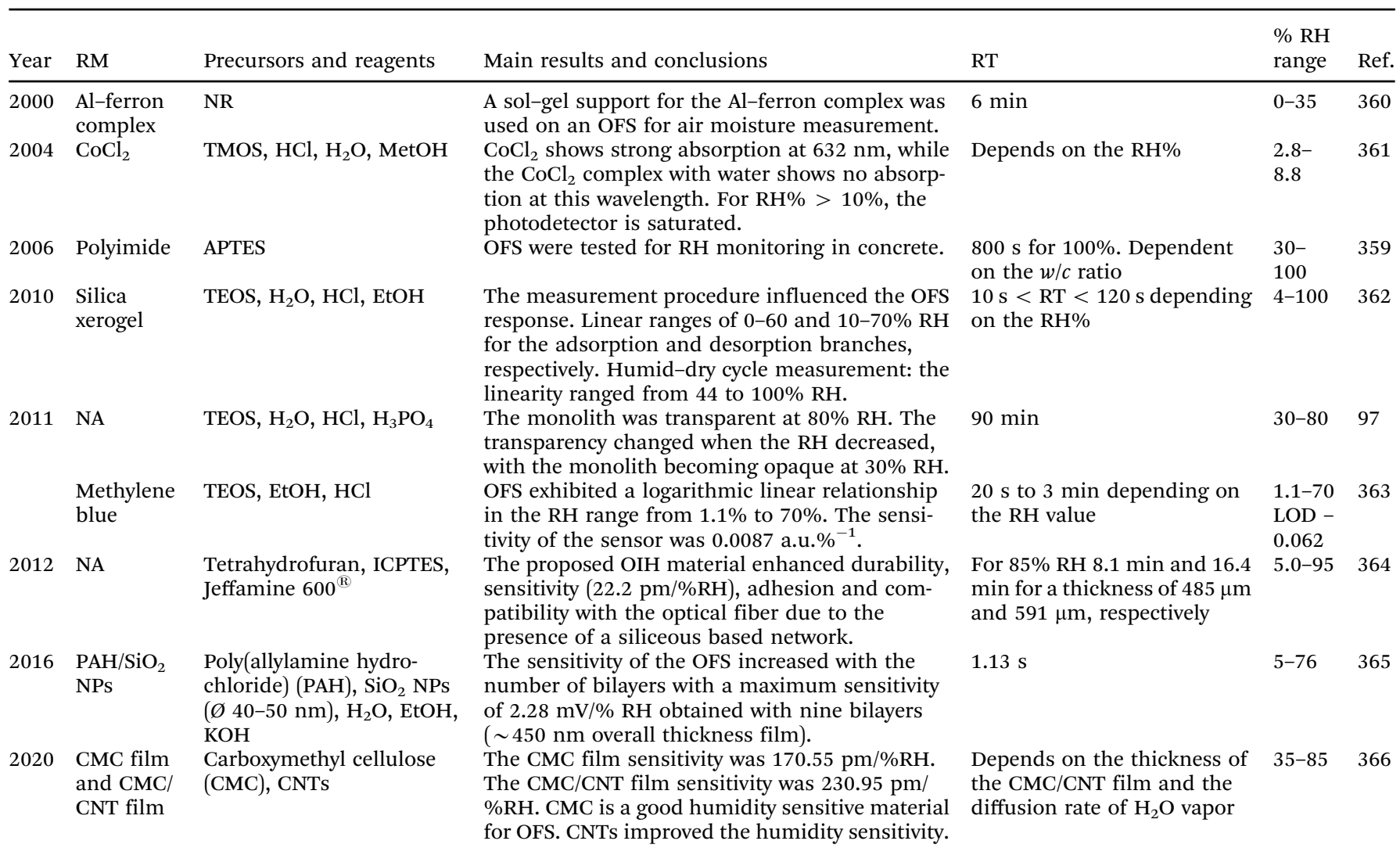

NA - not applied; NR - not reported. 
light-matter interactions, offering a wide range of functionalities and high performance in a single device.

In the last few decades, several research groups have focused their efforts on the design and the development of multiplexed integrated devices starting with the assessment of the technological steps for their fabrication. ${ }^{368-370}$ Considering all these advantages, multiplexed chemical sensing and fusion of sensors for physical and chemical analysis allowing obtaining accurate and insightful information are the main objectives of OFS developers.

$\mathrm{Fu}$ et al. reported the development of a multi-functional fiber sensor with two FBGs to monitor three parameters (e.g. strain, temperature and acoustic emission) simultaneously for SHM. ${ }^{371}$ The properties strain, temperature and acoustic emission were successfully measured using the reported OFS. This sensor showed potential and interesting properties to monitor aircraft bodies, concrete structures, and oil field equipment. The development of this sensor is a milestone in the multifunctional OFS progress. Nevertheless, studies in concrete need to be conducted to assess the OFS behavior. Thursby et al. ${ }^{372}$ reported a FBG sensor that was able to both detect ultrasound and measure strain. The development of multi-wavelength optical sources allowed the simultaneous interrogation of several gratings, which are necessary in the case of real-time measurements. However, information regarding the interpretation of results including reliability and repeatability is necessary. Mizutani and Groves reported the development of a FBG sensor for average surface strain, strain distribution and vibration from the reflection spectra. ${ }^{373}$

Cusano et al. ${ }^{367}$ envisioned two main lines in the development of multi-functional OFS, namely: local micro- and nanostructuring of optical fibers in order to increase the interaction between light and matter providing the foundational basis for integration of functional materials and the search for suitable deposition techniques for the integration of such materials at the micro- and nano-scales with clear geometries and shapes. The same research group designed and developed a multi-functional OFS to monitor the parameters of experiments running at CERN, the European Organization for Nuclear Research. ${ }^{369}$ The parameters considered were the temperature, strain, humidity, magnetic field and cryogenics of experiments taking place under harsh operating conditions of high energy physics experiments. The research group showed that the results were very promising, allowing concluding that the use of OFS was a robust and effective solution able to replace most of the conventional sensing technologies employed at that time.

Petropoulou et al. reported a two-parameter OFS for $\mathrm{pH}$ measurement and ammonia gas. The reported sensor showed a reliable response for high ammonia concentrations, and a fast and linear response in both alkaline and acidic environments. Nevertheless, the stability of the sprayed film on the surface of the OFS was limited due to the detachment of the deposited film. ${ }^{374}$

Although tremendous advances have been achieved in the development of multi-functional materials, the integration of such materials for the development of multi-functional OFS has not been fully reached particularly using sol-gel materials. Moreover, sensors monitoring in a single device more than three parameters simultaneously have not been reported hitherto for SHM of civil engineering structures. The literature reported so far shows that the number of OFS for detection of three parameters concurrently is very low, while sensors for sensing parameters above three are very scarce. ${ }^{158}$ Fig. 22 shows examples of the most representative multi-functional OFS based on FBGs, fluorescent chemosensors and polymers.

\section{Limitations and challenges of OFS functionalized with $\mathrm{OlH}$ sol-gel materials}

Regarding the development of OFS functionalized with $\mathrm{OIH}$ sol-gel materials, two categories of challenges are present. The first category is inherently related to the limitations of $\mathrm{OIH}$ sol-gel materials involved in the fabrication of OFS. The second type of challenge is in terms of sensing. Therefore, the two categories are clearly distinguished below.

\subsection{Limitations of OIH sol-gel materials}

Considering the literature assessed through this review, outstanding efforts had been made to detect/monitor different types of analytes in situ, in real time and in different environments with negligible or without any perturbance of the sample under study. A key number of features have been identified in the use of sol-gel materials for the development of multifunctional OFS in a wide range of applications, namely: flexibility, biocompatibility, low-cost production and real-time continuous monitoring, and ability to be used in harsh environments and monitor different parameters. OFS functionalized with $\mathrm{OIH}$ sol-gel materials have promising prospects in a wide diversity of fields as aforementioned. However, some constraints are still present.

Concerning the development of sol-gel materials, it should be kept in mind that several materials are virtually transparent in the visible range of the spectrum. Nevertheless, the presence of even very small pores may scatter the light at very short wavelengths. Very porous aerogels tend to have yellowish transmission and the use of organic substances in sol-gel matrices may turn yellow during the drying process at high temperatures, which may lead to transmission drops. The deposition technique of the sol-gel material on the tip of the optical fiber may also induce some limitations in obtaining a uniform coating.

Regarding deposition techniques, the most used one to coat a fiber is the dip coating method and, when using this technique, occasionally the film margins may show increased thickness due to surface tension effects. Additionally, the formation of a drop on the tip of the fiber may also happen, and the size and prominence of the drop generally depends on the viscosity of the material that is deposited. To minimize the drop formation, the viscosity of the materials may be tuned, although when using a high amount of inorganic precursor 
Multi-Functional Measurement Using a Single FBG Sensor

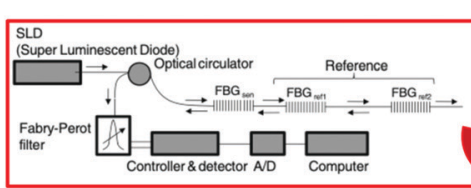

Experimental setup for multifunctional FBG sensor

Reflection spectra. FBGref1 and FBGref2 are used as references for temperature stabilization. FBGsen is mounted on the specimen.

Multi-Functional fibers comprising $\mathrm{Agl}-\mathrm{AgPO}_{3}-\mathrm{WO}_{3}$ glass and $\mathrm{PC} / \mathrm{PMMA}$ polymers for concurrent electrical conduction and light transmission

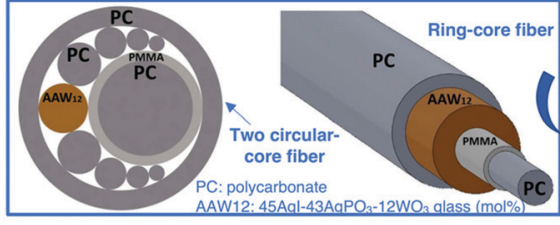

(a, b) $125 \mu \mathrm{m}$ and $250 \mu \mathrm{m} \varnothing$ single-core AAW15 glass fibers with acrylic coating (Ac)

(c) Two circular-core fiber with $125 \mu \mathrm{m} \varnothing$ AAW12 glass and $140 \mu \mathrm{m} \varnothing \mathrm{PC}$ cores.

(d) Ring-core fiber with a PC cladding ring of $45 \mu \mathrm{m}$ thickness,

an electrically conductive AAW12 glass ring of $90 \mu \mathrm{m}$

thickness, a PMMA ring of $25 \mu \mathrm{m}$ thickness, and a PC core of

$155 \mu \mathrm{m} \varnothing$.

AAW15: $45 \mathrm{Agl}-40-\mathrm{AgPO}_{3}-15 \mathrm{WO}_{3}$ glass (mol\%)
Multi-Functional Gas and $\mathrm{pH}$ and Fluorescent Sensors
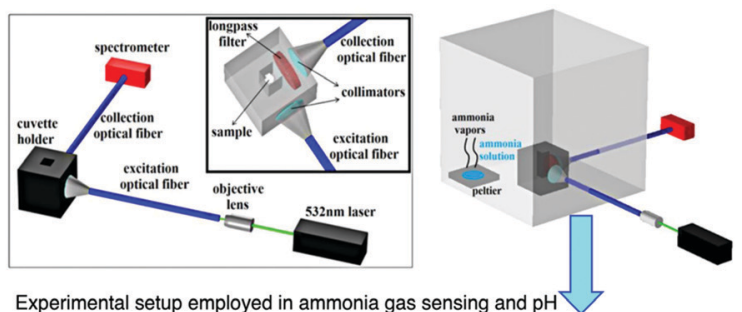

Experimental setup employed in ammonia gas sensing and $\mathrm{pH}$ sensing experiments

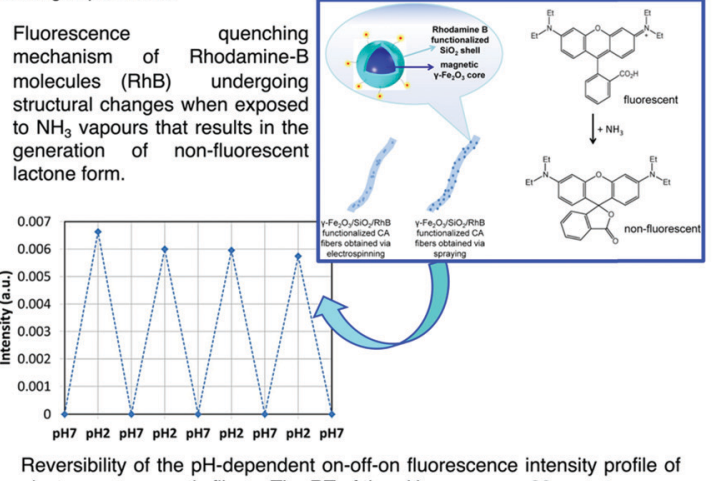

Reversibility of the pH-dependent on-off-on fluorescence intens
electrospun magnetic fibers. The RT of the pH sensor was $30 \mathrm{~s}$.

Fig. 22 Examples of different multi-functional OFS based on FBGs, fluorescent chemosensors and polymers. Reprinted and adapted from ref. 368,372 and 373.

compared to the organic precursor the viscosity is decreased as well as the coating thickness and when the coating thickness increases cracking and detachment from the fiber may occur. Therefore, controlling all processing parameters (e.g., viscosity, curing time, organic/inorganic ratio) is of extreme importance since this will allow obtaining uniform membranes with suitable properties to be used on the fiber tip and minimize the mentioned shortcomings.

Most of the OFS based on swellable OIHs doped with recognition molecules may experience leaching. This is a shortcoming particularly in cases in which the functionalized sensor is developed for long time periods. This is particularly relevant for concrete structures since they are developed for a service life of at least 100 years. Moreover, in the first curing ages, concrete shows $\mathrm{pH}$ values above 12.5 which may compromise the durability of the sensors. The long-term functionality is important as these sensors should, ideally, have a lifetime equal to or above 20 years. This life span is very difficult to achieve, particularly with traditional OIH sol-gel materials. On the other hand, only a few publications reported the use of OIHs in highly alkaline environments such as concrete. The available literature also showed that organic dyes are more prone to leak than inorganic fluorophores. The use of recognition molecules such as fluorescein faces some challenges since these materials photobleach quite fast.

Reflecting on all the information published and analyzed, it can be assumed that the performance of functionalized OFS with OIH sol-gel materials, at the current stage, is not so extraordinary to justify their use in relevant fields particularly in concrete structures. As a contradiction, functionalized OFS technology with sol-gel materials appears to have only potential as business value. These observations lead the authors to the evident key question: How to overcome this breach? The authors believe that space for optimization exists and in the case of concrete structures it seems that there is still a long way to run. Most of the chemical functionalization protocols used so far in this field are quite standard.

\subsection{Limitations of the sensing parameters of OFS functionalized with OIH sol-gel materials}

OFS functionalized with OIH materials do not use electricity; therefore, they can be used to monitor inflammable liquids or gases, since they are immune to sparks, thus being interesting alternatives in harsh environments (e.g., highly acidic, corrosive or highly alkaline). Moreover, since some of the OFS are chemically inert, their use is an interesting alternative in chemical reactors. These advantages are the main causes for the growth of OFS, at a steady pace, in a wide diversity of industries. Despite the noteworthy progress achieved in the past few years toward civil engineering and other fields, there are many crucial challenges to address and technological gaps to bridge before achieving the full potential of functionalized OFS with OIH sol-gel materials. Moreover, the number of available OFS that can accurately and reliably analyze and monitor the broad spectrum of concrete parameters (e.g., $\mathrm{pH}$, $\mathrm{Cl}^{-}$, alkali-silica reaction, humidity) is still very low. The integration process between OFS and OIH sol-gel materials is often very challenging and poses severe limitations in obtaining the performances theoretically expected. A direct comparison between the different OFS in terms of performances cannot be 
performed straightforwardly. Primarily, the diversity in the target molecule size and properties strongly affects the sensitivity performance. Secondly, the surface chemistry, in the case of multi-functional OFS, plays a vital role in defining the final properties of the OFS in terms of surface sensitivity and in terms of LODs. Thus, the comparison of different functionalized OFS is a challenging task and may lead to ambiguous and unclear results even for the same target molecule.

Considering the publications found and debated through the manuscript, it can be easily observed that most of the OFS functionalized with sol-gel materials for application in the civil engineering field focus on monitoring the $\mathrm{pH}$. However, most still require further optimization in sensor stability and assessment under field conditions before exploitation and routine use can be implemented. Regarding other concrete parameters, there are only a few reports on OFS using sol-gel materials that can monitor chloride ions in concrete and $\mathrm{RH} /$ moisture. As well as lack of assessment under field conditions and stability studies for long time performance. Most of the sensors reported for this purpose are electrochemical. On the other hand, OFS to monitor sodium and potassium ions in alkaline environments have not been reported until now.

Continuous monitoring of the abovementioned parameters would provide insightful information for screening and early detection of a broad range of major health conditions of a civil engineering structure. However, one of the main challenges lies in the detection of such parameters in highly alkaline environments such as concrete. Developing OIH sol-gel materials to functionalize OFS to achieve sensors highly sensitive and selective with suitable properties to be employed in highly alkaline environments $(\mathrm{pH}>12.5)$ is one way of tackling this major drawback.

Despite the developed multi-functional OFS reported, until now the engineering of sensors able to sense more than three parameters has been very challenging. This is mainly related to the limitations in combining different sensing principles into a single-sensor structure, while answering to individual parameters, regardless of one from another, with low crosstalk. The limitations in achieving OFS to monitor/detect more than three parameters may be connected to the limitations in combining different sensing transduction methods and/or sensing principles into a single device. As far as the authors' knowledge, melting the scientific boundaries between individual parameters, which are not related to each other, by establishing multidisciplinary teams is the key to tackling these shortcomings.

\section{Future research on $\mathrm{OlH}$ sol-gel materials for OFS}

The properties of sol-gel matrices were shown to be very auspicious for the encapsulation of different sensing probes including organic, inorganic, luminescent, and colorimetric dyes for detection of different analytes (e.g., pH, ions, biomarkers, gases) in a wide range of environments (solid, aqueous, biological, and gaseous). The proof of this is the available solutions employing sol-gel technology at industrial levels. ${ }^{375}$ Since the potential of these materials was fully recognized by the scientific community, several efforts have been directed not only towards specific applications but also towards optimizing, studying, modifying and creating new abilities. In this context, it is expected that sol-gel technology will have an increasingly growing contribution to the establishment of a mature luminescence sensing technology that will allow developing smart and reliable OFS with the ability to be integrated to monitor relevant parameters inside of different configurations that can go from civil engineering structures to the human body.

The studies reported through the manuscript present a key challenge to sensor technology development in the immediate future and require the intimate collaboration between different actors in different research fields. As it can be easily claimed, the ability of a given device to take the maximum advantage from the large set of physical/chemical transduction mechanisms is directly linked to the understanding of precise nanostructures with specific geometries, shapes and size constraints. The success in this direction is highly dependent on the integrative vision of several research disciplines. Encompassing unique sensing abilities in a relevant device will involve extensive know-how about physics, engineering, nanotechnology, and chemistry. All these disciplines must be related for interdisciplinary research, aimed at the successful exploitation of this attractive technology. In addition to this, machine learning and big data tools can be used for analyzing and explaining the vast sensor data from a certain study to identify patterns and correlations. These tools have already been successfully applied to OFS. ${ }^{376,377}$

Going toward materials engineering may enhance the binding uniformity and density in complex areas particularly in the presence of nanostructured surfaces. Additionally, for optimized surface chemistry, systems such as molecular binding amplification agents may ensure increased performances.

The long-term efforts and excitement in the development and application of OFS will be for sure extended to new fields and further accurate and commercial achievements will be made. The development in this field is limitless. The use of molecularly imprinted polymers (MIPs) on optical fiber sensors ${ }^{378-381}$ has already been reported. The authors believe that this field will progress fast and soon will achieve higher maturity, opening further opportunities in the development of optical fiber sensors.

Cuevas et al. reported a proof of concept in which a machine learning algorithm was instructed to classify the perturbations according to the distance where the perturbation was caused along a multimode OFS. ${ }^{376}$ Although there are still no commercially available multi-functional OFS for continuous monitoring of concrete parameters of civil engineering structures, it is expected that this type of sensor coupled with big data mined from this technology will replace traditional repair actions with predictive and proactive diagnostics. Such technology can pave the way for future development in sensors for real time SHM. As the interest grows, more efforts from both the research and engineering fields will help identify strategies to solve 
the current limitations and boundaries related to OFS functionalized with sol-gel materials.

The authors believe that it is very likely that multi-functional OFS will be able to monitor simultaneously different concrete parameters, and provide detailed information about concrete health. It is likely that multi-functional OFS to monitor concrete structures will be well established and commercially available within the next two decades. It is expected that the large sets of data and information collected from concrete structures using these sensors will ultimately generate predictive algorithms and bring disruptive procedures to the traditional industry of construction.

\section{Conclusions}

In this review, the authors have summarized and highlighted the main advances in OFS functionalized with OIH sol-gel based materials toward a wide range of applications with particular emphasis on the civil engineering field. The application of $\mathrm{OIH}$ sol-gel based materials as immobilization membranes in sensing systems has been demonstrated in a wide diversity of perspectives.

OFS have the ability to be integrated to monitor relevant parameters of different configurations that can range from civil engineering structures to the human body. This is the main reason why OFS devices offer high degrees of versatility and functionality. The basic and fundamental sensing mechanisms of OFS are well established and mature enough. Therefore, the major developments in the following years will be focused on improving the design, chemical membranes, and sensing schemes of OFS with lower LODs and high sensitivity. Soon, OFS with high accuracy and sensitivity will be available for a wide range of applications. The search for a chemical probe with the capacity to detect simultaneously multiple analytes and the ability to be easily incorporated in a sol-gel matrix or other polymeric membranes is one of the focuses of current research in almost all research areas (i.e., medical, civil engineering, aeronautic, biosensing, etc.). The development of sensors with fast response times (i.e., instantaneous, or almost), high selectivity, and portable and continuous monitoring capability is what the scientific community looks to improve every day. It can be concluded that OFS are becoming a mature technology and they have replaced conventional sensors in several real-world applications particularly in the measurement of physical properties such as temperature and strain monitoring of large-scale civil engineering structures.

Most of the OFS functionalized with sol-gel materials for application in the civil engineer field were focused on monitoring the $\mathrm{pH}$. However, most of them require further optimization in sensor stability and assessment under field conditions before exploitation and routine use can be implemented. Regarding OFS using sol-gel materials that can monitor chloride ions in concrete and $\mathrm{RH} /$ moisture, only a few studies were reported and are from the commercial status. On the other hand, OFS to monitor sodium and potassium ions in alkaline environments

such as concrete have not been reported hitherto. Moreover, despite the number of FBG and LPFG sensors developed for application in concrete structures, their application in situ and in real structures is still underdeveloped. Therefore, tests in contact with concrete are necessary as well as long-term studies in order to access the robustness of the proposed OFS. Moreover, OFS monitoring more than three parameters simultaneously are still in an embryonic phase.

The past two decades has witnessed enormous advances in the development of new OFS that range from fundamental synthesis of innovative sol-gel nanomaterials for OFS functionalization to proof of concepts. Despite the remarkable progress made in this mushrooming topic, challenges and constraints are still present. The development of multi-functional OFS systems demands the careful design of new OIH sol-gel materials together with a rational and consistent strategy to make OFS survive in the unfriendly and harsh environment of the civil engineering field, e.g., concrete structures.

\section{Abbreviations}

3-D

AAS

ANS

APTES

ASR

BB

BTB

BCG

CMC

CNTs

CPR

$\mathrm{CRa}$

CR

CRI

C-S-H

CTAB

CTAC

CTV

EtOH

FBG

GPTMS

ISE

LOD

Luc

LPFGs

MZI

MEMO

MR

MTES

MAPTS

MEDPIN

MetOH
Three-dimensional

Atomic absorption spectrophotometry

Ammonium salt of 8-anilino-1-

naphthalenesulfonic acid

3-Aminopropyl-triethoxysilane

Alkali-silica reaction

Bromophenol blue

Bromothymol blue

Bromocresol green

Carboxymethyl cellulose

Carbon nanotubes

Chlorophenol red

Concentration range

Cresol red

Cladding refractive index

Calcium silicate hydrate

Cetyltrimethylammonium bromide

Cetyltrimethylammonium chloride

Chloride threshold value

Ethanol

Fiber Bragg grating

3-Glycidoxypropyl-methyltriethoxysilane

Ion-selective electrode potentiometry

Limit of detection

Lucigenin

Long period fiber gratings

Mach-Zehnder interferometer

Trimethoxysilyl-propyl-methacrylate

Methyl red

Methyltriethoxysilane

$\gamma$-Methacryloxypropyl trimethoxysilane

7-Decyl-2-methyl-4-(3',5'-dichlorophen-4' one)indonaphth-1-ol

Methanol 


\begin{tabular}{|c|c|}
\hline NPs & Nanoparticles \\
\hline NDM & Non-destructive methods \\
\hline OS & Optical sensors \\
\hline OFS & Optical fiber sensors \\
\hline $\mathrm{OIH}$ & Organic-inorganic hybrid \\
\hline OSA & Optical spectrum analyzer \\
\hline OVTs & Optical voltage transformers \\
\hline PCF & Photonic crystal fiber \\
\hline PDMS & Polydimethylsiloxane \\
\hline Phph & Phenolphthalein \\
\hline PMMA & Polymethyl methacrylate \\
\hline POF & Plastic optical fibers \\
\hline PR & Phenol red \\
\hline PTES & Phenyltriethoxysilane \\
\hline PVA & Poly(vinyl alcohol) \\
\hline PVC & Poly(vinyl chloride) \\
\hline QDs & Quantum dots \\
\hline RCS & Reinforced concrete structures \\
\hline RH & Relative humidity \\
\hline RI & Refractive index \\
\hline $\mathrm{RM}$ & Recognition molecule \\
\hline RT & Response time \\
\hline SHM & Structural health monitoring \\
\hline SMF & Single mode fiber \\
\hline SPR & Surface plasmon resonance \\
\hline SRI & Surrounding refractive index \\
\hline TEOS & Tetraethoxysilane \\
\hline TIPT & Ti(Iv) isopropoxide \\
\hline$w / c$ & Water to cement ratio \\
\hline
\end{tabular}

\section{Author contributions}

Conceptualization: R. B. Figueira; formal analysis: R. B. Figueira, B. Ferreira, C. J. R. Silva; funding acquisition: R. B. Figueira and C. J. R. Silva; methodology: R. B. Figueira and C. J. R. Silva; writing - original draft preparation: R. B. Figueira; writing - review and editing: R. B. Figueira, J. M. de Almeida, C. J. R. Silva, L. Coelho; project administration: R. B. Figueira and C. J. R. Silva; resources: C. J. R. Silva and R. B. Figueira; supervision: R. B. Figueira. All authors have read and agreed to the published version of the manuscript apart from C. J. R. Silva.

\section{Conflicts of interest}

There are no conflicts to declare.

\section{Acknowledgements}

The authors would like to acknowledge the financial support provided by the project "SolSensors-Development of Advanced Fiber Optic Sensors for Monitoring the Durability of Concrete Structures", with reference POCI-01-0145-FEDER-031220 supported by the Program Budget COMPETE-Operational Program Competitiveness and Internationalization-COMPETE 2020 and the Lisbon. Regional Operational Program in its FEDER component and by the budget of FCT Foundation for Science and Technology, I.P., and thank Hugo Gomes for assisting in the conception and execution of Fig. 3. The authors acknowledge the support of the Centro de Química, CQUM, which is financed by national funds through the FCT Foundation for Science and Technology, I.P., under the project UID/QUI/00686/2020.

\section{References}

1 E. Hamidi-Asl, I. Palchetti, E. Hasheminejad and M. Mascini, Talanta, 2013, 115, 74-83.

2 M. Zayat, D. Almendro, V. Vadillo and D. Levy, in The Sol-Gel Handbook, ed. D. Levy and R. Zayat, Wiley-VCH Verlag GmbH \& Co. KGaA, 2015, pp. 1239-1280.

3 J. P. Mensing, A. Wisitsoraat, A. Tuantranont and T. Kerdcharoen, Sens. Actuators, B, 2013, 176, 428-436.

4 M. R. Detty, R. Ciriminna, F. V. Bright and M. Pagliaro, Acc. Chem. Res., 2014, 47, 678-687.

5 C. A. García-González, T. Budtova, L. Durães, C. Erkey, P. Del Gaudio, P. Gurikov, M. Koebel, F. Liebner, M. Neagu and I. Smirnova, Molecules, 2019, 24(9), 1815.

6 R. B. Figueira, C. J. R. Silva and E. V. Pereira, J. Coat. Technol. Res., 2014, 1-35.

7 O. Ola and M. M. Maroto-Valer, J. Photochem. Photobiol., C, 2015, 24, 16-42.

8 S. Esposito, Mater. Basel Switz., 2019, $12(4), 668$.

9 P. Nedeljko, M. Turel and A. Lobnik, Sens. Actuators, B, 2017, 246, 1066-1073.

10 C. K. Y. Leung, K. T. Wan, D. Inaudi, X. Bao, W. Habel, Z. Zhou, J. Ou, M. Ghandehari, H. C. Wu and M. Imai, Mater. Struct., 2015, 48, 871-906.

11 K. Bremer, M. Wollweber, F. Weigand, M. Rahlves, M. Kuhne, R. Helbig and B. Roth, Procedia Technol., 2016, 26, 524-529.

12 Y. Yue, J. J. Wang, P. A. M. Basheer, J. J. Boland and Y. Bai, Sens. Actuators, B, 2018, 257, 635-649.

13 B. J. Privett, J. H. Shin and M. H. Schoenfisch, Anal. Chem., 2010, 82, 4723-4741.

14 M. R. N. Monton, E. M. Forsberg and J. D. Brennan, Chem. Mater., 2012, 24, 796-811.

15 Y. Bao, Y. Huang, M. S. Hoehler and G. Chen, Sensors, 2019, 19, 877.

16 P. C. A. Jerónimo, A. N. Araújo, M. Conceição and B. S. M. Montenegro, Talanta, 2007, 72, 13-27.

17 A. K. Pathak and V. K. Singh, Optik, 2017, 149, 288-294.

18 Á. P. Timbó, P. V. F. Pinto, H. A. Pinho, L. P. de Moura, J. B. Chretien, F. W. Viana, R. G. D. Filho, E. B. da Silva, M. E. R. da Silva, J. W. M. Menezes, G. de, F. Guimarães and W. B. Fraga, Sens. Actuators, B, 2016, 223, 406-410.

19 L. Alwis, T. Sun and K. T. V. Grattan, Measurement, 2013, 46, 4052-4074.

20 M. Yin, B. Gu, Q.-F. An, C. Yang, Y. L. Guan and K.-T. Yong, Coord. Chem. Rev., 2018, 376, 348-392. 
21 C. J. Brinker and G. W. Scherer, Sol-gel science: the physics and chemistry of sol-gel processing, Academic Press, Boston, 1990.

22 U. Tiringer, I. Milošev, A. Durán and Y. Castro, J. Sol-Gel Sci. Technol., 2018, 1-12.

23 D. A. Leal, I. C. Riegel-Vidotti, M. G. S. Ferreira and C. E. B. Marino, Corros. Sci., 2018, 130, 56-63.

24 Z. Neščáková, K. Zheng, L. Liverani, Q. Nawaz, D. Galusková, H. Kaňková, M. Michálek, D. Galusek and A. R. Boccaccini, Bioact. Mater., 2019, 4, 312-321.

25 D. N. Joshi, S. R. Atchuta, Y. Lokeswara Reddy, A. Naveen Kumar and S. Sakthivel, Sol. Energy Mater. Sol. Cells, 2019, 200, 110023.

26 M. Hjiri, J. Mater. Sci.: Mater. Electron., 2020, 31, 5025-5031.

27 P. E. Imoisili, K. O. Ukoba and T.-C. Jen, J. Mater. Res. Technol., 2020, 9, 307-313.

28 F. Chiavaioli, P. Biswas, C. Trono, S. Jana, S. Bandyopadhyay, N. Basumallick, A. Giannetti, S. Tombelli, S. Bera, A. Mallick and F. Baldini, Anal. Chem., 2015, 87, 12024-12031.

29 T. Ramesh, K. L. Foo, H. R. A. J. Sam and M. Solayappan, Sci. Rep., 2019, 9, 1-17.

30 R. B. Figueira, Appl. Sci., 2017, 7, 1157.

31 C. Rodrigues, C. Félix, A. Lage and J. Figueiras, Eng. Struct., 2010, 32, 1993-2002.

32 R. B. Malla, A. Sen and N. W. Garrick, Sensors, 2008, 8, 2551-2568.

33 J. Nedoma, M. Fajkus, R. Martinek, J. Vanus, S. Kepak, R. Kahankova, R. Jaros, D. Cvejn and M. Prauzek, IFACPap., 2018, 51, 420-425.

34 P. Kara De Maeijer, G. Luyckx, C. Vuye, E. Voet, W. Van den bergh, S. Vanlanduit, J. Braspenninckx, N. Stevens and J. De Wolf, Infrastructures, 2019, 4, 36.

35 N. Cho, N. Kim, J. Jang and S. Chang, Smart Structures and Materials 2000: Smart Systems for Bridges, Structures, and Highways, International Society for Optics and Photonics, 2000, vol. 3988, pp. 339-348.

36 S. Yehia, T. Landolsi, M. Hassan and M. Hallal, Measurement, 2014, 52, 33-46.

37 M. Z. Marković, J. S. Bajić, M. Batilović, Z. Sušić, A. Joža and G. M. Stojanović, Sensors, 2019, 19, 844.

38 K. T. Wan and C. K. Y. Leung, Sens. Actuators Phys., 2007, 135, 458-464.

39 D. Luo, Y. Yue, P. Li, J. Ma, L. Ling Zhang, Z. Ibrahim and Z. Ismail, Measurement, 2016, 88, 96-103.

40 P. Blanc, X. Bourbon, A. Lassin and E. C. Gaucher, Cem. Concr. Res., 2010, 40, 851-866.

41 A. Behnood, K. Van Tittelboom and N. De Belie, Constr. Build. Mater., 2016, 105, 176-188.

42 G. Plusquellec, M. R. Geiker, J. Lindgård, J. Duchesne, B. Fournier and K. De Weerdt, Cem. Concr. Res., 2017, 96, 13-26.

43 W. Zhang, H. Min and X. Gu, Constr. Build. Mater., 2016, 123, 290-299.

44 R. B. Figueira, A. Sadovski, A. P. Melo and E. V. Pereira, Constr. Build. Mater., 2017, 141, 183-200.

45 R. B. Figueira, R. Sousa, L. Coelho, M. Azenha, J. M. de Almeida, P. A. S. Jorge and C. J. R. Silva, Constr. Build. Mater., 2019, 222, 903-931.
46 C. Andrade, in Corrosion of Steel in Concrete Structures, Woodhead Publishing, Oxford, 2016, pp. 269-288.

47 X. Zhu, G. Zi, W. Lee, S. Kim and J. Kong, Constr. Build. Mater., 2016, 124, 667-680.

48 V. Marcos-Meson, G. Fischer, C. Edvardsen, T. L. Skovhus and A. Michel, Constr. Build. Mater., 2019, 200, 490-501.

49 C. Andrade, Constr. Build. Mater., 2020, 230, 116804.

50 P. S. Humbert and J. Castro-Gomes, J. Cleaner Prod., 2019, 208, 448-457.

51 A. Barrias, J. R. Casas and S. Villalba, Sensors, 2018, 18, 980.

52 C. Sanchez, L. Rozes, F. Ribot, C. Laberty-Robert, D. Grosso, C. Sassoye, C. Boissiere and L. Nicole, Comptes Rendus Chim., 2010, 13, 3-39.

53 C. Sanchez, P. Belleville, M. Popall and L. Nicole, Chem. Soc. Rev., 2011, 40, 453-1152.

54 M. Faustini, L. Nicole, E. Ruiz-Hitzky and C. Sanchez, Adv. Funct. Mater., 2018, 28, 170158.

55 R. B. Figueira, Polymers, 2020, 12, 689.

56 C. Sanchez, L. Rozes, F. Ribot, C. Laberty-Robert, D. Grosso, C. Sassoye, C. Boissiere and L. Nicole, C. R. Chim., 2010, 13, 3-39.

57 N. Le Bail, S. Benayoun and B. Toury, J. Sol-Gel Sci. Technol., 2015, 75, 710-719.

58 B. Li, L. Baingam, K. Kurumisawa, T. Nawa and L. XiaoZhou, Constr. Build. Mater., 2018, 164, 554-569.

59 L. L. Hench and J. K. West, Chem. Rev., 1990, 90, 33-72.

60 H. Schmidt, J. Non-Cryst. Solids, 1985, 73, 681-691.

61 G. L. Wilkes, B. Orler and H. H. Huang, Polym. Prep., 1985, 26, 300-302.

62 M. A. Aegerter and M. Mennig, Sol-gel technologies for glass producers and users, Kluwer Academic Publishers, Boston, 2004.

63 T. Coradin and J. Livage, Encyclopedia of Inorganic Chemistry, John Wiley \& Sons, Ltd, 2006.

64 R. B. Figueira and C. J. R. Silva, World Scientific Reference of Hybrid Materials, World Scientific, 2019, pp. 145-192.

65 C. Brinker, A. Hurd, P. Schunk and G. Frye, J. Non-Cryst. Solids, 1992, 148, 424-436.

66 R. B. Figueira, R. Sousa and C. J. R. Silva, in Advances in Smart Coatings and Thin Films for Future Industrial and Biomedical Engineering Applications, ed. A. S. H. Makhlouf and N. Y. Abu-Thabit, Elsevier, 2020, pp. 57-97.

67 H. Dislich, J. Non-Cryst. Solids, 1986, 80, 115-121.

68 A. C. Pierre, Introduction to Sol-Gel Processing, Springer, US, 1998, pp. 347-386.

69 C.-S. Chu and C.-J. Su, Sens. Actuators, B, 2018, 255, 1079-1086.

70 F. Quignard, R. Valentin and F. Di Renzo, New J. Chem., 2008, 32, 1300-1310.

71 C. Sanchez and F. Ribot, New J. Chem., 1994, 18, 1007-1047.

72 C. Sanchez, G. J. D. A. A. Soler-Illia, F. Ribot, T. Lalot, C. R. Mayer and V. Cabuil, Chem. Mater., 2001, 13, 3061-3083.

73 H. Maleki, Chem. Eng. J., 2016, 300, 98-118.

74 T. Linhares, M. T. P. de Amorim and L. Durães, J. Mater. Chem. A, 2019, 7, 22768-22802. 
75 H. Maleki, L. Whitmore and N. Hüsing, J. Mater. Chem. A, 2018, 6, 12598-12612.

76 S. Yun, H. Luo and Y. Gao, J. Mater. Chem. A, 2015, 3, 3390-3398.

77 R. Menzel, S. Barg, M. Miranda, D. B. Anthony, S. M. Bawaked, M. Mokhtar, S. A. Al-Thabaiti, S. N. Basahel, E. Saiz and M. S. P. Shaffer, Adv. Funct. Mater., 2015, 25, 28-35.

78 B. Yuan, J. Zhang, Q. Mi, J. Yu, R. Song and J. Zhang, ACS Sustainable Chem. Eng., 2017, 5, 11117-11123.

79 Z. Shariatinia and A. Esmaeilzadeh, Water Environ. Res., 2019, 91, 1624-1637.

80 F. Yu, Y. Li and J. Ma, Nanotechnology in Environmental Science, John Wiley \& Sons, Ltd, 2018, pp. 191-208.

81 H. Zhuo, Y. Hu, Z. Chen, X. Peng, L. Liu, Q. Luo, J. Yi, C. Liu and L. Zhong, J. Mater. Chem. A, 2019, 7, 8092-8100.

82 S. Korkmaz and I. A. Kariper, J. Energy Storage, 2020, 27, 101038.

83 Y. Ananthan, K. K. Sanghamitra and N. Hebalkar, Nanotechnology for Energy Sustainability, John Wiley \& Sons, Ltd, 2017, pp. 937-966.

84 I. K. Moon, S. Yoon, K.-Y. Chun and J. Oh, Adv. Funct. Mater., 2015, 25, 6976-6984.

85 Z. Wang, Y. Wang, Y. Chen, M. Yousaf, H. Wu, A. Cao and R. P. S. Han, Adv. Funct. Mater., 2019, 29, 1807467.

86 M. A. B. Meador, S. Wright, A. Sandberg, B. N. Nguyen, F. W. Van Keuls, C. H. Mueller, R. Rodríguez-Solís and F. A. Miranda, ACS Appl. Mater. Interfaces, 2012, 4, 6346-6353.

87 T. Lu, Q. Li, W. Chen and H. Yu, Compos. Sci. Technol., 2014, 94, 132-138.

88 H. Chen, X. Wang, J. Li and X. Wang, J. Mater. Chem. A, 2015, 3, 6073-6081.

89 J. Du, L. Liu, Z. Hu, Y. Yu, Y. Zhang, S. Hou and A. Chen, ACS Sustainable Chem. Eng., 2018, 6, 4008-4015.

90 J. P. de Oliveira, G. P. Bruni, M. J. Fabra, E. da Rosa Zavareze, A. López-Rubio and M. Martínez-Sanz, Food Hydrocolloids, 2019, 89, 337-350.

91 R. Djellabi, L. Zhang, B. Yang, M. R. Haider and X. Zhao, Sep. Purif. Technol., 2019, 229, 115830.

92 L. An, J. Wang, D. Petit, J. N. Armstrong, K. Hanson, J. Hamilton, M. Souza, D. Zhao, C. Li, Y. Liu, Y. Huang, Y. Hu, Z. Li, Z. Shao, A. O. Desjarlais and S. Ren, Nano Lett., 2020, 20, 3828-3835.

93 F. Ghajeri, Z. Topalian, A. Tasca, S. H. M. Jafri, K. Leifer, P. Norberg and C. Sjöström, Curr. Opin. Green Sustainable Chem., 2018, 12, 101-109.

94 H. H. Qazi, A. B. bin Mohammad and M. Akram, Sensors, 2012, 12, 16522-16556.

95 A. Khadour and J. Waeytens, in Eco-Efficient Repair and Rehabilitation of Concrete Infrastructures, ed. F. PachecoTorgal, R. E. Melchers, X. Shi, N. D. Belie, K. V. Tittelboom and A. Sáez, Woodhead Publishing, 2018, pp. 97-121.

96 A. Samadi-Maybodi, V. Rezaei and S. Rastegarzadeh, Spectrochim. Acta, Part A, 2015, 136(Part B), 832-837.

97 H. Li, D. Jin, Q. Yu and H. Tu, J. Power Sources, 2011, 196, 3836-3840.
98 A. Kulkarni, J.-H. Lee, J.-D. Nam and T. Kim, Sens. Actuators, B, 2010, 150, 154-159.

99 C.-S. Chu, J. Lumin., 2013, 135, 5-9.

100 B. Schyrr, S. Pasche, E. Scolan, R. Ischer, D. Ferrario, J.-A. Porchet and G. Voirin, Sens. Actuators, B, 2014, 194, 238-248.

101 S. Shrivastava, N. Jadon and R. Jain, TrAC, Trends Anal. Chem., 2016, 82, 55-67.

102 A. A. Elabd and M. S. Attia, J. Lumin., 2015, 165, 179-184.

103 J. Li, D. Yim, W.-D. Jang and J. Yoon, Chem. Soc. Rev., 2017, 46, 2437-2458.

104 S.-H. Park, J. Y. Hyun and I. Shin, Chem. Sci., 2018, 10, 56-66.

105 H. D. Duong, Y. Shin and J. I. Rhee, Microchem. J., 2019, 147, 286-295.

106 A. Wojcik and L. C. Klein, Appl. Organomet. Chem., 1997, 11, 129-135.

107 Z. Tao, E. C. Tehan, Y. Tang and F. V. Bright, Anal. Chem., 2006, 78, 1939-1945.

108 C.-S. Chu and C.-Y. Chuang, J. Lumin., 2014, 154, 475-478. 109 D. Wencel, M. Barczak, P. Borowski and C. McDonagh, J. Mater. Chem., 2012, 22, 11720-11729.

110 A. Parvathy Rao and A. Venkateswara Rao, J. Mater. Sci., 2010, 45, 51-63.

111 W. Lin, J. Zheng, J. Zhuo, H. Chen and X. Zhang, Surf. Coat. Technol., 2018, 345, 177-182.

112 I. Klimant, F. Ruckruh, G. Liebsch, A. Stangelmayer and O. S. Wolfbeis, Microchim. Acta, 1999, 131, 35-46.

113 Optical Sensor Technology, https://www.presens.de/, accessed 22 December 2020.

114 R. Correia, S. James, S.-W. Lee, S. P. Morgan and S. Korposh, J. Opt., 2018, 20, 073003.

115 O. S. Wolfbeis, Anal. Chem., 2000, 72, 81-90.

116 O. S. Wolfbeis, Anal. Chem., 2002, 74, 2663-2677.

117 O. S. Wolfbeis, Anal. Chem., 2004, 76, 3269-3284.

118 O. S. Wolfbeis, Anal. Chem., 2006, 78, 3859-3874.

119 O. S. Wolfbeis, Anal. Chem., 2008, 80, 4269-4283.

120 X.-D. Wang and O. S. Wolfbeis, Anal. Chem., 2013, 85, 487-508.

121 X. Wang and O. S. Wolfbeis, Chem. Soc. Rev., 2014, 43, 3666-3761.

122 X. Wang and O. S. Wolfbeis, Anal. Chem., 2016, 88, 203-227.

123 X. Wang and O. S. Wolfbeis, Anal. Chem., 2020, 92, 397-430.

124 J. O. W. Norris, Analyst, 1989, 114, 1359-1372.

125 R. Narayanaswamy, Analyst, 1993, 118, 317-322.

126 C. I. Merzbacher, A. D. Kersey and E. J. Friebele, Smart Mater. Struct., 1996, 5, 196-208.

127 A. Rogers, Meas. Sci. Technol., 1999, 10, R75-R99.

128 B. Kuswandi, R. Andres and R. Narayanaswamy, Analyst, 2001, 126, 1469-1491.

129 C. K. Y. Leung, NDT\&E Int., 2001, 34, 85-94.

130 B. Lee, Opt. Fiber Technol., 2003, 9, 57-79.

131 S. W. James and R. P. Tatam, Meas. Sci. Technol., 2003, 14, R49-R61. 
132 A. K. Sharma, R. Jha and B. D. Gupta, IEEE Sens. J., 2007, 7, 1118-1129.

133 C. McDonagh, C. S. Burke and B. D. MacCraith, Chem. Rev., 2008, 108, 400-422.

134 T. L. Yeo, T. Sun and K. T. V. Grattan, Sens. Actuators Phys., 2008, 144, 280-295.

135 M. Majumder, T. K. Gangopadhyay, A. K. Chakraborty, K. Dasgupta and D. K. Bhattacharya, Sens. Actuators Phys., 2008, 147, 150-164.

136 K. K. K. Annamdas and V. G. M. Annamdas, Fiber Optic Sensors and Applications VII, International Society for Optics and Photonics, 2010, vol. 7677, p. 76770R.

137 K. Peters, 2011.

138 J. Chen, B. Liu and H. Zhang, Front. Optoelectron. China, 2011, 4, 204-212.

139 R. Bogue, Sens. Rev., 2011, 31(4), 304-309.

140 M.-S. Steiner, A. Duerkop and O. S. Wolfbeis, Chem. Soc. Rev., 2011, 40, 4805-4839.

141 J. W. Kemling, A. J. Qavi, R. C. Bailey and K. S. Suslick, J. Phys. Chem. Lett., 2011, 2, 2934-2944.

142 N. Sabri, S. A. Aljunid, M. S. Salim, R. B. Ahmad and R. Kamaruddin, J. Phys. Conf. Ser., 2013, 423, 012064.

143 G. Rego, A Review of Refractometric Sensors Based on Long Period Fibre Gratings, https:/www.hindawi.com/jour nals/tswj/2013/913418/, accessed 4 November 2019.

144 F. Berghmans and H. Thienpont, OFC 2014, 2014, pp. 1-3. 145 G. Kostovski, P. R. Stoddart and A. Mitchell, Adv. Mater., 2014, 26, 3798-3820.

146 M. Pospíšilová, G. Kuncová and J. Trögl, Sensors, 2015, 15, 25208-25259.

147 A. Ricciardi, A. Crescitelli, P. Vaiano, G. Quero, M. Consales, M. Pisco, E. Esposito and A. Cusano, Analyst, 2015, 140, 8068-8079.

148 A. Urrutia, J. Goicoechea and F. J. Arregui, Optical Fiber Sensors Based on Nanoparticle-Embedded Coatings, https:// www.hindawi.com/journals/js/2015/805053/, accessed 28 May 2020.

149 R. Di Sante, Sensors, 2015, 15, 18666-18713.

150 W. Moerman, L. Taerwe, W. D. Waele, J. Degrieck and R. Baets, Struct. Concr.

151 P. Vaiano, B. Carotenuto, M. Pisco, A. Ricciardi, G. Quero, M. Consales, A. Crescitelli, E. Esposito and A. Cusano, Laser Photonics Rev., 2016, 10, 922-961.

152 M. A. Schmidt, A. Argyros and F. Sorin, Adv. Opt. Mater., 2016, 4, 13-36.

153 A. Barrias, J. R. Casas and S. Villalba, Sensors, 2016, 16, 748.

154 C. E. Campanella, A. Cuccovillo, C. Campanella, A. Yurt and V. M. N. Passaro, Sensors, 2018, 18(9), 3115.

155 A. K. Sharma, A. K. Pandey and B. Kaur, Opt. Fiber Technol., 2018, 43, 20-34.

156 H.-E. Joe, H. Yun, S.-H. Jo, M. B. G. Jun and B.-K. Min, Int. J. Precis. Eng. Manuf.-Green Technol., 2018, 5, 173-191.

157 F. Galeotti, M. Pisco and A. Cusano, Nanoscale, 2018, 10, 22673-22700.

158 S. Pevec and D. Donlagić, Opt. Eng., 2019, 58, 072009.
159 X. Lu, P. J. Thomas and J. O. Hellevang, Sensors, 2019, 19, 2876.

160 Q. Chai, Y. Luo, J. Ren, J. Zhang, J. Yang, L. Yuan and G. Peng, Opt. Eng., 2019, 58, 072007.

161 H. Wang, P. Xiang and L. Jiang, Sens. Actuators Phys., 2019, 285, 414-426.

162 C. Chen and J. Wang, Analyst, 2020, 145, 1605-1628.

163 Y. Zheng, Z.-W. Zhu, W. Xiao and Q.-X. Deng, Opt. Fiber Technol., 2020, 54, 102127.

164 R. P. C. L. Sousa, R. B. Figueira, S. P. G. Costa and M. M. M. Raposo, ACS Sens., 2020, 5(12), 3678-3709.

165 V. Bhatia and A. M. Vengsarkar, Opt. Lett., 1996, 21, 692-694.

166 Fiber Optic Cable | Corning, https://www.corning.com/ emea/en/products/communication-networks/products/ fiber-optic-cable.html, accessed 4 November 2019.

167 M. Poulain, M. Poulain and J. Lucas, Mater. Res. Bull., 1975, 10, 243-246.

168 G. E. Snopatin, V. S. Shiryaev, V. G. Plotnichenko, E. M. Dianov and M. F. Churbanov, Inorg. Mater., 2009, 45, 1439.

169 A. R. Prado, A. G. Leal-Junior, C. Marques, S. Leite, G. L. de Sena, L. C. Machado, A. Frizera, M. R. N. Ribeiro and M. J. Pontes, Opt. Express, 2017, 25, 30051-30060.

170 C. Markos, A. Stefani, K. Nielsen, H. K. Rasmussen, W. Yuan and O. Bang, Opt. Express, 2013, 21, 4758-4765.

171 G. Woyessa, A. Fasano, C. Markos, A. Stefani, H. K. Rasmussen and O. Bang, Opt. Mater. Express, 2017, 7, 286-295.

172 A. Gierej, M. Vagenende, A. Filipkowski, B. Siwicki, R. Buczynski, H. Thienpont, S. Van Vlierberghe, T. Geernaert, P. Dubruel and F. Berghmans, J. Light Technol., 2019, 37, 1916-1923.

173 A. Leal-Junior, A. Theodosiou, C. Díaz, C. Marques, M. Pontes, K. Kalli and A. Frizera-Neto, Polymers, 2018, 10, 674 .

174 C. Yeh, Handbook of fiber optics: theory and applications, Academic Press, 2013.

175 O. S. Wolfbeis, R. Reisfeld and I. Oehme, Optical and Electronic Phenomena in Sol-Gel Glasses and Modern Application, Springer, 1996, pp. 51-98.

176 D. K. Kim, J. Kim, S.-L. Lee, S. Choi, S. J. Jeong, M. S. Kim and Y. W. Lee, J. Nanosci. Nanotechnol., 2020, 20, 257-262.

177 T. Allsop, L. Zhang and I. Bennion, Opt. Commun., 2001, 191, 181-190.

178 L. Zeni, C. Perri, N. Cennamo, F. Arcadio, G. D’Agostino, M. Salmona, M. Beeg and M. Gobbi, Sci. Rep., 2020, 10, 11154.

179 G. Chang, Y. Tatsu, T. Goto, H. Imaishi and K. Morigaki, Talanta, 2010, 83, 61-65.

180 O. Habib, D. O. Demirkol and S. Timur, Food Anal. Methods, 2012, 5, 188-194.

181 N. Dasgupta, S. Ranjan, D. Mundekkad, C. Ramalingam, R. Shanker and A. Kumar, Food Res. Int., 2015, 69, 381-400.

182 K.-C. Hsu, L.-G. Sheu, K.-P. Chuang, S.-H. Chang and Y. Lai, Opt. Express, 2005, 13, 3795-3801.

183 O. Prakash, R. Mahakud, S. K. Dixit and U. Nundy, Opt. Commun., 2006, 263, 65-70. 
184 (6) (PDF) Point-by-point Bragg grating inscription in singlemode microstructure fibre using NIR femtosecond laser, https:/www.researchgate.net/publication/40723336_Pointby-point_Bragg_grating_inscription_in_single-mode_ microstructure_fibre_using_NIR_femtosecond_laser, accessed 4 November 2019.

185 J. Thomas, E. Wikszak, T. Clausnitzer, U. Fuchs, U. Zeitner, S. Nolte and A. Tünnermann, Appl. Phys. A: Mater. Sci. Process., 2007, 86, 153-157.

186 S. A. Slattery, D. N. Nikogosyan and G. Brambilla, J. Opt. Soc. Am. B, 2005, 22, 354-361.

$187 \mathrm{~J}$. Geng, J. Wu and X. Zhao, Second International Conference on Smart Materials and Nanotechnology in Engineering, International Society for Optics and Photonics, 2009, vol. 7493, p. 74931I.

188 J.-R. Lee, C.-Y. Yun and D.-J. Yoon, Meas. Sci. Technol., 2009, 21, 017002.

189 C. H. Tan, Y. G. Shee, B. K. Yap and F. R. M. Adikan, Sens. Actuators Phys., 2016, 246, 123-128.

190 T. H. Nguyen, T. Venugopala, S. Chen, T. Sun, K. T. V. Grattan, S. E. Taylor, P. A. M. Basheer and A. E. Long, Sens. Actuators, B, 2014, 191, 498-507.

191 J. Bartelmess, D. Zimmek, M. Bartholmai, C. Strangfeld and M. Schäferling, Analyst, 2020, 145, 2111-2117.

192 P. Childs, A. C. L. Wong, W. Terry and G. D. Peng, Meas. Sci. Technol., 2008, 19, 065301.

193 Y. Lei and Z.-P. Zheng, Review of Physical Based Monitoring Techniques for Condition Assessment of Corrosion in Reinforced Concrete, https:/www.hindawi.com/journals/ mpe/2013/953930/, accessed 26 October 2017.

194 H. J. Patrick, A. D. Kersey and F. Bucholtz, J. Light. Technol., 1998, 16, 1606.

195 Xuewen Shu, Lin Zhang and I. Bennion, J. Light. Technol., 2002, 20, 255-266.

196 P. Pilla, C. Trono, F. Baldini, F. Chiavaioli, M. Giordano and A. Cusano, Opt. Lett., 2012, 37, 4152-4154.

197 C. S. Cheung, S. M. Topliss, S. W. James and R. P. Tatam, J. Opt. Soc. Am. B, 2008, 25, 897-902.

198 A. Cusano, A. Iadicicco, P. Pilla, L. Contessa, S. Campopiano, A. Cutolo and M. Giordano, Opt. Express, 2006, 14, 19-34.

199 I. D. Villar, I. R. Matías, F. J. Arregui and P. Lalanne, Opt. Express, 2005, 13, 56-69.

200 P. Wang and Q. Liu, Biomedical Sensors and Measurement, Springer-Verlag, Berlin Heidelberg, 2011.

201 Q. Wang and Y. Liu, Measurement, 2018, 130, 161-176.

202 M. Amanzadeh, S. M. Aminossadati, M. S. Kizil and A. D. Rakić, Measurement, 2018, 128, 119-137.

203 E. Vorathin, Z. M. Hafizi, N. Ismail and M. Loman, Opt. Laser Technol., 2020, 121, 105841.

204 H. D. Duong and J. I. Rhee, Sens. Actuators, B, 2008, 134, 423-426.

205 M. N. Gonçalves and M. M. Werneck, Measurement, 2019, 147, 106891.

206 J. Peng, S. Jia, J. Bian, S. Zhang, J. Liu and X. Zhou, Sensors, 2019, 19(13), 2860.
207 B. Wu, C. Zhao, B. Xu and Y. Li, Sens. Actuators, B, 2018, 255, 3011-3016.

208 L. Coelho, J. M. M. M. de Almeida, J. L. Santos and D. Viegas, Appl. Opt., 2015, 54, 10342-10348.

209 C.-S. Chu and C.-A. Lin, Sens. Actuators, B, 2014, 195, 259-265.

210 M. Calcerrada, C. García-Ruiz and M. González-Herráez, Laser Photonics Rev., 2015, 9, 604-627.

211 C. Bariáin, I. R. Matías, F. J. Arregui and M. López-Amo, Sens. Actuators, B, 2000, 69, 127-131.

212 Y. Li, Z. Xu, S. Tan, F. Fang, L. Yang, B. Yuan and Q. Sun, J. Phys. Appl. Phys., 2019, 52, 493002.

213 M. Lobry, D. Lahem, M. Loyez, M. Debliquy, K. Chah, M. David and C. Caucheteur, Biosens. Bioelectron., 2019, 142, 111506.

214 J. Lao, P. Sun, F. Liu, X. Zhang, C. Zhao, W. Mai, T. Guo, G. Xiao and J. Albert, Light: Sci. Appl., 2018, 7, 1-11.

215 E. Preter, R. A. Katims, V. Artel, C. N. Sukenik, D. Donlagic and A. Zadok, Opt. Mater. Express, 2014, 4, 903-915.

216 L. Coelho, D. Viegas, J. L. Santos and J. M. M. M. de Almeida, Sens. Actuators, B, 2014, 202, 929-934.

217 Z. Yazdizadeh, H. Marzouk and M. A. Hadianfard, Constr. Build. Mater., 2017, 137, 505-512.

218 K. Ahn Jin, in Comprehensive Pediatric Hospital Medicine, ed. L. B. Zaoutis and V. W. Chiang, Mosby, Philadelphia, 2007, pp. 125-132.

219 L. J. Parrott, A Review of Carbonation in Reinforced Concrete, Cement and Concrete Association, 1987.

220 E. Possan, W. A. Thomaz, G. A. Aleandri, E. F. Felix and A. C. P. dos Santos, Case Stud. Constr. Mater., 2017, 6, 147-161.

221 S. von Greve-Dierfeld, B. Lothenbach, A. Vollpracht, B. Wu, B. Huet, C. Andrade, C. Medina, C. Thiel, E. Gruyaert, H. Vanoutrive, I. F. Saéz del Bosque, I. Ignjatovic, J. Elsen, J. L. Provis, K. Scrivener, K.-C. Thienel, K. Sideris, M. Zajac, N. Alderete, Ö. Cizer, P. Van den Heede, R. D. Hooton, S. Kamali-Bernard, S. A. Bernal, Z. Zhao, Z. Shi and N. De Belie, Mater. Struct., 2020, 53, 136.

222 S. Taheri, Constr. Build. Mater., 2019, 204, 492-509.

223 Y. Abbas, W. Olthuis and A. van den Berg, Constr. Build. Mater., 2015, 100, 194-200.

224 S. Islam, R. A. Rahman, Z. B. Othaman, S. Riaz and S. Naseem, J. Ind. Eng. Chem., 2015, 23, 140-144.

225 O. Omikrine Metalssi, A. Aït-Mokhtar and P. Turcry, Constr. Build. Mater., 2020, 230, 116997.

226 L. Li, A. A. Sagüés and N. Poor, Cem. Concr. Res., 1999, 29, 315-321.

227 L. Li, J. Nam and W. H. Hartt, Cem. Concr. Res., 2005, 35, 277-283.

228 Sol-gel derived potentiometric pH sensors. PubMedNCBI, https:/www.ncbi.nlm.nih.gov/pubmed/15679353, accessed 4 December 2019.

229 Development of pH-Sensitive Substrates for Optical Sensor Applications, https://scite.ai/reports/development-of-phsensitive-substrates-for-JjYw5k, accessed 2 December 2019.

230 N. Othman, W. F. Hanim, U. M. Noor and S. Hana, AIP Conf. Proc., 2016, 1774, 050014. 
231 D. Razo-Medina, E. Alvarado-Méndez and M. Trejo-Durán, Procedia Technol., 2017, 27, 271-273.

232 C. A. Browne, D. H. Tarrant, M. S. Olteanu, J. W. Mullens and E. L. Chronister, Anal. Chem., 1996, 68, 2289-2295.

233 Highly Durable Double Sol-Gel Layer Ratiometric Fluorescent $\mathrm{pH}$ Optrode Based on the Combination of Two Types of Quantum Dots and Absorbing $\mathrm{pH}$ Indicators | Analytical Chemistry, https://pubs.acs.org/doi/10.1021/ ac302178z, accessed 4 December 2019.

234 R. P. C. L. Sousa, B. Ferreira, M. Azenha, S. P. G. Costa, C. J. R. Silva and R. B. Figueira, Polymers, 2020, 12, 371.

235 C. Malins, H. G. Glever, T. E. Keyes, J. G. Vos, W. J. Dressick and B. D. MacCraith, Sens. Actuators, B, 2000, 67, 89-95.

236 A. Lobnik, N. Majcen, K. Niederreiter and G. Uray, Sens. Actuators, B, 2001, 74, 200-206.

237 M. A. Villegas, M. A. García, S. E. Paje and J. Llopis, J. Eur. Ceram. Soc., 2002, 22, 1475-1482.

238 E. Wang, K.-F. Chow, V. Kwan, T. Chin, C. Wong and A. Bocarsly, Anal. Chim. Acta, 2003, 495, 45-50.

239 H. D. Duong, O.-J. Sohn, H. T. Lam and J. I. Rhee, Microchem. J., 2006, 84, 50-55.

240 S. Dong, M. Luo, G. Peng and W. Cheng, Sens. Actuators, B, 2008, 129, 94-98.

241 S. Jurmanović, Š. Kordić, M. D. Steinberg and I. M. Steinberg, Thin Solid Films, 2010, 518, 2234-2240.

242 P. Fabbri, F. Pilati, L. Rovati, R. McKenzie and J. Mijovic, Opt. Mater., 2011, 33, 1362-1369.

243 N. Deepa and A. Balaji Ganesh, Measurement, 2015, 59, 337-343.

244 S. Islam, N. Bidin, S. Riaz, S. Naseem and F. M. Marsin, Sens. Actuators, B, 2016, 225, 66-73.

245 S. Islam, N. Bidin, S. Riaz and S. Naseem, J. Ind. Eng. Chem., 2016, 34, 258-268.

246 V. Bhardwaj, A. K. Pathak and V. K. Singh, J. Biomed. Opt., 2017, 22, 057001.

247 G. Rosace, E. Guido, C. Colleoni, M. Brucale, E. Piperopoulos, C. Milone and M. R. Plutino, Sens. Actuators, B, 2017, 241, 85-95.

248 S. Islam, H. Bakhtiar, N. Bidin, S. Riaz and S. Naseem, J. Sol-Gel Sci. Technol., 2018, 86, 42-50.

249 A. K. Pathak, T. Khanikar and V. K. Singh, 2018 3rd International Conference on Microwave and Photonics (ICMAP), 2018, pp. 1-2.

250 C. P. Atkins, J. D. Scantlebury, P. J. Nedwell and S. P. Blatch, Cem. Concr. Res., 1996, 26, 319-324.

251 T. Cheewaket, C. Jaturapitakkul and W. Chalee, Constr. Build. Mater., 2012, 37, 693-698.

252 D. Boubitsas and L. Tang, Mater. Struct., 2014, 48, 2641-2658.

253 F. Pargar, D. A. Koleva and K. Van Breugel, Sensors, 2017, 17, 2482.

254 A. James, E. Bazarchi, A. A. Chiniforush, P. Panjebashi Aghdam, M. R. Hosseini, A. Akbarnezhad, I. Martek and F. Ghodoosi, Constr. Build. Mater., 2019, 224, 1026-1039.

255 J. Chen, X. Ma, H. Wang, P. Xie and W. Huang, Constr. Build. Mater., 2018, 161, 598-605.
256 X. Lu, Cem. Concr. Res., 1997, 27, 293-302.

257 G. K. Glass, Y. Wang and N. R. Buenfeld, Cem. Concr. Res., 1996, 26, 1443-1449.

258 Y. Takeshita, T. R. Martz, K. S. Johnson and A. G. Dickson, Anal. Chem., 2014, 86, 11189-11195.

259 A. O. S. Solgaard, M. Geiker, C. Edvardsen and A. Küter, Mater. Struct., 2014, 47, 335-350.

260 S. Madhu, R. Kalaiyarasi, S. K. Basu, S. Jadhav and M. Ravikanth, J. Mater. Chem. C, 2014, 2, 2534-2544.

261 A. Dehghan, K. Peterson, G. Riehm and L. Herzog Bromerchenkel, Constr. Build. Mater., 2017, 148, 85-95.

262 C. Lopez-Moreno, I. V. Perez and A. M. Urbano, Food Chem., 2016, 194, 687-694.

263 J. Bujes-Garrido and M. J. Arcos-Martínez, Talanta, 2016, 155, 153-157.

264 D. B. de Graaf, Y. Abbas, J. Gerrit Bomer, W. Olthuis and A. van den Berg, Anal. Chim. Acta, 2015, 888, 44-51.

265 D. L. Rocha and F. R. P. Rocha, Microchem. J., 2013, 108, 193-197.

266 J.-L. Tang and J.-N. Wang, Smart Mater. Struct., 2007, 16, 665.

267 S. K. Abi Kaed Bey, C. C. Chun Lam, T. Sun and K. T. V. Grattan, Sens. Actuators Phys., 2008, 141, 390-395.

268 Y. Abbas, W. Olthuis and A. van den Berg, Sens. Actuators, $B, 2013,188,433-439$.

269 U. Angst, B. Elsener, C. K. Larsen and Ø. Vennesland, J. Appl. Electrochem., 2010, 40, 561-573.

270 L. Ding, Z. Li, Q. Ding, X. Shen, Y. Yuan and J. Huang, Sens. Actuators, B, 2018, 260, 763-769.

271 W. Xiao, L. Ding, J. He and J. Huang, Opt. Mater., 2019, 98, 109467.

272 Y. Abbas, F. Pargar, D. A. Koleva, K. van Breugel, W. Olthuis and A. van den Berg, Constr. Build. Mater., 2018, 174, 376-387.

273 M. A. Climent-Llorca, E. Viqueira-Pérez and M. M. LópezAtalaya, Cem. Concr. Res., 1996, 26, 1157-1161.

274 C. P. Atkins, M. A. Carter and J. D. Scantlebury, Cem. Concr. Res., 2001, 31, 1207-1211.

275 M. Jin, J. Xu, L. Jiang, Y. Xu and H. Chu, Ionics, 2015, 21, 2981-2992.

276 F. Pargar, H. Kolev, D. A. Koleva and K. van Breugel, J. Mater. Sci., 2018, 53, 7527-7550.

277 M. Jin, L. Jiang and Q. Zhu, Constr. Build. Mater., 2017, 143, 1-15.

278 Y. Tian, P. Zhang, K. Zhao, Z. Du and T. Zhao, Sensors, 2020, 20, 1394.

279 S. Karthick, S.-J. Kwon, H. S. Lee, S. Muralidharan, V. Saraswathy and R. Natarajan, RSC Adv., 2017, 7, 31252-31263.

280 T. Blaz, J. Migdalski and A. Lewenstam, Analyst, 2005, 130, 637-643.

281 J. Ha, S. M. Martin, Y. Jeon, I. J. Yoon, R. B. Brown, H. Nam and G. S. Cha, Anal. Chim. Acta, 2005, 549, 59-66.

282 Fabrication and evaluation of a highly durable and reliable chloride monitoring sensor for civil infrastructure - RSC Advances (RSC Publishing), DOI: 10.1039/C7RA05532C, https://pubs.rsc.org/en/content/articlehtml/2017/ra/c7ra05 532c, accessed 4 December 2019. 
283 C. C. C. Lam, R. Mandamparambil, T. Sun, K. T. V. Grattan, S. V. Nanukuttan, S. E. Taylor and P. A. M. Basheer, IEEE Sens. J., 2009, 9, 525-532.

284 N. P. Illsley and A. S. Verkman, Biochemistry, 1987, 26, 1215-1219.

285 M. J. Ruedas-Rama, A. Orte, E. A. H. Hall, J. M. Alvarez-Pez and E. M. Talavera, Analyst, 2012, 137, 1500-1508.

286 A. S. Verkman, M. C. Sellers, A. C. Chao, T. Leung and R. Ketcham, Anal. Biochem., 1989, 178, 355-361.

287 T. M. Calafut and J. A. Dix, Anal. Biochem., 1995, 230, 1-7. 288 J. R. Inglefield and R. D. Schwartz-Bloom, Methods San Diego Calif, 1999, 18, 197-203.

289 C. D. Geddes, Dyes Pigm., 2000, 45, 243-251.

290 A. Ma and Z. Rosenzweig, Anal. Chem., 2004, 76, 569-575. 291 C. D. Geddes, K. Apperson, J. Karolin and D. J. S. Birch, Anal. Biochem., 2001, 293, 60-66.

292 Q. Zheng and L. D. Lavis, Curr. Opin. Chem. Biol., 2017, 39, 32-38.

293 Quenching of lucigenin fluorescence, https:/pubs.acs.org/ doi/pdf/10.1021/j100909a011, accessed 12 December 2019.

294 D. O. McPolin, P. A. M. Basheer, A. E. Long, W. Xie, T. Sun and K. T. V. Grattan, IEEE Sens. J., 2009, 9, 1537-1545.

295 M. Dhouib, D. Conciatori and L. Sorelli, Cold Regions Engineering 2019, 2019, pp. 391-397.

296 G. Gao, Y. Cao, W. Liu, D. Li, W. Zhou and J. Liu, Anal. Methods, 2017, 9, 5570-5579.

297 H. Bischof, M. Rehberg, S. Stryeck, K. Artinger, E. Eroglu, M. Waldeck-Weiermair, B. Gottschalk, R. Rost, A. T. Deak, T. Niedrist, N. Vujic, H. Lindermuth, R. Prassl, B. Pelzmann, K. Groschner, D. Kratky, K. Eller, A. R. Rosenkranz, T. Madl, N. Plesnila, W. F. Graier and R. Malli, Nat. Commun., 2017, 8, 1-12.

298 Sodium Sensor-K-12 STEM technology, http://einstein world.com/product/sodium-sensor/, accessed 13 May 2020.

299 W. Chen and H. J. H. Brouwers, Cem. Concr. Res., 2010, 40, 716-722.

300 Lea's Chemistry of Cement and Concrete - 4th Edition, https:/www.elsevier.com/books/leas-chemistry-of-cementand-concrete/hewlett/978-0-7506-6256-7, accessed 7 September 2018.

301 J. Junsomboon and J. Jakmunee, Determination of Potassium, Sodium, and Total Alkalies in Portland Cement, Fly Ash, Admixtures, and Water of Concrete by a Simple Flow Injection Flame Photometric System, https://www. hindawi.com/journals/jamc/2011/742656/, accessed 13 May 2020.

302 R. M. F. Batista, E. Oliveira, S. P. G. Costa, C. Lodeiro and M. M. M. Raposo, Tetrahedron Lett., 2008, 49, 6575-6578.

303 A. G. Volkov, S. Paula and D. W. Deamer, Bioelectrochem. Bioenerg., 1997, 42, 153-160.

304 I. Danielewicz-Ferchmin and A. R. Ferchmin, Phys. B: Condens. Matter, 1998, 245, 34-44.

305 M. Á. Sanjuán, E. Estévez and C. Argiz, Appl. Sci., 2019, 9, 992. 306 C. M. Browne, G. Ferguson, M. A. McKervey, D. L. Mulholland, T. O'Connor and M. Parvez, J. Am. Chem. Soc., 1985, 107, 2703-2712.
307 R. M. F. Batista, E. Oliveira, S. P. G. Costa, C. Lodeiro and M. M. M. Raposo, Tetrahedron, 2011, 67, 7106-7113.

308 Y. Yang and W. Gao, Chem. Soc. Rev., 2019, 48, 1465-1491.

309 O. S. Wolfbeis and B. P. H. Schaffar, Anal. Chim. Acta, 1987, 198, 1-12.

310 J. F. Alder, D. C. Ashworth, R. Narayanaswamy, R. E. Moss and I. O. Sutherland, Analyst, 1987, 112, 1191-1192.

311 B. P. H. Schaffar, O. S. Wolfbeis and A. Leitner, Analyst, 1988, 113, 693-697.

312 J. N. Roe, F. C. Szoka and A. S. Verkman, Analyst, 1990, 115, 353-358.

313 M. E. Díaz-García, F. Alava-Moreno and A. Sanz-Medel, Microchim. Acta, 1994, 113, 211-222.

314 Z. Zhujun, J. L. Mullin and W. R. Seitz, Anal. Chim. Acta, 1986, 184, 251-258.

315 F. Buchholz, N. Buschmann and K. Cammann, Sens. Actuators, B, 1992, 9, 41-47.

316 K. Ertekin, M. Tepe, B. Yenigül, E. U. Akkaya and E. Henden, Talanta, 2002, 58, 719-727.

317 K. Ertekin, B. Yenigül and E. U. Akkaya, J. Fluoresc., 2002, 12, 263-268.

318 Z. Sui, N. J. Hanan, S. Phimphivong, R. J. Wysocki and S. S. Saavedra, Lumin. J. Biol. Chem. Lumin., 2009, 24, 236-242.

319 S. Ast, T. Schwarze, H. Müller, A. Sukhanov, S. Michaelis, J. Wegener, O. S. Wolfbeis, T. Körzdörfer, A. Dürkop and H.-J. Holdt, Chem. - Eur. J., 2013, 19, 14911-14917.

320 Demonstration of a fibre-optic sensing technique for the measurement of moisture absorption in concrete - IOP science, https://iopscience.iop.org/article/10.1088/0964-1726/ 15/2/N03, accessed 31 October 2019.

321 L. Ruiz Valero, V. Flores Sasso and E. Prieto Vicioso, Case Stud. Constr. Mater., 2019, 10, e00228.

322 V. Vitiello, R. Castelluccio and M. Del Rio Merino, Constr. Build. Mater., 2020, 244, 118107.

323 W. Zhou, Z. Xu, D. Ross, J. Dignan, Y. Fan, Y. Huang, G. Wang, A. C. Bagtzoglou, Y. Lei and B. Li, Sens. Actuators, $B, 2019,298,126857$.

324 Soil moisture sensor, https://iotsens.com/soil-moisturesensor/, accessed 19 May 2020.

325 L.-R. Zheng, H. Tenhunen and Z. Zou, Smart Electronic Systems, John Wiley \& Sons, Ltd, 2018.

326 W. Meng, S. Wu, X. Wang and D. Zhang, Sens. Actuators, B, 2020, 315, 128058.

327 A. Voss, M. Pour-Ghaz, M. Vauhkonen and A. Seppänen, Cem. Concr. Res., 2016, 89, 158-167.

328 A. Voss, P. Hosseini, M. Pour-Ghaz, M. Vauhkonen and A. Seppänen, Mater. Des., 2019, 181, 107967.

329 X. Deng, H. Gu, L. Yang, H. Lyu, Y. Cheng, L. Pan, Z. Fu, L. Cui and L. Zhang, Measurement, 2020, 150, 107052.

330 T.-G. Kang, J.-K. Park, G.-H. Yun, H. H. Choi, H.-J. Lee and J.-G. Yook, Sens. Actuators, B, 2019, 282, 145-151.

331 J. Dai, H. Zhao, X. Lin, S. Liu, T. Fei and T. Zhang, Sens. Actuators, B, 2020, 304, 127270.

332 S. A. Kolpakov, N. T. Gordon, C. Mou and K. Zhou, Sensors, 2014, 14, 3986-4013. 
333 S. K. Khijwania, K. L. Srinivasan and J. P. Singh, Sens. Actuators, B, 2005, 104, 217-222.

334 Y. Wang, Y. Liu, F. Zou, C. Jiang, C. Mou and T. Wang, Sensors, 2019, 19(10), 2263.

335 W. Yuan, H. Qian, Y. Liu, Z. Wang and C. Yu, Micromachines, 2019, 10(8), 521.

336 G. Yan, Y. Liang, E.-H. Lee and S. He, Opt. Express, 2015, 23, 15624-15634.

337 M. Kaya, P. Sahay and C. Wang, Sens. Actuators, B, 2013, 176, 803-810.

338 S. Zhang, X. Dong, T. Li, C. C. Chan and P. P. Shum, Opt. Commun., 2013, 303, 42-45.

339 S. Zheng, Y. Zhu and S. Krishnaswamy, Sens. Actuators, B, 2013, 176, 264-274.

340 J. Shi, D. Xu, W. Xu, Y. Wang, C. Yan, C. Zhang, D. Yan, Y. He, L. Tang, W. Zhang, T. Liu and J. Yao, J. Light Technol., 2017, 35, 4789-4795.

341 E. Maciak, Sensors, 2019, 19(3), 629.

342 R. Qi, X. Lin, J. Dai, H. Zhao, S. Liu, T. Fei and T. Zhang, Sens. Actuators, B, 2018, 277, 584-590.

343 A. M. Shrivastav, D. S. Gunawardena, Z. Liu and H.-Y. Tam, Sci. Rep., 2020, 10, 6002.

344 J. Mathew, Y. Semenova, G. Rajan and G. Farrell, Electron. Lett., 2010, 46, 1341-1343.

345 M. De, T. K. Gangopadhyay and V. K. Singh, Sensors, 2019, 19, 464 .

346 Y. Wang, C. Shen, W. Lou and F. Shentu, Sens. Actuators, B, 2016, 234, 503-509.

347 K. Ni, C. C. Chan, L. Chen, X. Dong, R. Huang and Q. Ma, Opt. Fiber Technol., 2017, 33, 56-59.

348 C. Bian, Y. Cheng, W. Zhu, R. Tong, M. Hu and T. Gang, IEEE Sens. J., 2020, 20, 5759-5765.

349 M. Elsalamawy, A. R. Mohamed and E. M. Kamal, Alex. Eng. J., 2019, 58(4), 1257-1264.

350 M. Stefanoni, U. M. Angst and B. Elsener, Sci. Rep., 2018, 8, 7407.

351 J. Ahlström, J. Tidblad, B. Sederholm and L. Wadsö, Mater. Corros., 2016, 67, 1049-1058.

352 L. S. M. Alwis, T. Sun and K. T. V. Grattan, Procedia Eng., 2016, 168, 1317-1320.

353 D. Cao, H. Fang, F. Wang, H. Zhu and M. Sun, Sensors, 2018, 18, 4431.

354 K. Yan, J. Liu, N. Sun and W. Zhong, in Tenth International Symposium on Precision Engineering Measurements and Instrumentation, International Society for Optics and Photonics, 2019, vol. 11053, p. 1105326.

355 M. R. Islam, M. M. Ali, M.-H. Lai, K.-S. Lim and H. Ahmad, Sensors, 2014, 14, 7451-7488.

356 L. Labrador-Páez, K. Soler-Carracedo, M. HernándezRodríguez, I. R. Martín, T. Carmon and L. L. Martin, Opt. Express, 2017, 25, 1165-1172.

357 A. B. Petermann, T. Hildebrandt, U. Morgner, B. W. Roth and M. Meinhardt-Wollweber, Sensors, 2018, 18, 2383.

358 M. A. Md Johari, M. I. M. Abdul Khudus, M. H. Bin Jali, A. Al Noman and S. W. Harun, Optik, 2019, 185, 558-565.
359 T. L. Yeo, D. Eckstein, B. McKinley, L. F. Boswell, T. Sun and K. T. V. Grattan, Smart Mater. Struct., 2006, 15, N40.

360 J. C. Campo, M. A. Perez, M. Gonzalez and F. J. Ferrero, Proceedings of the 17th IEEE Instrumentation and Measurement Technology Conference [Cat. No. 00CH37066], 2000, vol. 1, pp. 273-276.

361 S. Tao, C. B. Winstead, R. Jindal and J. P. Singh, IEEE Sens. J., 2004, 4, 322-328.

362 J. Estella, P. de Vicente, J. C. Echeverría and J. J. Garrido, Sens. Actuators, B, 2010, 149, 122-128.

363 Z. Zhao and Y. Duan, Sens. Actuators, B, 2011, 160, 1340-1345.

364 S. F. H. Correia, P. Antunes, E. Pecoraro, P. P. Lima, H. Varum, L. D. Carlos, R. A. S. Ferreira and P. S. André, Sensors, 2012, 12, 8847-8860.

365 F. U. Hernandez, S. P. Morgan, B. R. Hayes-Gill, D. Harvey, W. Kinnear, A. Norris, D. Evans, J. G. Hardman and S. Korposh, IEEE Trans. Biomed. Eng., 2016, 63, 1985-1992.

366 J. Li, J. Zhang, H. Sun, Y. Yang, Y. Ye, J. Cui, W. He, X. Yong and Y. Xie, Opt. Commun., 2020, 467, 125740.

367 M. Consales, M. Pisco and A. Cusano, Photonic Sens., 2012, 2, 289-314.

368 M. Rioux, Y. Ledemi, S. Morency, E. S. de Lima Filho and Y. Messaddeq, Sci. Rep., 2017, 7, 43917.

369 A. Cusano, A. Cusano, G. Breglio, G. Breglio, M. Consales, M. Giordano, M. Giordano, A. Cutolo, A. Cutolo, B. S. Buontempo, P. Petagna and M. Bajko, Frontiers in Optics 2013 (2013), paper FTh4B.1, Optical Society of America, 2013, p. FTh4B.1.

370 Z. Xiang, L. Wan, Z. Gong, Z. Zhou, Z. Ma, X. OuYang, Z. He and C. C. Chan, Micromachines, 2019, 10(12), 866.

371 T. Fu, J. Fan, C. Wang, T. Liu and J. Leng, Proc. SPIE, 2008, 6933, 693317.

372 G. Thursby, B. Culshaw and D. C. Betz, Fatigue Fract. Eng. Mater. Struct., 2008, 31, 660-673.

373 Y. Mizutani and R. M. Groves, Exp. Mech., 2011, 51, 1489-1498.

374 A. Petropoulou, S. Kralj, X. Karagiorgis, I. Savva, E. Loizides, M. Panagi, T. Krasia-Christoforou and C. Riziotis, Sci. Rep., 2020, 10, 367.

375 V. N. G. \& C. KG, Sol-gel coatings, http://www.europeancoatings.com/Raw-materials-technologies/Applications/ Protective-Marine-coatings/Sol-gel-coatings-shelter-forhistorical-window-glass, accessed 25 June 2020.

376 A. R. Cuevas, M. Fontana, L. Rodriguez-Cobo, M. Lomer and J. M. López-Higuera, J. Light Technol., 2018, 36, 3733-3738.

377 P. Westbrook, APL Photonics, 2020, 5, 020401.

378 S. Lépinay, A. Ianoul and J. Albert, Talanta, 2014, 128, 401-407.

379 A. Rico-Yuste and S. Carrasco, Polymers, 2019, 11, 1173.

380 N. Cennamo, M. Pesavento, S. Marchetti and L. Zeni, in Advanced Materials for Defense, ed. R. Fangueiro and S. Rana, Springer International Publishing, Cham, 2020, pp. 17-24.

381 A. Chiappini, L. Pasquardini and A. M. Bossi, Sensors, 2020, 20, 5069. 